\section{To: (Receiving Organization) \\ Distribution}

5. Proj./Prog./Dept./Div.:

8. originator Remarks:

For Approval and Release:

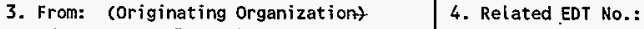

Environmental and Nuclear Initiatives

6. Design Authority/ Design Agent/Cog. 1 7. Purchase Order No.: Engr.:

WT Watson

10. System/Bldg./Facility:

12. Major Assm. Dwg. No.:

11. Receiver Remarks:

11A. Design Baseline Document?

[X] Yes [] No

13. Permit/Permit Application No.:

14. Required Response Date:

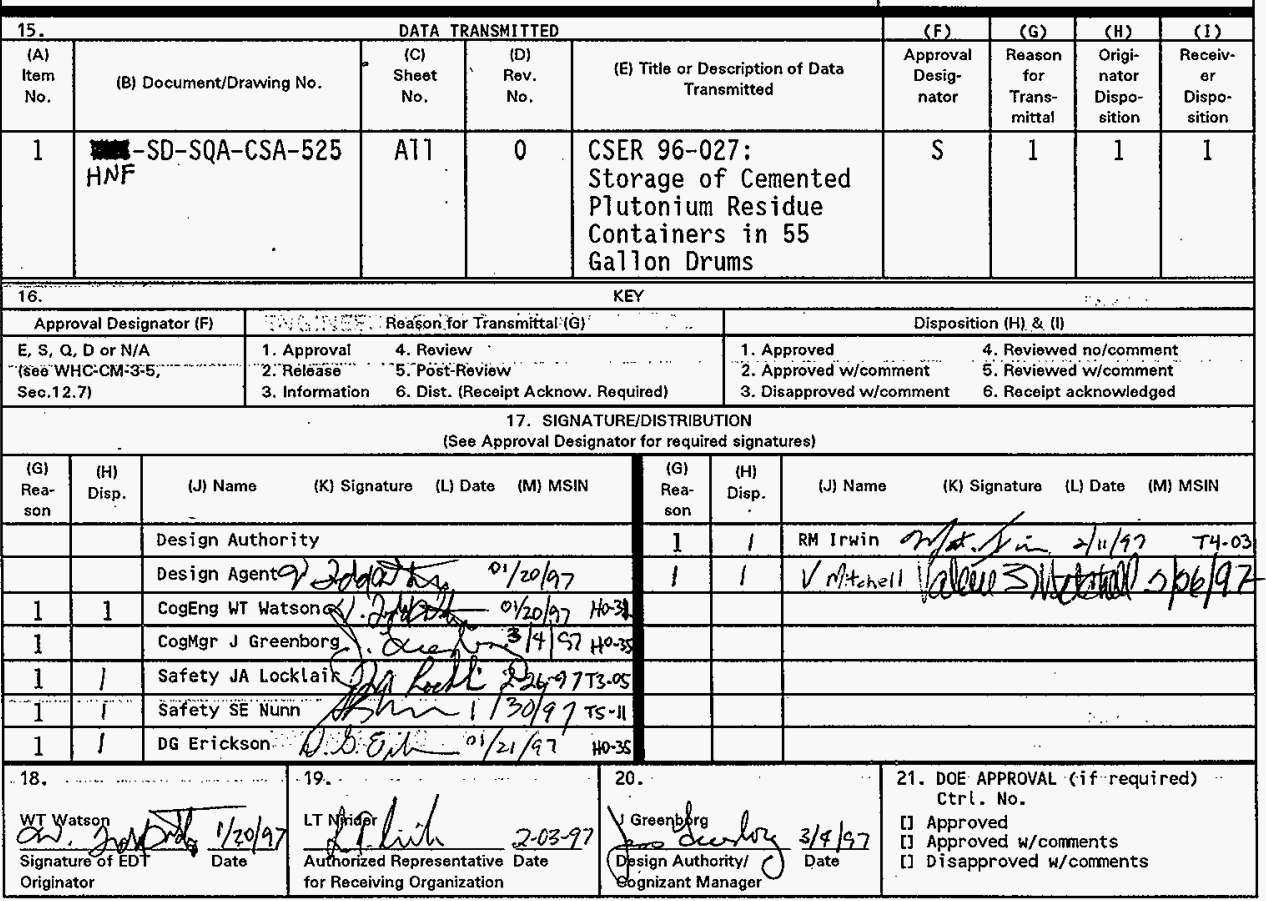

BD-7400-172-2(05/96) GEF097 
1. Identification Number:

USO SCREENING

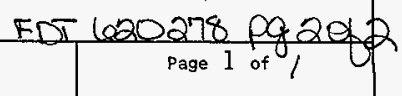

SWMFE-USQ-97-009

2. Title: CSER 97-27: Storage of Cemented Plutonium Residue Containers in 55 gallon drums

INSTRUCTIONS: Respond to each question and provide justification for each response. A restatement of the question does not constitute a satisfactory justification or basis. An adequate justification provides sufficient explanation such that an independent reviewer could reach the same conclusion based on the information provided [DOE 5480.21, 10.e.1].

QUESTIONS

1. Does the proposed change or occurrence represent a change to the facility or procedures as described in the Authorization Basis?
[] $N / A$
$[X]$ No
[] Yes/Maybe

BASIS: The proposed change evaluates a waste form (cemented $\mathrm{Pu}$ ) and demonstrates that this form meets the criticality safety requirements even when the volume of waste is $<20 \%$ of the drum volume. Therefore, a $200 \mathrm{~g} 1$ imit is appropriate for this packaged waste form. The anatysis conforms to the section 6.2 .12 criticality safety program described in the CWC authorization basis, WHC-SD-WM-SAR-049,

2. Does the proposed change or occurrence represent conditions that have not been analyzed in the Authorization Basis?
[] n/A [X] No
[] Yes/Maybe

BAsIs: The proposed change demonstrates that this waste form packaging meets the criticality safety program as analyzed in the authorization basis.

3. Does the proposed change represent a test or experiment NOT described in the Authorization Basis that may affect the safe operation of the facility?
[] N/A
$[X]$ No
[] Yes/Maybe

BAsis: There are no tests or experiments involved in this change.

4. Does the proposed change or occurrence represent a change to the Technical Safety Requirements or a reduction in the margin of safety defined in the Technical Safety Requirements?
[] N/A
$[X]$ No
[] Yes/Maybe

BASIS: The criticality program administrative control (2.11) from the authorization basis TSR chapter 7 is complied with completely by the CSER analysis proposed.

USQE \#1

$$
\text { R.M. Irwin }
$$

(Print Name)

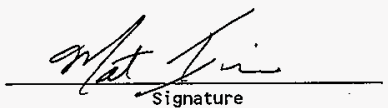

Date:

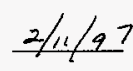

USQE \#2 R. Ames

If there is a YES/MAYBE response to questions 1, 2, 3, or 4, then a USQ Evaluation must be completed.

The following guidance should be considered when completing this screening. This guidance should not be considered allinclusive; additional factors may need to be considered depending on the nature of the proposed change.

Does the proposed change:

1) Modify, add, or delete a safety class function of a structure, system or component stated in the authorization basis?

2) Alter the design of a structure, system or component as described in the authorization basis?

3) Modify, add, or delete the description of operation, operating environment, or analyses of any system or component described in the authorization basis?

4) Modify, add, delete or conflict with any of the design bases stated in the authorization basis?

5) Conflict with the principle or general design criteria stated in the authorization basis?

6) Modify, add, or delete any plant design features described in the authorization basis?

7) Modify, add, or delete a flow diagram or facility drawing provided in the authorization basis?

8) Create the potential for new system or component interactions (e.g., seismic, electrical breaker coordination)? 


\title{
CSER 96-027: Storage of Cemented Plutonium Residue Containers in 55 Gallon Drums
}

\author{
W. T. Watson \\ Fluor Daniel Northwest, Inc., Richland, WA 99352 \\ U.S. Department of Energy Contract DE-AC06-96RL13200 \\ EDT/ECN: 620278 \\ UC: 610 \\ Org Code: 403 \\ B\&R Code: \\ Charge Code: E56008 \\ Total Pages: 55 \\ Key Words: plutonjum, sand, s?ag, crucjble, 55 gallon drum, \\ cementation, plutonium finishing plant \\ Abstract: A nuclear criticality safety analysis has been performed for \\ the storage of residual plutonium cementation containers, produced at \\ the Plutonium Finishing Plant, in 55 gallon drums. This CSER increases \\ the limit of total plutonium stored in each 55 gallon drum from 100 to \\ 200 grams.
}

TRADEMARK DISCLAIMER. Reference herein to any specific commercial product, process, or service by trade name, trademark, manufacturer, or otherwise, does not necessarily constitute or imply its endorsement, recommendation, or favoring by the United States Government or any agency thereof or its contractors or subcontractors.

Printed in the United States of America. To obtain copies of this document, contact: Document Control Services, P.0. Box 950, Mailstop H6-08, Richland WA 99352, Phone (509) 372-2420; Fax (509) 376-4989.
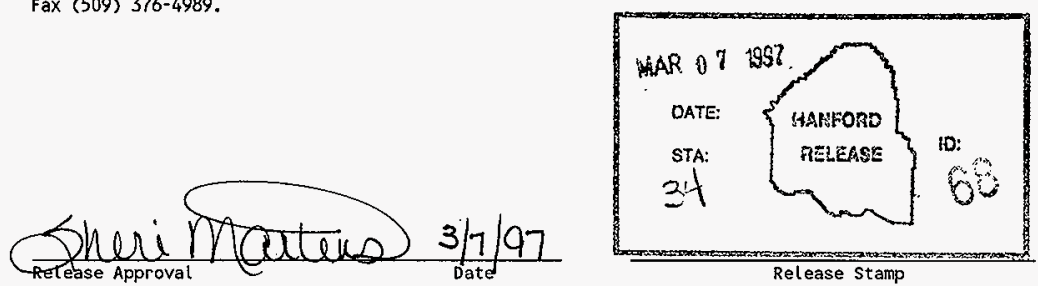

Approved for Public Release 
HNF-SD-SQA-CSA-525 Rev. 0

\section{CONTENTS}

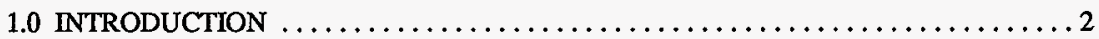

2.0 DESCRIPTION OF SYSTEM AND FACILITY $\ldots \ldots \ldots \ldots \ldots \ldots \ldots \ldots \ldots \ldots \ldots \ldots$

3.0 REQUIREMENTS DOCUMENTATION $\ldots \ldots \ldots \ldots \ldots \ldots \ldots \ldots \ldots \ldots$

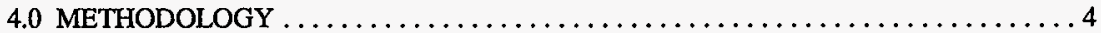

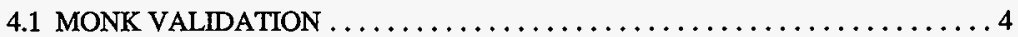

5.0 DISCUSSION OF CONTINGENCIES $\ldots \ldots \ldots \ldots \ldots \ldots \ldots \ldots \ldots \ldots \ldots \ldots \ldots \ldots \ldots$

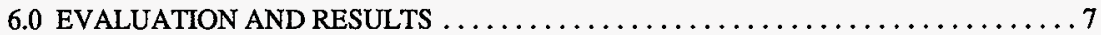

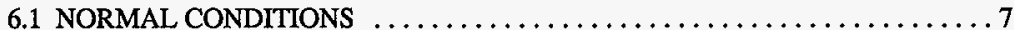

6.2 OFF-NORMAL CONDITIONS $\ldots \ldots \ldots \ldots \ldots \ldots \ldots \ldots \ldots \ldots$

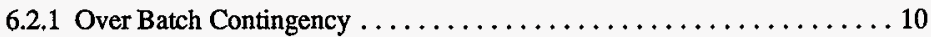

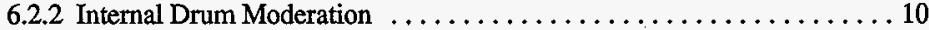

6.2.3 External Drum Moderation Contingency ................. 10

6.2.4 Cement Composition Contingency $\ldots \ldots \ldots \ldots \ldots \ldots \ldots \ldots \ldots \ldots \ldots$

6.2.5 Additional Can of Material Contingency .................. 13

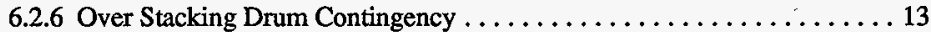

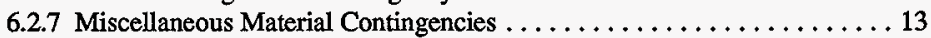

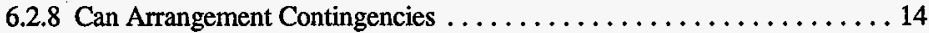

6.2.9 Loss of Spacing Contingency: Drum Crushing $\ldots \ldots \ldots \ldots \ldots \ldots$

7.0 DESIGN FEATURES AND ADMINISTRATIVELY CONTROLLED LIMITS AND

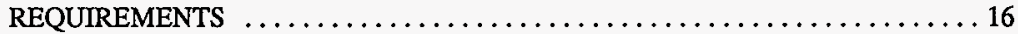

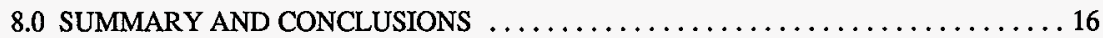

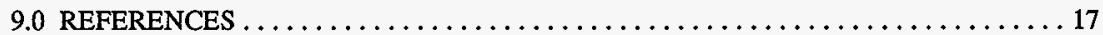

APPENDIX A

INDEPENDENT REVIEW COMMENTS AND CHECKLIST $\ldots \ldots \ldots \ldots \ldots$ A - 1 APPENDIX B

MONK INPUT FILES $\ldots \ldots \ldots \ldots \ldots \ldots \ldots \ldots \ldots \ldots \ldots \ldots \ldots$ B -1 
HNF-SD-SQA-CSA-525 Rev. 0

This page intentionally left blank 
HNF-SD-SQA-CSA-525 Rev. 0

CSER-96-027

Title: CSER 96-027: Storage of Cemented Plutonium Residue Containers in 55 Gallon Drums

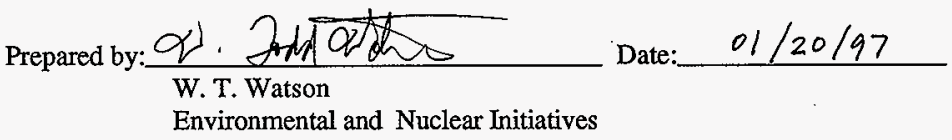

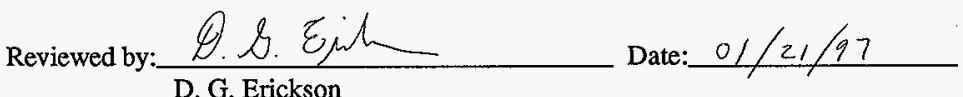

D. G. Erickson Criticality and Shielding

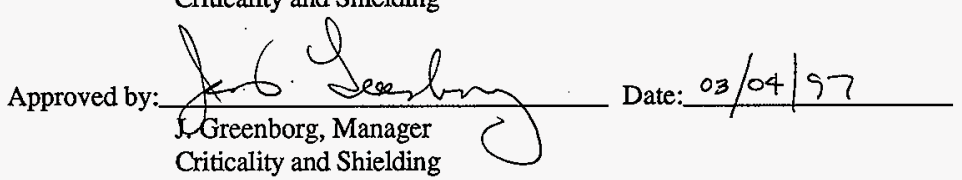

1 
HNF-SD-SQA-CSA-525 Rev. 0

\subsection{INTRODUCTION}

A nuclear criticality safety analysis has been performed for the 55 gallon drum storage arrangement of the residual plutonium cementation containers produced at the Plutonium Finishing Plant (PFP). The plutonium stabilization program at PFP takes Sand, Slag, and Crucible (SS\&C) scrap and cements it within bagged cans. The cans are then loaded, unconstrained in position, within 55 gallon drums up to a limit for the total amount of plutonium in a given drum. The purpose of this CSER is to increase the total limit of plutonium stored in each 55 gallon drum from $100 \mathrm{~g}$ to $200 \mathrm{~g}$.

The normal and off-normal conditions for the storage array of drums were analyzed by performing explicit calculations of the geometry and materials involved. Normal conditions were conservatively modeled by assuming the most reactive normal material composition (maximum normal moderation and material density), position of the cans within the drums, and an essentially infinite two-dimensional array of drums stacked 4 drums high. Several off-normal contingencies were analyzed. These included: plutonium over batch in a can; interspersed moderation between the drums; interspersed moderation within the drums, including an extra can within a fraction of the drums; crushing the drums because of a storage building catastrophe; and stacking the drums in 5 or 6 layers.

This evaluation demonstrates that $200 \mathrm{~g}$ of plutonium in cement may be safely stored in each 55-gallon drum if a number of administrative controls are maintained. Stacking the drums as many as six high is acceptable with no other contingency, while stacking the drums four high is shown to be acceptable with other contingencies. Concentrating the plutonium tends to increase the reactivity, but it has been shown that each can may contain up to $113 \mathrm{~g}$ of plutonium. Increasing the hydrogen content of the cement increases the reactivity, but at feasible water concentrations the storage remains safe. The steel in the drum absorbs significant fractions of thermal neutrons, thereby reducing the system reactivity. The plastic liner used in the drums acts as a neutron shield, lowering interaction between drums. Either the steel drum must be present with a mass of at least $16 \mathrm{~kg}$ or the polyethylene liner $(0.229 \mathrm{~cm}$ thick) must be present.

\subsection{DESCRIPTION OF SYSTEM AND FACILITY}

A criticality safety evaluation has been performed for the process of stabilizing SS\&C scrap for long term storage by a cementation process (Hess 1996). The SS\&C scrap is mixed with cement and water within .5-1/2-in. $(14 \mathrm{~cm})$ inner diameter and 7-in. $(17.8 \mathrm{~cm})$ inner height cylindrical slip cover cans. The exact composition of the cement and the exact amount of water in each mixture is not well known. Typical cement composition for the process is documented (PFD-Z-180-00004, Slag and Crucible Dissolver Flowsheet) and the approximate amount of added cement and water are determined and recorded for each can. Table 2-1 gives the cement composition used for normal conditions. This composition actually contains a higher than average free water content according to process operations engineers. More typical compositions have 
contained about $8 \mathrm{wt} \%$ free water and hydrogen concentrations of about $2.3 \mathrm{wt} \%$. The total water added to the cement should be between 25 and 32 percent of the total weight in order for the cement to cure. The cement composition is combined with the desired amount of plutonium in a can to obtain the final composition of the cemented material used in the computer model. A cemented residue bulk density of $2.059 \mathrm{~g} / \mathrm{cm}^{3}$ was used for all calculations. The isotope $\mathrm{Pu}-239$ is used to model all plutonium in all calculations.

Table 2-1. Normal condition expected cement composition.

\begin{tabular}{|c|c|c|c|}
\hline Compound & Weight Fraction & Element & Weight Fraction \\
\hline $\mathrm{CaF}$ & 0.102 & $\mathrm{H}$ & 0.04132 \\
\hline $\mathrm{MgO}$ & 0.112 & $\mathrm{O}$ & 0.49146 \\
\hline $\mathrm{Ca}(\mathrm{OH})_{2}$ & 0.551 & $\mathrm{~F}$ & 0.03267 \\
\hline $\mathrm{H}_{2} \mathrm{O}$ (unbound) & 0.235 & $\mathrm{Mg}$ & 0.06779 \\
\hline & & $\mathrm{Ca}$ & 0.36675 \\
\hline
\end{tabular}

The cans are made of electrolytic chrome-coated steel with a wall thickness of 0.0012 in. $(0.003 \mathrm{~cm})$. The composition of the can was modeled as solid steel (composition supplied by the manufacturer), ignoring the ultra-thin chrome plating. Because chrome has a larger thermal neutron absorption cross section than iron, this simplification should be conservative. The can manufacturer lists 16 elements in the can composition. Only those elements that make up at least $0.1 \mathrm{wt} \%$ or more of the can were considered for the model composition. Also, all trace elements in the can composition that have a thermal neutron absorption cross section larger than natural iron were replaced with iron in the model. The modeled can composition is listed in table 2-3. Each can is bagged in polyvinyl chloride (PVC) plastic of thickness 0.012 in. $(0.03 \mathrm{~cm})$ before being placed in the drum. Under normal operating conditions, the cans are sometimes double or triple bagged to contain contamination that is present. All cases, unless otherwise specified, were modeled with a single PVC bag containing each can.

Table 2-3. Composition of the steel can containing the cemented plutonium residue.

\begin{tabular}{|c|c|}
\hline Element & Weight Percent \\
\hline $\mathrm{C}$ & 0.5 \\
\hline $\mathrm{Al}$ & 0.1 \\
\hline $\mathrm{Si}$ & 0.6 \\
\hline $\mathrm{P}$ & 0.2 \\
\hline $\mathrm{S}$ & 0.2 \\
\hline $\mathrm{Fe}$ & 98.3 \\
\hline $\mathrm{Sn}$ & 0.1 \\
\hline
\end{tabular}


The cans are placed into 55 gallon UN1A2 drums that each have a rigid internal polyethylene liner that is $0.09 \mathrm{in} .(0.23 \mathrm{~cm})$ thick. The drum was modeled with an inner radius of $11.25 \mathrm{in} .(28.575 \mathrm{~cm})$, a wall thickness of $0.06 \mathrm{in} .(0.15189 \mathrm{~cm})(16$ gage), and an internal height of 33.25 in. $(84.455 \mathrm{~cm})$. The drum material was assumed to be standard carbon steel $(1 \%$ carbon) with a bulk density of $7.86 \mathrm{~g} / \mathrm{cm}^{3}$. This steel composition should provide a somewhat conservative estimate for the calculated reactivities because most other steels contain nickel and chromium replacing small amounts of iron and often have bulk densities closer to $8 \mathrm{~g} / \mathrm{cm}^{3}$. The mass of each cementation can may contain up to $2 \mathrm{wt} \%$ plutonium (about $113 \mathrm{~g}$ ). This $2 \mathrm{wt} \%$ limit per can was established by Safeguards as the maximum concentration of plutonium for unguarded storage. The attractiveness level of low concentrations of plutonium in a cement matrix is very low. Cans are added to the drum up to the drum limit for total plutonium mass. The drums will be stacked together in an array three or four drums high for storage. It is planned to stack the drums on wooden palettes which would provide a vertical spacing of about $10 \mathrm{~cm}$ between the drums. For modeling purposes, the palettes and the spacing they provide has been neglected, which should produce a conservative result. The storage location is expected to be within metal-wall or concrete-wall buildings at the Hanford Site. Because the drum arrays are modeled as infinite in two dimensions, the walls are ignored in the modeling. The floor of the storage facility is assumed to be a concrete floor with a high moisture content for modeling purposes. The ceiling of the storage facility is modeled as an eight-in.-thick concrete slab placed directly above the top layer of drums.

\subsection{REQUIREMENTS DOCUMENTATION}

There are no unique requirements applicable to this evaluation.

\subsection{METHODOLOGY}

The MONK6B code was used for this analysis. MONK6B is a commercially licensed code from the British ANSWERS organization (UKEAE 1988). The MONK6B code uses pointwise cross sections from the United Kingdom Nuclear Data Library (UKNDL). It is currently verified per MONK6B quality assurance plan WHC-SD-SQA-CSWD-20017 (Miller, 1994) and validated on the SUN2 and SUN4 workstations in the science and engineering computing center (SECC). A copy of the executable code for the preferred computer platform was received from the vendor. The verification of this code was received along with the code. A description of the code validation for use on plutonium systems, such as those found in PFP is included below.

\subsection{MONK VALIDATION}

\section{Validation Procedure}

The validation of the method used in the analysis consists of testing the ability of the MONK6A code (UKEAE, 1988) and neutron cross-sections in calculation of known critical 
configurations from various benchmark experiments with plutonium as the fissile material. Such analyses determine a calculational bias (the deviation of calculated $k_{\text {eff }}$ from unity) and the uncertainties culminating from the experimental and calculational errors.

The safety criteria for future calculations on undetermined systems requires that the biasadjusted $\mathrm{k}_{\text {eff }}$ does not exceed 0.95 at the $95 \%$ confidence interval. This is expressed by the following equation:

$$
k_{\text {eff }}=k_{\text {calc }}-\text { bias }+\left(U_{b}^{2}+U_{c}^{2}\right)^{\frac{1}{2}} \leq 0.95
$$

where: $\quad \mathrm{k}_{\text {calc }}=\mathrm{k}$ value given by the calculation of the system

bias $=$ mean difference $\left(k_{\text {cak }}-1.0\right)$ for benchmark criticals

$\mathrm{U}_{\mathrm{b}}=95 \%$ confidence level uncertainty in bias determination

$\mathrm{U}_{\mathrm{c}}=95 \%$ confidence level uncertainty in new calculation.

Thus, the bias-adjusted $\mathrm{k}_{\text {eff }}$ includes the statistical uncertainties.

\section{Generic Validation of Plutonium Systems}

A report by Maklin and Miller (1992) presents the results of calculations to determine a generic bias for plutonium configurations, as encountered in the PFP. Seventy benchmark experiments were calculated, ranging from simple metal spheres to highly diluted ( $9 \mathrm{~g}$ plutonium per liter) plutonium nitrate solution spheres, and compacts of $\mathrm{PuO}_{2}$ blended with polystyrene. A mean $\mathrm{k}_{\text {eff }}$ value of 1.0047 was determined over the full experimental range, with an average standard deviation of 0.0097 .

The direct calculational bias is thus +0.0047 (average $\mathbf{k}_{\mathrm{err}}$ greater than unity). Accounting for the uncertainties using tolerance limit analysis, the report then concludes that:

At least $95 \%$ of all critical experiments of this type computed by the MONK6A code will produce calculated $\mathrm{k}_{\text {eff }}$ values greater than 0.9857 with $95 \%$ confidence.

For a standard deviation ( $\sigma$ ) of 0.01 or less for the convergence of a future calculation $\left(U_{c}\right)$, the 0.9857 value is lowered to 0.9855 . Rounded conservatively, a value of +0.015 can be used for $\left[-\operatorname{bias}\left(U_{b}^{2}-U_{c}^{2}\right)^{1 / 3}\right]$. On this basis, it is determined that the true $k_{\text {eff }}$ of an analyzed configuration with plutonium will not exceed 0.95 with a $95 \%$ confidence level if the calculated value $\left(\mathrm{k}_{\text {calce }}, \sigma \leq 0.01\right)$ is limited to a maximum of 0.935 .

The $95 \%$ confidence level on $99.9 \%$ of the data is 0.9699 . So a subcritical margin of $5 \%$ is $3.5 \%$ larger than the uncertainties between the $95.0 \%$ and the $99.9 \%$ coverage of the benchmark data. 


\section{HNF-SD-SQA-CSA-525 Rev. 0}

\section{Validation of MONK6B}

The validation of MONK6B code on the SUN microcomputer was documented in Miller (1994). The essence of the validation was cross-correlation of calculational results obtained with this code version and computer with results for identical model input done on a CRAY machine with MONK6A. Also, the equivalence of MONK6A and MONK6B was well documented by the vendor in the verification package shipped with the software.

\subsection{DISCUSSION OF CONTINGENCIES}

Over batch -The volume of the can is $2.74 \mathrm{~L}$ and the bulk density of the cemented material is $2.059 \mathrm{~g} / \mathrm{cm}^{3}$ so that a completed filled can will contain about $5652 \mathrm{~g}$ of cemented material. The maximum plutonium concentration is normally limited to $2 \mathrm{wt} \%$ so that the total plutonium in a single can is $113 \mathrm{~g}$. If a can were to be double batched, it could contain as much as $226 \mathrm{~g}$ of plutonium. The contingent conditions have $2 \%$ or $4 \%$ of the drums in the array containing three cans: one with $226 \mathrm{~g}$ and two with $66.67 \mathrm{~g}$ of plutonium. The total amount of plutonium in the drum is $359.3 \mathrm{~g}$, or about 1.8 times the $200 \mathrm{~g}$ limit.

Internal moderation - The cemented material in the cans contains both water and calcium hydroxide which act to moderate the system. Normally the material will contain significant amounts of calcium fluoride and magnesium oxide and trace quantities of other compounds like calcium iodide and silicon oxide that do not provide significant moderation. For the contingency condition the cement will be modeled with different free water contents up to $65 \mathrm{wt} \%$ (7.8 wt\% hydrogen) for all cans in the model.

Interspersed moderation - Interspersed moderation between the drums and or within the drums (between the cans) from $0 \%$ to $100 \% \mathrm{H}_{2} \mathrm{O}$ will be considered to account for sprinklers or fire fighting sprays. The presence of more than very low density water, such as humid air, in the room is considered as a contingent condition, and will therefore be evaluated.

Cement composition - The cement composition, most importantly its water or hydrogen concentration, may vary. The cement is modeled with different unbound water concentrations ranging from 8 to $65 \mathrm{wt} \%$. The larger unbound water concentrations would likely produce cement that would not cure and would therefore be rejected.

Additional cans of material - Because the drums are packaged, one can at a time, by hand, human error could lead to the placing of an additional can in the drum after the $200 \mathrm{~g}$ limit has already been attained. Two contingent conditions will be considered where 8 percent or 16 percent of the drums in the array contain four cans: three with $66.67 \mathrm{~g}$ of plutonium and one can that has $113 \mathrm{~g}$ of plutonium.

Over stacking of drums - It is planned to stack these drums in a large array that is up to four drum levels high. Infinite two-dimensional arrays that contain five levels and six levels will be evaluated as a contingent conditions. 


\section{HNF-SD-SQA-CSA-525 Rev. 0}

Packaging material - The drum, its liner, and the cementation can materials reduce the reactivity of the configuration. For the most reactive can geometry each of these materials will be replaced with void or with reduced thickness material to assess the effects upon reactivity.

Loss of spacing - Normal conditions place the drums, with sides touching, in a square array. The drums act as the agent to maintain required spacing of the packaged plutonium bearing materials. Drums used for this purpose are typically certified to meet strength requirements necessary for legal shipping purposes in the United States. No mechanism could cause the loss of spacing for the array of drums other than a catastrophic event that crushed the array of drums. Partial crushing of the entire array of drums is considered as a contingent condition. Drum integrity must be maintained. The drums must be protected from significant corrosion because the loss of the drum iron both eliminates neutron absorbing material and weakens the drum containment.

\subsection{EVALUATION AND RESULTS}

Significant work related to this evaluation was performed in a prior study of plutonium storage in 55 gallon drums: Packaging, Storage and Disposal of Solid Waste (55-Gallon Drums, Unrestricted H/Pu Only) (Carter 1980). This report investigated a large number of parameters concerning the storage of plutonium waste in 55 gallon drums including, hydrogen to plutonium ratio, fissile shape (height to diameter ratios), and bulk density. Information learned from this report helped direct the chosen parameter studies performed in this report. In general, situations where the hydrogen content of the material is high and where the fissile material is concentrated into smaller volumes are expected to be the most reactive.

All uncertainties reported in these results are indicative of the one sigma stochastic precision of the calculation. Input filenames, usually beginning with "cemd", are given for each case where results are reported. These input files may be found in Appendix B.

\subsection{NORMAL CONDITIONS}

Several configurations were investigated to determine the credible configuration within the drum with near maximum reactivity. Based upon the previous study (Carter 1980), it was expected that a configuration where the plutonium was stored with the highest density would provide for nearly optimal reactivity. Therefore, all physical can placements within the drum considered in this evaluation used two or three cans of cemented residue with the total amount of plutonium in each drum equal to $200 \mathrm{~g}$. All normal calculations were performed for a rectangular array of drums with dimensions: $\infty \times \infty \times 4$, unless specified otherwise.

Six different physical can arrangements were considered to be representative of the more reactive credible arrangements that could be attained. Figure 6-1 shows a sketch of the five different arrangements considered. One arrangement used 4 cans in the drum, three arrangements used three cans in the drum and the other two used two can in the drum. For the 4 can arrangement (Case 1), each can was modeled containing equal amounts of plutonium (50 g). Case 2 has three cans arranged in the bottom center of each drum with each can touching its two 
Figure 6-1. Sketch of the 5 normal condition can arrangements.

Case 1 (plan view)

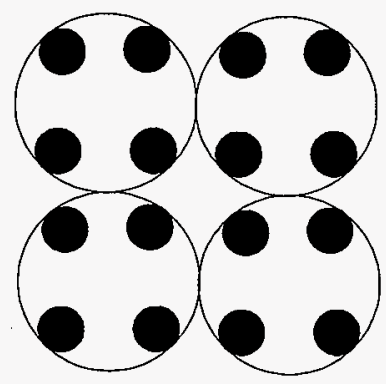

Case 3 (plan view)

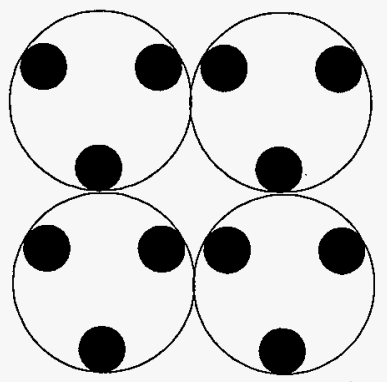

Case 6

\section{(side view)}

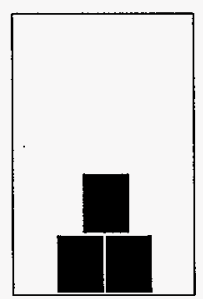

Case 2 (plan view)
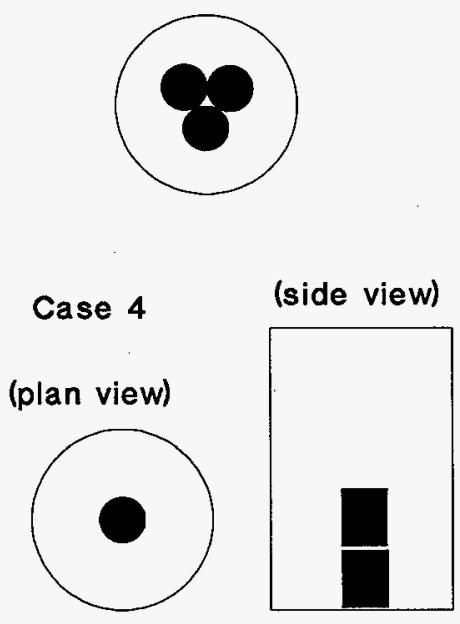

Case 5 (plan view)

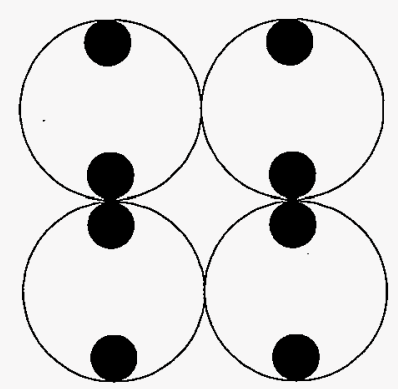


neighbors. Case 3 has three cans arranged in the bottom of each drum at the drum sides with the cans spaced at 120 degree angles about the drum center. Case 6 has 3 cans: two arranged side by side at the drum center with a third can resting on top the other two at the drum center. For each of the three can arrangements, the cases were modeled with equal amounts of plutonium each can $(67 \mathrm{~g})$ and with $113 \mathrm{~g}$ in one can and $43.5 \mathrm{~g}$ in the other two cans (Case 3). Case 4 has two cans, one on top of the other, at the drum center. Case 5 also contains two cans, but places them both at the drum bottom at opposite sides of the drum. For both of the two can arrangements, the cases were modeled with equal amounts of plutonium in the cans $(100 \mathrm{~g})$ and with 113 grams in one can and $87 \mathrm{~g}$ in the other can. Table 6-1 summarizes the results of the calculations for these five arrangements. Case 2 , with $66.67 \mathrm{~g}$ of plutonium per can, was also analyzed for a finite array $(5 \times 5 \times 4)$ surrounded by concrete walls. The results from this finite array are indicative of the difference in reactivity expected between a very large array and a smaller array surrounded with reflective materials. For the finite array considered, $\mathrm{k}_{\text {eff }}=0.600 \pm 0.003$, indicating that an infinite array most likely produces conservative results.

Table 6-1. Results of normal condition can arrangement study.

\begin{tabular}{|c|c|c|c|c|c|c|c|}
\hline \multirow{2}{*}{ Case } & \multirow{2}{*}{$\begin{array}{l}\text { Model } \\
\text { File Name }\end{array}$} & \multicolumn{4}{|c|}{ Plutonium in Each Can (g) } & \multirow{2}{*}{$\mathrm{k}_{\mathrm{eff}}$} & \multirow{2}{*}{ Uncertainty } \\
\hline & & 1 & 2 & 3 & 4 & & \\
\hline 1 & cemd1_a & 50 & 50 & 50 & 50 & 0.698 & 0.002 \\
\hline 2 & cemd2_a & 66.7 & 66.7 & 66.7 & N/A & 0.729 & 0.002 \\
\hline 2 & cemd2_2a & 113 & 43.5 & 43.5 & N/A & 0.707 & 0.002 \\
\hline 3 & cemd3_a & 66.7 & 66.7 & 66.7 & N/A & 0.695 & 0.002 \\
\hline 3 & cemd3_2a & 113 & 43.5 & 43.5 & N/A & 0.679 & 0.002 \\
\hline 4 & cemd4_a & 100 & 100 & N/A & N/A & 0.686 & 0.002 \\
\hline 4 & cemd4_2a & 113 & 87 & N/A & $\mathrm{N} / \mathrm{A}$ & 0.684 & 0.002 \\
\hline 5 & cemd5_a & 100 & 100 & $\mathrm{~N} / \mathrm{A}$ & N/A & 0.686 & 0.002 \\
\hline 5 & cemd5_2a & 113 & 87 & N/A & N/A & 0.686 & 0.002 \\
\hline 6 & cemd2_3a & 66.7 & 66.7 & 66.7 & N/A & 0.714 & 0.002 \\
\hline
\end{tabular}

The most reactive situation was found to be for Case 2 (cemd2_a) with the plutonium equally distributed among the cans. This case is the physical arrangement that most approximates a sphere in shape. Because a spherical arrangement would likely be more reactive, a case was modeled where $200 \mathrm{~g}$ of plutonium would be uniformly distributed in a sphere of cement with volume equal to that of two cans. The sphere was placed in each drum of the array at its bottom center and was not covered with either the steel can or PVC bag that usually contains the cement. For this situation, the predicted $k_{\text {eff }}$ was $0.734 \pm 0.002$ (sphere1), or just slightly above that of the most reactive realistic case. 


\subsection{OFF-NORMAL CONDITIONS}

For off-normal conditions the following contingencies were considered: over batch, over stacking, extra can in a drum, cement composition/moderation, interspersed moderation, packaging material, unconventional can placement, and loss of spacing due to drum crushing. Each of these contingencies will be covered individually in the sections following. Except for the over stacking contingency, all of these contingency calculations were performed for a rectangular array of drums with dimensions: $\infty \times \infty \times 4$. The positioning of the cans within the drums is exactly like that for the normal condition case that showed the greatest reactivity except for the contingency with the added can.

\subsubsection{Over Batch Contingency}

For the over batch analysis, the contingent condition has $2 \%$ or $4 \%$ of the drums in the array containing three cans: one with $226 \mathrm{~g}$ and two with $66.67 \mathrm{~g}$ of plutonium. The over batched drums were assumed to be located directly above one another in the array and regularly spaced every 5 drums in each lateral direction. When $2 \%$ of the drums have the over batch, the calculated $\mathrm{k}_{\mathrm{eff}}=0.734 \pm 0.003$ (cemd2_a_ob3). When $4 \%$ of the drums have the over batch, the calculated $k_{\text {eff }}=0.735 \pm 0.003$ (cemd2_a_ob2).

\subsubsection{Internal Drum Moderation}

The cement composition presented in Table 2-2 was used to model the maximum realistic $\mathrm{H} / \mathrm{Pu}$ ratio for the cemented plutonium residue. Using this cement composition, a parameter study of water vapor density interspersed within each drum was completed to determine the maximum reactivity. Table 6-2 shows the results of this study. For very low water vapor concentrations the reactivity is increased slightly above the dry case. As the concentration of water vapor increases, the reactivity declines as the cans in each drum become isolated from those in neighboring drums. When the void space in each drum filled with water, the complete reflection enhances the reactivity in each drum. 
Table 6-2. Results of the internal moderation parameter study.

\begin{tabular}{|c|c|c|c|}
\hline $\begin{array}{c}\text { Water Density Surrounding } \\
\text { Cans in Drum }\left(\mathrm{g} / \mathrm{cm}^{3}\right)\end{array}$ & $\mathrm{k}_{\text {eff }}$ & Uncertainty & $\begin{array}{c}\text { Model } \\
\text { Filename }\end{array}$ \\
\hline 0.0 & 0.729 & 0.002 & cemd2_a \\
\hline 0.0001 & 0.734 & 0.002 & cemd2_1 \\
\hline 0.0005 & 0.734 & 0.002 & vemd2_k \\
\hline 0.001 & 0.729 & 0.002 & cemd2_j \\
\hline 0.005 & 0.718 & 0.002 & cemd2_f \\
\hline 0.01 & 0.707 & 0.002 & cemd2_g \\
\hline 0.1 & 0.594 & 0.002 & cemd2_h \\
\hline 1.0 & 0.658 & 0.002 & cemd2_i \\
\hline
\end{tabular}

\subsubsection{External Drum Moderation Contingency}

For the interspersed moderation contingency analysis, a parameter study of $\mathrm{H}_{2} \mathrm{O}$ densities in the region surrounding the drums was performed. Water densities between $0 \%$ and $100 \%$ of full density were calculated to find the most reactive density. The results of the parameter study can be found in Table 6-3.

Table 6-3. Results of interspersed moderation parameter study.

\begin{tabular}{|c|c|c|c|}
\hline $\begin{array}{c}\text { Water Density Surrounding } \\
\text { Cans in Drum }\left(\mathrm{g} / \mathrm{cm}^{3}\right)\end{array}$ & $\mathbf{k}_{\text {eff }}$ & Uncertainty & Model Filename \\
\hline 0.0005 & 0.734 & 0.002 & cemd2_m \\
\hline 0.005 & 0.728 & 0.002 & cemd2_b \\
\hline 0.01 & 0.727 & 0.002 & cemd2_c \\
\hline 0.1 & 0.658 & 0.002 & cemd2_d \\
\hline 1.0 & 0.520 & 0.002 & cemd2_e \\
\hline
\end{tabular}

\subsubsection{Cement Composition Contingency}

Because the cement composition and moisture (or hydrogen) concentration may vary, a study of this effect was performed. In the cement's final form, hydrogen is present both bound to the calcium and in unbound water. The cement composition was varied by increasing the weight fraction of unbound water in the cement while maintaining the relative proportions of the other constituents. The plutonium content of each can was maintained at $66.67 \mathrm{~g}$ and the most reactive 
normal arrangement of cans was utilized. The cement composition of all cans in the array was modified by this contingency. The unbound water content was modeled ranging from $8 \mathrm{wt} \%$ (2.7 wt\% hydrogen) to $65 \mathrm{wt} \%$ (7.8 wt\% hydrogen). Figure 6-2 shows the predicted value of $\mathrm{k}_{\text {eff }}$ as a function of the total hydrogen concentration in each can (cemd2_ac1, 3, 5, 7, 9, 11, 13, 15, 17). A cement composition with unbound water content as high as $65 \mathrm{wt} \%$ is very unlikely, and still only produces keff $=0.865 \pm 0.002$ (cemd2_ac17). At this high of a bound water concentration the cement would likely not cure as a solid. The results in figure 6-2 assume that the bulk density of the cement remains constant at $2.059 \mathrm{~g} / \mathrm{cm}^{3}$. This is an unrealistic assumption for large hydrogen (water) concentrations. For example, at a hydrogen concentration of $5.8 \mathrm{wt} \%$, the density of the cement would likely be below $1.3 \mathrm{~g} / \mathrm{cm}^{3}$ because of the large water content. The results shown in figure 6-2 for the higher hydrogen concentrations are conservative (i.e. the reported reactivities are higher than would actually be expected).

\subsubsection{Additional Can of Material Contingency}

The contingent condition has $2 \%$ or $4 \%$ of the drums in the array containing four cans: one with $113 \mathrm{~g}$ and three with $66.67 \mathrm{~g}$ of plutonium. The physical arrangement of the cans is similar to normal condition case 2, except that one of the three cans from that model is replaced with one containing $113 \mathrm{~g}$, with the replaced $(66.67 \mathrm{~g})$ can now being placed at on top of the three cans at the barrel center. The additional can drums were assumed to be located directly above one another in the array and regularly spaced every 5 drums in each lateral direction. When $2 \%$ of the drums have the additional can the calculated $k_{\text {eff }}=0.737 \pm 0.003$ (cemd2_a_xc1). When $4 \%$ of the drums have the over batch the calculated $k_{\text {eff }}=0.737 \pm 0.003$ (cemd2_a_xc2).

\subsubsection{Over Stacking Drum Contingency}

For this contingency, the two-dimensional infinite array of drums was stacked 5 and 6 drums high. Table 6-4 provides the results of this study.

Table 6-4. Reactivity as a function of array stacking height.

\begin{tabular}{|c|c|c|c|}
\hline $\begin{array}{c}\text { Array Stack Height } \\
\text { (Number of Drums) }\end{array}$ & $k_{\text {eff }}$ & Uncertainty & Model Filename \\
\hline 4 & 0.729 & 0.002 & cemd2_a \\
\hline 5 & 0.753 & 0.002 & cemd2_ahi5 \\
\hline 6 & 0.767 & 0.002 & cemd2_ahi6 \\
\hline
\end{tabular}


Figure 6-2. Reactivity $\left(k_{e f f}\right)$ shown as a function of the cement hydrogen concentration.

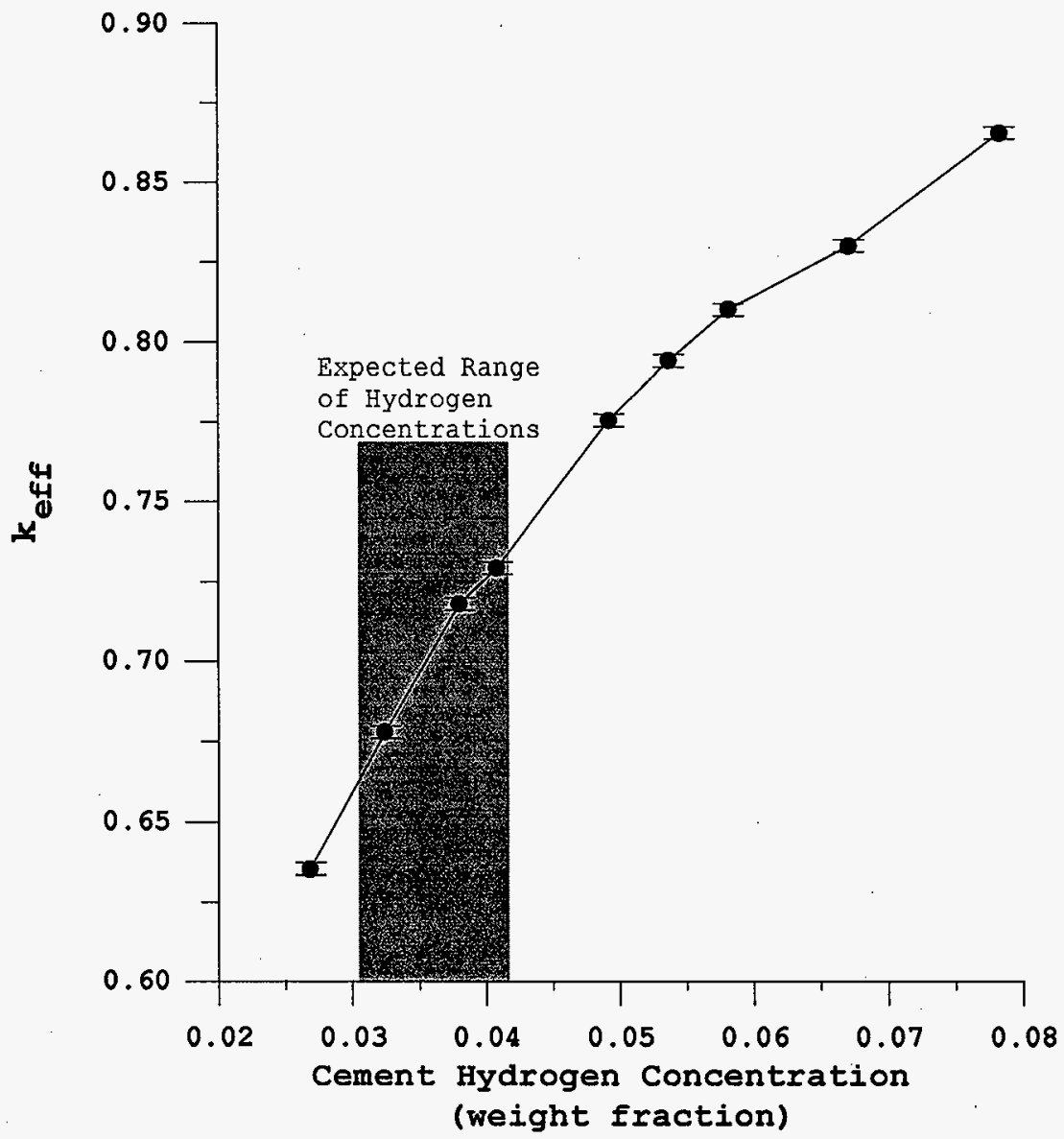




\subsubsection{Miscellaneous Material Contingencies}

Several materials are present in the geometry that act as neutron absorbers or neutron shields. These materials are primarily found in the drum, the drum liner, and the can. Several small cases were investigated that give an indication of the importance of these materials in reducing the reactivity.

To investigate the effects of the drum and its liner several cases were investigated. A case was run where the wall thickness of the steel drum was reduced to one-half its original thickness. A case was run where only the steel drum was replaced with void. A case was run replacing only the polyethylene liner with void. A case was run that replaced material in both the drum and its liner with void. The normal can spacings and arrangements were maintained for all of these cases. Table 6-5 summarizes the results of this study. It is obviously incredible for both the drum and liner to not exist. The importance of having either the drum or its liner present is clearly indicated. An administrative control will be placed upon the drum thickness and total mass. Use of a polyethylene liner, from a criticality standpoint, is optional.

Table 6-5. Results of drum and drum liner material contingency studies.

\begin{tabular}{|l|c|c|c|}
\hline Case Description & $\mathrm{k}_{\text {eff }}$ & Uncertainty & $\begin{array}{c}\text { Model } \\
\text { Filename }\end{array}$ \\
\hline Steel drum wall thickness reduced by $50 \%$ & 0.768 & 0.002 & cemd2_ahd \\
\hline Steel drum wall material replaced with void & 0.913 & 0.002 & cemd2_and \\
\hline Polyethylene drum liner material replaced with void & 0.861 & 0.002 & cemd2_anp \\
\hline $\begin{array}{l}\text { Both steel drum and polyethylene liner materials } \\
\text { replaced with void }\end{array}$ & 1.013 & 0.002 & cemd2_andp \\
\hline
\end{tabular}

The most reactive normal condition can arrangement was modeled with the can material replaced by void. The reactivity was found to increase by less than 1 percent, giving a value of $0.744 \pm 0.002$ for $k_{\text {ent }}$ (cemd2_anc).

\subsubsection{Can Arrangement Contingencies}

If the can arrangement within the drum is truly unconfined, then placing the cans in locations within the drum where they would not likely be found should be considered. The worst arrangements of this sort would place cans in the bottom layer of drums at the top of the drum and cans in the next higher layer of drums at the bottom of the drums. Since other materials have not been excluded from placement in the drums, this could be achieved, for instance by filling the drum with lightweight packaging material (like shredded paper or contaminated clothing) before loading the cans. Figure 6-3 shows a sketch of the two can arrangements considered. The calculated values of $k_{\text {eff }}$ for the two cases are: $0.771 \pm 0.002$ (case 1c, filename: cemd2_aerict), and $0.791 \pm 0.002$ (case 2c, filename: cemd2_aeric). 
HNF-SD-SQA-CSA-525 Rev. 0

Figure 6-3. Sketch of the two contingency can arrangements.

Case 1 (plan view)

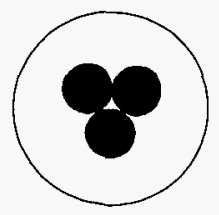

(side view)

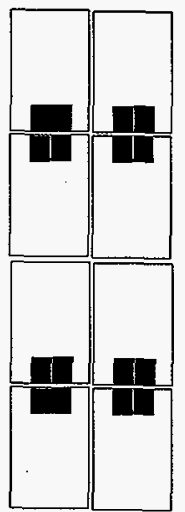

(side view)

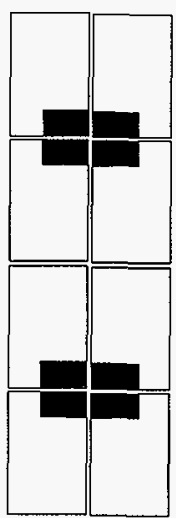


Because these can arrangement contingencies increase the reactivity over the normal can arrangements considered and do not represent incredible arrangements, they are not true contingencies. In order to verify that these can arrangements would be acceptable given other contingencies, case $2 \mathrm{c}$ was run with the steel drum wall thickness reduced by $50 \%$ and was run with a cement hydrogen concentration of $5.8 \mathrm{wt} \%$ (in normal drum). The calculated values for these conditions were: $k_{\text {eff }}=0.821 \pm 0.003$ (cemd2_aerichd) with a reduced steel drum wall thickness, and $\mathrm{k}_{\mathrm{eff}}=0.865 \pm 0.003$ (cemd2_aricc13) with a cement hydrogen concentration of $5.8 \mathrm{wt} \%$.

\subsubsection{Loss of Spacing Contingency: Drum Crushing}

The storage building for these drums may fail under certain natural disaster conditions, such as an earthquake. The roof and roof supporting beams could come down upon these drums during such an event. Using the can arrangement described for case $2 \mathrm{c}$ in the can arrangement contingency (Section 6.2.8), each drum in the 4-high array was crushed to the height of one layer of upright internal cementation cans (about $20 \mathrm{~cm}$ ). The total mass of both polyethylene and of steel in the drums was maintained in the model by increasing their input bulk densities by the inverse of the fraction of volume lost when the drum height was reduced. The calculated reactivity under this severely crushed condition was $\mathrm{k}_{\text {eff }}=0.765 \pm 0.003$ (cemd2_ariccr). The reactivity was also calculated without maintaining the mass of polyethylene and steel, but by simply reducing the height of the drum and liner to a height of about $20 \mathrm{~cm}$. For this situation the reactivity is $\mathrm{k}_{\text {eff }}=0.880 \pm 0.004$ (cemd2_ariccr1).

There might be concern if cans were released from the drums during such an accident. However, these drums under beam loading are expected to deform and crush rather than rupture or shear because of the ductile and strength properties of the steel drums. Therefore, under credible accidents, few cans would be expected to be released from the drums. Those cans that are released from the drums are unlikely to coalesce because the matrix of drums will keep them separated. The interspersed steel drums will act as a neutron absorber for these few uncontained cans, maintaining safe reactivities.

\subsection{DESIGN FEATURES AND ADMINISTRATIVELY CONTROLLED LIMITS AND REQURREMENTS}

The administratively controlled limits applicable to this evaluation are:

1) Stacking heights shall not exceed 4 drums high,

2) Each cementation can may not contain more than $113 \mathrm{~g}$ of plutonium,

3) Each drum may not contain more that $200 \mathrm{~g}$ of total plutonium, and

4) The steel drum mass (empty) must exceed $16 \mathrm{~kg}$. 


\subsection{SUMMARY AND CONCLUSIONS}

This analysis has shown that the operation described above in Section 2, under the controls listed in Section 7 is safe from a criticality standpoint. No single identified credible contingency was able to exceed the criticality safety limit of $k_{\text {en }}=0.95$.

This evaluation demonstrates that $200 \mathrm{~g}$ of plutonium in cement may be safely stored in each 55-gallon drum if a number of administrative controls are maintained. Normal arrangements of the drums typically result in $k_{\text {efr }}$ values below 0.8 Stacking the drums as many as six high is acceptable with no other continency, while stacking the drums four high is shown to be acceptable with other contingencies. Concentrating the plutonium tends to increase the reactivity, but it has been shown that each can may contain up to $113 \mathrm{~g}$ of plutonium, with a maximum of $200 \mathrm{~g}$ per drum. The steel in the drum absorbs significant fractions of thermal neutrons, thereby reducing the system reactivity. The plastic liner used in the drums acts as a neutron shield, lowering interaction between drums. Either the steel drum must be present with a mass of at least $16 \mathrm{~kg}$ or the polyethylene liner $(0.229 \mathrm{~cm}$ thick $)$ must be present.

\subsection{REFERENCES}

Carter, R. D., 1980, Criticality Safety Analysis Report CSAR 80-021: Packaging, Storage and Disposal of Solid Waste (55-Gallon Drums, Unrestricted H/Pu Only), Rockwell Hanford Company, Richland, Washington.

Hess, A. L., 1996, CSER 96-013: Cementation Process, Glovebox HA-20MB at PFP, WHC-SDSQA-CSA-513, Rev. 1, Westinghouse Hanford Company, Richland, Washington.

Macklin, L.L. and E.M. Miller, 1992, CCVR 91-001; MONK6A Pu Validation, WHC-SD-SQA-CSWD-20015, REV. 0, Westinghouse Hanford Company, Richland, Washington.

Miller, E.M., 1994, CCVR 94-001; MONK6B Pu Validation, WHC-SD-SQA-CSWD-20019, REV. 0, Westinghouse Hanford Company, Richland, Washington.

UKEAE, 1988, MONK6A Monte Carlo Code for Criticality Calculations, Users Manual, AEEW R2195, Answers Business Center, Winfirth Technology Centre, Dorchester, Dorset, DT2 8DH, United Kingdom. 
HNF-SD-SQA-CSA-525 Rev. 0

APPENDIX A

\section{INDEPENDENT REVIEW COMMENTS AND CHECKLIST}

$A-1$ 
An independent technical review of CSER 96-027: Storage of Cemented Plutonium Residue Containers in 55 Gallon Drums was done by D. G. Erickson, Senior Scientist, in the Criticality and Shielding group. His comments are as follows:

The objective of this CSER is to increase the approved plutonium mass limit allowed in the 55-gallon drums loaded with cementation cans from. The current limit of $100 \mathrm{~g}$ was analyzed and approved in 1980 in CSAR 80-021 by Roger D. Carter. This CSER increases the approved limit to $200 \mathrm{~g}$. per 55 -gallon drum.

The analysis addressed normal drum and cementation can mass loadings and spacings. It was noticed as a part of this review that the most reactive credible geometry may not have been used for all normal and off normal analyses. Additional cases were requested and were run as a result. The results of those cases are reported in the off-normal section, along with several offnormal perturbations to very the criticality safety of the geometry.

All identified off-normal contingencies were also addressed. These include overbatching in cans and drums, internal and external moderation, cement composition, additional cans, drum overstacking, loss of absorbing or isolating materials, and loss of spacing. All normal and contingency conditions are subcritical with an adequate margin of safety.

The computer code input files were checked for correctness of geometry, materials and atom densities. Output files were checked for adequate convergence.

The CSER was reviewed and several editorial and spelling comments were made. Additional cases were requested to verify the worst credible condition were analyzed. Additional information on case identifiers was requested, and has been added to the final CSER.

Conservatism was introduced into the authors models by assuming the maximum plutonium mass loading for each drum, the worst moisture content for each cementation can, and minimizing the number of cans that may be in a drum. All reported results were for an infnite array in both lateral directions, with drums stacked 4 to 6 high. A comparison of a finite concrete reflected array to the infinite array was also made and was shown to be less reactive.

The analysis shows that internal moderation of the material in the cans has only a small effect on the $k_{\text {eff }}$ Interspersed moderation up to and including full density water encompassing all drums has a $k_{\text {eff }}$ well below the safety limit, and therefore bounds any conceivable water flooding.

The most reactive credible normal case had a $\mathbf{k}_{\text {eff }}<0.8$, significantly less than the criticality safety limit of 0.95 , and all credible off-normal cases were also below the criticality safety limit.

Based on the examination of the input data, assumptions and computer output this reviewer concurs with the conclusions of the CSER. It is acceptable to increase the mass loading of the 55-gallon drums loaded with cementation cans from $100 \mathrm{~g}$ of plutonium to $200 \mathrm{~g}$ of plutonium. 


\section{CHECKLIST FOR INDEPENDENT REVIEW}

Document Reviewed: CSER 96-027 Storage of Cemented Plutonium

Residue Containers in 55 Gallon Drums.

Author: $W$. T. Watson

Yes No N/A

[X] [ ] [ ] Problem completely defined.

[X] [ ] [ ] Necessary assumptions explicitly stated and supported.

[X] [ ] [ ] Computer codes and data files documented.

[X] [ ] [ ] Data checked for consistency with original source information as applicable.

[X] [ ] [ ] Mathematical derivations checked including dimensional consistency of results.

[X] [ ] [ ] Models appropriate and used within range of validity or use outside range of established validity justified.

[ ] [ ] [X] Hand calculations checked for errors.

[X] [ ] [ ] code run streams correct and consistent with analysis documentation.

[X] [ ] [ ] Code output consistent with input and with results reported in analysis documentation.

[X] [ ] [ ] Acceptability limits on analytical results applicable and supported. Limits checked against sources.

[X] [ ] [ ] safety margins consistent with good engineering practices.

[X] [ ] [ ] Conclusions consistent with analytical results and applicable limits.

[X] [ ] [ ] Results and conclusions address all points required in the problem statement.

[X] [ ] [ ] Have all reasonable accidents been considered?

[X] [ ] [ ] Has low density water (steam) been evaluated as a moderator?

[X] [ ] [ ] Is the fuel and other hardware composition correct?

[X] [ ] [ ] Are the cases considered conservative? Too conservative?

[X] [ ] [ ] Do the computer models adequately reflect the actual geometry? Have cross sectional cuts of the geometry been made and do they show the desired geometry?

[X] [ ] [ ] Has the analysis been reviewed by safety? This may not be required in a preliminary design.

[X] [ ] [ ] Has the reviewer completed the Criticality safety Course for Managers and Engineers?

Date completed__ March 1996

Reviewed by: Q. D. Eul Date $01 / 21 / 97$

NOTE: Any hand calculations, notes, or summaries generated as part of this review should be signed, dated, and attached to this checklist. Materials should be labeled and recorded so that it is intelligible to a technically-qualified third party. 


\section{APPENDIX B}

\section{MONK INPUT FILES}

* CEMD1_a Array of Dnums, 4 cans $50 \mathrm{~g}$ Pu ea arrange drum side FISSION

* \#MATERIALs \#NUClIDEs

*

$7 \quad 14$ NUCNAMES

* Mat \#1 Cement/Pu (normal (high) water content, $50 \mathrm{~g}$ Pu per can)

* density weightfractions

WGT 2.059 HINH2O 0.04095600 .487085 F19 0.032381 MG 0.067182 CA 0.363486 PU239 0.008910

* Mat \#2 Carbon Steel $1 \%$ C $7.86 \mathrm{~g} / \mathrm{cm}^{3}$

CONC C 0.003941 FE 0.0839103

*

* Mar $\# 3$ Steel (slip cover can)

WGT 7.9 C 0.005 AL27 0.001 \$1 0.006 P31 0.002 \$32 0.002 FE $0.983 \mathrm{SN} 0.001$

$+$

* Mat \#4 PVC [(CH2CH(Cl)]n

WGT 0.9 HINH 200.048386 C $0.384338 \mathrm{CL} 0.567275$

* Mat \#5 Water Vapor (mixed with void)

WGT 0.005 HINH2O 0.11188500 .888115

*

* Mat \#6 Polyethylene (CH2)n

WGT 0.96 HINH2O 0.14397 C 0.856303

* Mat \#7 Concrete, conservative Hanford (dens $=2.35 \mathrm{~g} / \mathrm{cm} 3$ )

CONC AL27 0.003358 CA 0.002614 FE 0.001344

HINH 200.00702300 .045396 \$I 0.01290 S

$*$

* PART \#1 Cementation can (cemented resiđue, steel can, PVC bag) NEST 3

ZCYL 16.98517 .8130 .033

ZCYL $3 \quad 6.98817 .8160 .030$

ZCYL $4 \quad 7.01817 .8460 .000$

* PART \#2 4 Cans near drum side (Case 1), including space in drum CLUSTER 5

ZROD ORIGIN 15.08115 .0810 .0000 P1 7.01817 .846

ZROD ORTGIN 15.081 -15.081 0.0000 P1 7.018 17.846

ZROD ORIGIN - $15.081-15.0810 .0000$ P1 7.01817 .846

ZROD ORIGIN - $15.081 \quad 15.0810 .0000$ P1 7.01817 .846

* 55 Gal 17C drum inner: 22.5 in $\mathrm{DD}, 33.25$ in inside height

* drum lined with 0.09 in thick poly $\rightarrow$ (22.32 ID, $33.07 \mathrm{IH})$

ZROD 0 28.3464 83.9978

* PART \#3 Drum with Poly liner (inside cube box of space)

NEST 4

ZCYL P2 28.3464 $84.3783 \quad 0.3805$

ZCYL $628.575 \quad 84.6069 \quad 0.15189$

ZCYL 228.7268984 .758790 .0

CUBOID $028.72728 .72784 .759-28.727-28.727-0.001$

* PART \#4 Artay of dnums: $X$ by $Y$ by $Z$

ARRAY 114

* Part (\#3) placed in array 4 times

(3)*4

* PART \#5 Array container / Concrete Floor (12in) \& Ceiling (8in)

NEST 2

CUBOID P4 57.454 57.454 339.040.00.0 0.

* ceiling $(339.04 \mathrm{~cm}+8 \mathrm{in})$ floor $(0-12 \mathrm{in})$

CUBOID $757.45457 .454359 .360 .00 .0-30.48$

* reflective surfaces on $X$ and $Y$ surfaces of outer cube

ALBEDO 1.0 1.0 0.0 1.0 1.0 0.0

* strtstage, endstage, thistperstage, time( $\mathrm{min}),-1$

$\begin{array}{llll}-6 & 30 & 1000 & 300\end{array}$

\author{
MULTIPOINT 4 \\ 29.29. 10. 1 \\ 29. 29. 95.1 \\ 29. 29.180 . 1 \\ 29. $29.265,1$ \\ END \\ CODE 7 \\ PSsVWpC \\ * yz \\ 0.143 .78 85. 57.443 .7885 . $0.143 .78-5$. \\ * yz \\ 13.657.4 20. $13.6 .120 .13 .657 .4-2$. \\ $* \mathrm{xy}$ \\ .157 .48 . 57.457 .48 .1 .18 . \\ BND
}

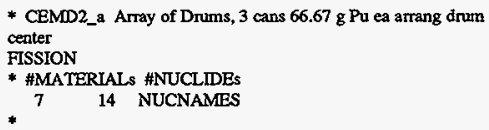

* Mat \#1 Cement/Pu (nomal (high) water content, $66.67 \mathrm{~g}$ Pu per can)

* density weightfractions

WGT 2.059 HINH2O 0.04083300 .485625 F19 0.032284 MG 0.066981 CA 0.362397 PU239 0.011881

* Mat \#2 Carbon Steel $1 \%$ C $7.86 \mathrm{~g} / \mathrm{cm} 3$

CONC C 0.003941 FE 0.0839103

*

* Mat \#3 Steel (slip cover can)

WGT 7.9 C 0.005 AL27 0.001 SI 0.006 P31 0.002 \$32 0.002 FE 0.983 SN 0.001

* Mat \#4 PVC [(CH2CH(Cl)]n

WGT 0.9 HINH2O 0.048386 C 0.384338 CL 0.567275

* Mat \#5 Water Vapor (mixed with yoid)

WGT 0.005 HINH2O 0.11188500 .888115

*

* Mat \#6 Polyethylene (CH2)n

WGT 0.96 HINH2O $0.14397 \mathrm{C} \quad 0.856303$

* Mat \#7 Concrete, conservative Hanford (dens=2.35 g/cm3)

CONC AL27 0.003358 CA 0.002614 FE 0.001344

HINH2O 0.007023 O 0.045396 SI 0.012905

$\mathrm{CM}$

* PART \#1 Cementation can (cemented residue, steel can, PVC bag) NEST 3

ZCYL $1 \quad 6.98517 .8130 .033$

ZCYL 36.98817 .8160 .030

ZCYL $4 \quad 7.01817 .8460 .000$

* PART \#2 3 Cans near drim center (Case 2), including space in drum

CLUSTER 4

ZROD ORIGIN 0.00008 .10370 .0000 P1 7.01817 .846

ZROD ORIGIN 7.0181 -4.05190 .0000 P1 7.01817 .846

ZROD ORIGIN - $7.0181-4.05190 .0000$ P1 7.018 17.846

* 55 Gal 17C drum inner. 22.5 in ID, 33.25 in inside height

* drum lined with 0.09 in thick poly $\rightarrow(22.32 \mathrm{ID}, 33.07 \mathrm{IH})$

ZROD 0 28.3464 83.9978 
- PART \#3 Drum with Poly liner (inside cube box of space) NEST 4

ZCYL P2 28.3464 84.37830 .3805

ZCYL $6 \quad 28.575 \quad 84.6069 \quad 0.15189$

ZCYL 228.7268984 .758790 .0

CUBOID $028.72728 .72784 .759-28.727-28.727-0.001$

* PART \#4 Array of drums: $X$ by $Y$ by $Z$

ARRAY 114

- Part (\#3) placed in array 4 times

(3)*4

* PART \#5 Array container / Concrete Floor (12in) \& Ceiling (8in)

NEST 2

CUBOID P4 57.454 57.454 339.04 0.00.0 0.

* ceiling $(339.04 \mathrm{~cm}+8$ in) floor $(0-12$ in $)$

CUBOID 7 57.454 57.454 359.36 0.0 0.0 -30.48

* reflective surfaces on $X$ and $Y$ surfaces of outer cube

ALBEDO 1.0 1.0 0.0 1.0 1.0 0.0

* strtstage, endstage, \#histperstage, time(min), -1

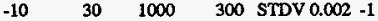

MULTIPOINT 4

29. 29. 10. 1

29. 29. 95.1

29. 29. 180.1

29. 29. 265.1

BND

CODE 7

PSsVWpC

$* x y$

$0.128 .785 .57 .428 .785 .0 .128 .7-5$.

$* \mathrm{yz}$

14 38. 10. 38. 38. 10. 141910 .

* $\mathrm{xy}$

.157 .48 .57 .457 .48 .1 .18 .

END

* CBMD2_2a Atray of Drums, 3 cans (2@ 43.5g, 1@ 113g) Pu ea arrange drum center

FISSION

* HMATERIALs \#NUCLIDEs

$8 \quad 14$ NUCNAMES

* Mat \#1 Cement/Pu (normal (high) water content, $43.5 \mathrm{~g}$ Pu per can)

* density weightfractions

WGT 2.059 HINH2O 0.04100300 .487654 F19 0.032419 MG 0.067261 CA 0.363911 PU239 0.007752

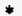

* Mat $\$ 2$ Carbon Steel $1 \%$ C $7.86 \mathrm{~g} / \mathrm{cm} 3$

CONC C 0.003941 FE 0.0839103

$*$

* Mat \#3 Steel (slip cover can)

WGT 7.9 C 0.005 AL27 0.001 SI 0.006 P31 0.002 S32 0.002 FE 0.983 SN 0.001

* Mat \#4 PVC [(CH2CH(Cl)]n

WGT 0.9 HINH2O 0.048386 C 0.384338 CL 0.567275

*

* Mat \#5 Water Vapor (mixed with void)

WGT 0.005 HINH2O 0.111885 O 0.888115

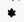

* Mat \#6 Polyethylene (CH2)n

WGT 0.96 HINH2O 0.14397 C 0.856303

*

* Mat $\# 7$ Concrete, conservative Hanford (dens $=2.35 \mathrm{~g} / \mathrm{cm} 3$ )

CONC AL27 0.003358 CA 0.002614 FE 0.001344 HINH 200.007023 O 0.045396 SI 0.012905

*

* Mat \#8 Cement/Pu (normal (high) water content, 113 g Pu per can)

* density weightfractions

WGT 2.059 HINH2O 0.04049200 .481567 F19 0.032014 MG 0.066421 CA 0.359369 PU239 0.020138
CM

* PART \#1 Cementation can (cemerted residue $43.5 \mathrm{~g} \mathrm{Pu}$, steel can, PVC bag)

NEST 3

ZCYL $1 \quad 6.98517 .8130 .033$

ZCYL $3 \quad 6.98817 .8160 .030$

ZCYL 47.01817 .8460 .000

* PART \#2 3 Cans near drum center (Case 2), including space in drum

CLUSTER 4

ZROD ORIGIN $0.0000 \quad 8.10370 .0000$ P6 7.018 17.846

ZROD ORIGIN 7.0181 -4.0519 0.0000 P1 7.018 17.846

ZROD ORIGIN $-7.0181-4.05190 .0000$ P1 7.01817 .846

* $55 \mathrm{Gal} 17 \mathrm{C}$ drum inner: 22.5 in ID, 33.25 in inside height

* drum lined with 0.09 in thick poly $\rightarrow(22.32 \mathrm{~W}, 33.07 \mathrm{HH})$

ZROD 028.346483 .9978

* PART \#3 Drum with Poly liner (inside cube box of space)

NEST 4

ZCYL P2 28.3464 $84.3783 \quad 0.3805$

ZCYL $6 \quad 28.575 \quad 84.60690 .15189$

ZCYL 228.7268984 .758790 .0

CUBOID 0 28.727 28.727 84.759 -28.727-28.727-0.001

* PART \#4 Array of drums: X by Y by Z

ARRAY 114

- Part (\#3) placed in array 4 times

$(3)^{*} 4$

* PART \#5 Array container / Concrete Floor (12in) \& Ceiling (8in)

NEST 2

CUBOID P4 57.45457 .454339 .040 .00 .00

* ceiling(339.04cm+8in) fioor $(0-12$ in $)$

CUBOID $757.45457 .454359 .360 .00 .0-30.48$

* reflective surfaces on $X$ and $Y$ surfaces of outer cube

ALBEDO 1.01 .00 .01 .01 .00 .0

* PART \#6 Cementation can (cemented residue $113 \mathrm{~g}$ Pu, steel can, PVC bag)

NEST 3

ZCYL $8 \quad 6.98517 .8130 .033$

ZCYL $3 \quad 6.98817 .8160 .030$

ZCYL $4 \quad 7.01817 .8460 .000$

* strtstage, endstage, fhistperstage, time(min), -1

$\begin{array}{lllll}-5 & 30 & 1000 & 300 & \text { STDV } 0.002-1\end{array}$

MULTPOINT 4

29. 29. 10. 1

29. 29. 95.1

29. 29. 180. 1

29. 29. 265. 1

END

CODE 7

PSsVWpC

* xy

$0.129 .85 .57 .429 .85,0.129,-10$

* yz

1938. 10. 38. 38. 10. 191910.

* $\mathrm{xy}$

19. $1920.38 .19 .20 .1919-1$

END

* CEMD2_3a Array of Drums, 3 cans $66.67 \mathrm{~g}$ Pu ea arrang drum center

FISSION

* \#MATERIALs \#NUCIDEs

$7 \quad 14$ NUCNAMES

* Mat \#1 Cement/Pu (notmal (high) water content, 66.67 g Pu per can)

- density weightfractions

WGT 2.059 HINH2O 0.04083300 .485625 F19 0.032284 MG 0.066981 CA 0.362397 PU2390.011881 
* Mat $\# 2$ Carbon Steel $1 \%$ C $7.86 \mathrm{~g} / \mathrm{cm} 3$ CONC C $0.003941 \mathrm{FE} 0.0839103$

* Mat \#3 Steel (slip cover can)

WGT 7.9 C 0.005 AL27 0.001 SI 0.006 P31 0.002 \$32 0.002 FE 0.983 SN 0.001

* Mat \#4 PVC [(CH2CH(C)]n

WGT 0.9 HNNH2O 0.048386 C $0.384338 \mathrm{Cl} 0.567275$

*

* Mat 45 Water Vapor (mixed with void)

WGT 0.005 HINH2O 0.11188500 .888115

* Mat \#6 Polyethylene ( $\mathrm{CH} 2$ )n

WGT $0.96 \mathrm{HINH} 200.14397 \mathrm{C} 0.856303$

$*$

* Mat \#7 Concrete, conservative Hanford (dens $=2.35 \mathrm{~g} / \mathrm{cm} 3$ )

CONC AL27 0.003358 CA 0.002614 FE 0.001344 HINH2O 0.00702300 .045396 SI 0.012905

CM

- PART \#1 Cementation can (cemented residue, steel can, PVC bag) NEST 3

ZCYL 1 6.985 17.8130 .033

ZCYL $3 \quad 6.98817 .8160 .030$

ZCYL $4 \quad 7.01817 .8460 .000$

* PART \#2 3 Cans near drum center, one stacked (Case 2_3), including space in Grum

CLUSTER 4

ZROD ORIGIN $0.0000 \quad 7.01810 .0000$ P1 7.018 17.846

ZROD ORIGIN $0.0000-7.01810 .0000$ P1 7.01817 .846

ZROD ORIGIN $0.0000 \quad 0.000017 .8461$ P1 7.01817 .846

* 55 Gal $17 \mathrm{C}$ drum inner 22.5 in ID, 33.25 in inside height

* drum lined with 0.09 in thick poly $\rightarrow$ (22.32 ID, $33.07 \mathrm{IH})$

ZROD 028.346483 .9978

* PART \#3 Drum with Poly liner (inside cube box of space) NEST 4

ZCYL P2 28.3464 84.3783 0.3805

ZCYL $6 \quad 28.575 \quad 84.60690 .15189$

ZCYL 228.7258984 .758790 .0

CUBOID 0 28.727 28.727 84.759-28.727 -28.727 -0.001

* PART \#4 Array of drums; $X$ by $Y$ by $Z$

ARRAY 114

* Part (\#3) placed in array 4 times

(3)*4

* PART \#S Array container / Concrete Foor (12in) \& Ceiling (8in)

NEST 2

CUBOID P4 57.454 57.454 339.04 0.00.0 0

* ceiling $(339.04 \mathrm{~cm}+8 \mathrm{in})$ floor $(0-12 \mathrm{in})$

CUBOID $757.45457 .454359 .360 .00 .0-30.48$

* reflective surfaces on $X$ and $Y$ surfaces of outer cube

ALBEDO 1.0 1.00.01.01.00.0

* strtstage, endstage, \#histperstage, time(min), -1

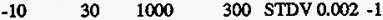

MULTIPOINT 4

29. 29. 10. 1

29. 29. 95.1

29. 29. 180.1

29. 29. 265. 1

END

CODB 7

PSsVWpC

* yz

0.128 .785 . $57.428 .785 .0 .128 .7-5$.

+ yz

$28.757 .440 .28 .7 .140 .28 .7657 .4-2$.

* xy

.157 .48 .57 .457 .48 .1 .18 .

END
* CEMD3_a Array of Drums, 3 cars $66.67 \mathrm{~g}$ Pu ea arrange drum

side

FISSION

* \#MAERIALs \#NUCliDEs

$7 \quad 14$ NUCNAMES

*

* Mat \#1 Cement/Pu (normal (high) water content, $66.67 \mathrm{~g}$ Pu per

can)

* density weightractions

WGT 2.059 HINH2O 0.04083300 .485625 F19 0.032284 MG 0.066981 CA 0.362397 PU239 0.011881

* Mat \#2 Carbon Steel $1 \%$ C $7.86 \mathrm{~g} / \mathrm{cm}^{3}$

CONC C 0.003941 FE 0.0839103

- Mat \#3 Steel (slip cover can)

WGT 7.9 C 0.005 AL27 0.001 \$I 0.006 P31 0.002 \$32 0.002 FE 0.983 SN 0.001

* Mat \#4 PVC [(CH2CH(C) $)]$

WGT 0.9 HINH 200.048386 C 0.384338 CL 0.567275

* Mat \#5 Water Vapor (mixed with void)

WGT 0.005 HINH2O 0.11188500 .888115

* Mat \#6 Polyethylene (CH2)n

WGT 0.96 HINH2O 0.14397 C 0.856303

* Mat \#7 Concrete, conservative Hanford (dens=2.35 g/cm3)

CONC AL27 0.003358 CA 0.002614 FE 0.001344 HINH 200.00702300 .045396 SI 0.012905

CM

* PART \#1 Cementation can (cemented residue, steel can, PVC bag) NEST 3

ZCYL $1 \quad 6.98517 .8130 .033$

ZCYL $3 \quad 6.98817 .8160 .030$

ZCYL $4 \quad 7.01817 .8460 .000$

* PART \#2 3 Cans near drum side (Case 3), including space in drum CLUSTER 4

ZROD ORIGIN 0.0000-21.3280.0000 P1 7.018 17.846

ZROD ORIGIN $18.47 \quad 10.66 \quad 0.0000$ P1 7.01817 .846

ZROD ORIGIN - $18.47 \quad 10.66 \quad 0.0000$ P1 7.01817 .846

* $55 \mathrm{Gal} 17 \mathrm{C}$ drum inner: 22.5 in ID, 33.25 in inside hejght

* dnum lined with 0.09 in thick poly $\rightarrow(22.32 \mathrm{ID}, 33.07 \mathrm{IH})$

ZROD 028.346483 .9978

- PART \#3 Drum with Poly liner (inside cube box of space)

NEST 4

ZCYL P2 28.3464 $84.3783 \quad 0.3805$

ZCYL $628.575 \quad 84.60690 .15189$

ZCYL 228.7268984 .758790 .0

CUBOID $028.72728 .72784 .759-28.727-28.727-0.001$

* PART \#4 Array of drums: $X$ by $Y$ by $Z$

ARRAY 114

- Part (\#3) placed in array 4 times

$(3) * 4$

- PART \#5 Array container/Concrete Floor (I2in) \& Ceiling (8in)

NEST 2

CUBOID P4 57.454 57.454 339.040.00.0 0.

* ceiling(339.04cm+8in) floor (0-12in)

CUBOD $757.45457 .454359 .360 .00 .0-30.48$

* reflective surfaces on $X$ and $Y$ surfaces of outer cube

ALBEDO 1.01 .00 .01 .01 .00 .0

PERIODIC Y

* strtstage, endstage, fhistperstage, time(min), -1

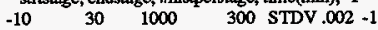

MULTIPOINT 4

29. 29. 10. 1

29. 29. 95.1

29. 29. 180.1

29. 29. 265. 1 
END

CODE 7

PSsVWpC

* yz

$0.139 .485 .57 .439 .485 .0 .139 .4-5$.

* yz

28.757.4 20. $28.7 .120 .28 .757 .4-2$

* xy

.157 .48 . $57.457 .48, .1 .18$.

END

* CEMD3_2a Array of Drums, 3 cans (2@ 43.5g, 1@ 113g) Pu ea arrange drum side

FISSION

* \#MATERIALs \#NUCLIDEs

$8 \quad 14$ NUCNAMES

* Mat \#1 Cement/Pu (normal (high) water content, 43.5 g Pu per can)

* density weightfractions

WGT 2.059 HINH2O $0.041003 \quad 00.487654$ F19 0.032419 MG 0.067261 CA 0.363911 PU239 0.007752

*

* Mat \#2 Carbon Steel $1 \%$ C $7.86 \mathrm{~g} / \mathrm{cm} 3$

CONC C 0.003941 FE 0.0839103

* Mar \#3 Steel (slip cover can)

WGT 7.9 C 0.005 AL27 0.001 SI 0.006 P31 0.002 S32 0.002 FE 0.983 SN 0.001

* Mat \#4 PVC I(CH2CH(C)]n

WGT 0.9 HINH2O 0.048386 C 0.384338 CL 0.567275

*

* Mat 45 Water Vapor (mixed with void)

WGT 0.005 HINH2O 0.11188500 .888115

* Mat \#6 Polyethylene (CH2)n

WGT 0.96 HINH2O $0.14397 \mathrm{C} 0.856303$

$\bullet$

* Mat \#7 Concrete, conservative Hanford (dens $=2.35 \mathrm{~g} / \mathrm{cm} 3$ )

CONC AL27 0.003358 CA 0.002614 FE 0.001344 HINH2O 0.00702300 .045396 SI 0.012905

$\bullet$

* Mat \#8 Cement/Pu (normal (high) water content, $113 \mathrm{~g}$ Pu per can)

* density weightfractions

WGT 2.059 HINH2O 0.04049200 .481567 F19 0.032014 MG 0.066421 CA 0.359369 PU239 0.020138

$\mathrm{CM}$

* PART \#1 Cementation can (cemented residue $43.5 \mathrm{~g} \mathrm{Pu,} \mathrm{steel} \mathrm{can,}$ PVC bag)

NEST 3

ZCYL $1 \quad 6.98517 .8130 .033$

ZCYL $3 \quad 6.98817 .8160 .030$

ZCXL $4 \quad 7.018 \quad 17.8460 .000$

* PART \#2 3 Cans near drum side (Case 3), including space in drum CLUSTER 4

ZROD ORIGIN $0.0000-21.3280 .0000$ P6 7.01817 .846

ZROD ORIGIN $18.47 \quad 10.66 \quad 0.0000$ P1 7.01817 .846

ZROD ORIGIN $-18.47 \quad 10.66 \quad 0.0000$ P1 7.01817 .846

* 55 Gal 17C drum inner: 22.5 in ID, 33.25 in inside height

* drum lined with 0.09 in thick poly $\rightarrow$ (22.32 ID, $33.07 \mathrm{IH})$

ZROD 028.346483 .9978

* PART \#3 Drum with Poly liner (inside cube box of space)

NEST 4

ZCYL P2 28.3464 $84.3783 \quad 0.3805$

ZCYL $628.575 \quad 84.60690 .15189$

ZCYL 228.7268984 .758790 .0

CUBOID $028.72728 .72784 .759-28.727-28.727-0.001$

* PART \#4 Array of drums: $X$ by $Y$ by $Z$

ARRAY 114
- Part (\#3) placed in array 4 times

(3) $* 4$

* PART \#5 Array container / Concrete Floor (12in) \& Ceiling (8in)

NEST 2

CUBOID P4 57.454 57.454 339.040.00.0 0.

* ceiling(339.04cm+8in) floor (0-12in)

CUBOM $757.45457 .454359 .360 .00 .0-30.48$

* reflective surfaces on $X$ and $Y$ sturfaces of outer cube

ALBEDO 1.0 1.0 0.0 1.0 1.0 0.0

* PART \#6 Cementation can (cemented residue $113 \mathrm{~g}$ Pu, steel can, PVC bag)

NEST 3

ZCYL $8 \quad 6.98517 .8130 .033$

ZCYL $3 \quad 6.98817 .8160 .030$

ZCYL $4 \quad 7.018 \quad 17.8460 .000$

- strtstage, endstage, thistperstage, time(min), -1

$\begin{array}{llll}-5 & 30 & 1000 & 180\end{array}$

MULTPONNT 4

29. 29. 10.1

29. 29. 95.1

29. 29. 180.1

29. 29. 265. 1

END

CODE 7

PSsVWpC

* xy

0.129 .85 . 57.429 .85 . $0.129 .-10$.

* yz

1938. 10. 38.38. 10. 191910 .

* xy

19. 19 20. 38. 19. 20. $1919-1$

END

* CEMD4_a Array of Drums, 2 cans (2@ 100g) Pu arrange drum center, stacked

FISSION

* \#MATERLALs \#NUCLIDEs

$7 \quad 14$ NUCNAMES

* Mat \#1 Cement/Pu (normal (high) water content, $100 \mathrm{~g}$ Pu per can)

* density weightfractions

WGT 2.059 HINH2O 0.04058700 .482706 F19 0.032090 MG 0.066578 CA 0.360218 PU239 0.017821

* Mat $\$ 2$ Carton Steel $1 \%$ C $7.86 \mathrm{~g} / \mathrm{cm}^{3}$

CONC C $0.003941 \mathrm{FE} 0.0839103$

*

* Mar \#3 Steel (slip cover can)

WGT 7.9 C 0.005 AL27 0.001 SI 0.006 P31 0.002 S32 0.002 FE 0.983 SN 0.001

* Mat \#4 PVC [(CH2CH(Cl)]

WGT 0.9 HNH 200.048386 C 0.384338 CL 0.567275

* Mat \#5 Water Vapor (mixed with void)

WGT 0.005 HINH2O 0.11188500 .888115

*

* Mat \#6 Polyethylene (CH2)n

WGT 0.96 HINH2O 0.14397 C 0.856303

* Mat $\# 7$ Concrete, conservative Hanford (dens $=2.35 \mathrm{~g} / \mathrm{cm} 3$ )

CONC AL270.003358 CA 0.002614 FE 0.001344

HINH2O 0.007023 O 0.045396 SI 0.012905

CM

* PART \#1 Cementation can (cemented residue 43.5g Pu, steel can, PVC bag)

NEST 3

ZCYL 16.98517 .8130 .033 
ZCYL $3 \quad 6.98817 .8160 .030$

ZCYL $4 \quad 7.01817 .8460 .000$

* PART \#2 3 Cans near drum center (Case 4), including space in drum

CLUSTER 3

ZROD ORIGLN $0.0000 \quad 0.00000 .0000$ P1 7.01817 .846

ZROD ORIGIN $0.0000 \quad 0.000017 .8461$ P1 7.01817 .846

- $55 \mathrm{Gal} 17 \mathrm{C}$ dnum inner: 22.5 in ID, 33.25 in inside height

* drum lined with 0.09 in thick poly $\rightarrow(22.32 \mathrm{ID}, 33.07 \mathrm{IH})$

ZROD 028.346483 .9978

- PART \#3 Drum with Poly liner (inside cube box of space) NEST 4

ZCYL P2 28.3464 $84.3783 \quad 0.3805$

ZCYL, $6 \begin{array}{llll}28.575 & 84.6069 & 0.15189\end{array}$

ZCYL 228.7268984 .758790 .0

CUBOID 0 28.727 28.727 84.759-28.727 -28.727 -0.001

* PART \#4 Array of drums: X by Y by $Z$

ARRAY 1 i 4

* Part (\#3) placed in array 4 times

$(3) * 4$

* PART \#5 Anay container / Concrete Floor (12in) \& Ceiling (8in)

NEST 2

CUBOID P4 57.454 57.454 339.04 0.0 0.0 0 .

* ceiling(339.04cm+8in) floor $(0-12 \mathrm{in})$

CUBOID 7 57.454 57.454 359.36 0.0 0.0 -30.48

* reflective suffaces on $X$ and $Y$ surfaces of outer cube

ALBEDO 1.0 1.0 0.0 1.0 1.0 0.0

* stristage, endstage, fhistperstage, time(min), -1

$\begin{array}{llllll}-5 & 30 & 1000 & 300 & & \end{array}$

MULTIPOINT 4

29. 29. 10. 1

29. 29. 95.1

29. 29. 180. 1

29. 29. 265 . 1

END

CODE 7

PSsVWpC

* yz

0.128 .785 .57 .428 .785 . 0.128 .7 -5.

* yz

28.7 57.4 40. 28.7 .140 .28 .757 .4 -2.

* $x y$

.1 57.4 8. 57.4 57.48..1.18.

END

*CEMD4_2a Array of Drums, 2 cans $(1 @ 113 \mathrm{~g}, 1 @ 87 \mathrm{~g}$ ) Pu arrange drum center, stacked

FISSION

* \#MATERIALs \#NUCLIDEs $8 \quad 14$ NUCNAMES

$*$

* Mat \#1 Cement/Pa (nomal (high) water content, $87 \mathrm{~g}$ Pu per can)

- density weightfractions

WGT 2.059 HINH2O 0.04068300 .483844 F19 0.032165 MG 0.066735 CA 0.361068 PU239 0.015504

*

* Mat \#2 Carbon Steel $1 \%$ C $7.86 \mathrm{~g} / \mathrm{cm}^{3}$

CONC C 0.003941 FE 0.0839103

* Mat \#3 Steel (slip cover can)

WGT 7.9 C 0.005 AL27 0.001 SI 0.006 P31 $0.002 \$ 320.002$ FE 0.983 SN 0.001

* Mat \#4 PVC [(CH2CH(C)]n

WGT 0.9 HINH2O 0.048386 C 0.384338 a 0.567275

* Mat \#S Water Vapor (mixed with void)

WGT 0.005 HINH2O 0.11188500 .888115

* Mat \#6 Polyethylene (CH2)n

\author{
WGT 0.96 HINH2O 0.14397 C 0.856303 \\ * Mat \#7 Concrete, conservative Hanford (dens=2.35 $\mathrm{g} / \mathrm{cm} 3$ ) \\ CONC AL27 0.003358 CA 0.002614 FB 0.001344 \\ HINH2O 0.00702300 .045396 SI 0.012905 \\ * Mat \#8 Cement/Pu (normal (high) water content, $113 \mathrm{~g}$ Pu per can) \\ * density weightfractions \\ WGT 2.059 HINH2O 0.04049200 .481567 F19 0.032014 \\ MG 0.066421 CA 0.359369 PU239 0.020138 \\ $\mathrm{CM}$ \\ - PART \#1 Cementation can (cemented residue $87 \mathrm{~g} \mathrm{Pu}$, steel can, \\ PVC bag) \\ NEST 3 \\ ZCYL $1 \quad 6.98517 .8130 .033$ \\ ZCYL $3 \quad 6.98817 .8160 .030$ \\ ZCYL $4 \quad 7.01817 .8460 .000$ \\ * PART \#2 3 Cans near dnum center (Case 4), including space in \\ drum \\ CLUSTER 3 \\ ZROD ORIGIN 0.0000 0.0000 0.0000 P6 7.018 17.846 \\ ZROD ORIGIN $0.0000 \quad 0.000017 .8461$ P1 7.018 17.846 \\ * 55 Gal 17C drum inner: 22.5 in ID, 33.25 in inside height \\ - dum lined with 0.09 in thick poly $\rightarrow$ (22.32 ID, 33.07 IH) \\ ZROD 0 28.3464 83.9978 \\ * PART \#3 Drum with Poly liner (inside cube box of space) \\ NEST 4 \\ ZCYL P2 $28.346484 .3783 \quad 0.3805$ \\ ZCYL $6 \quad 28.575 \quad 84.60690 .15189$ \\ ZCYL 2 28.72689 84.75879 0.0 \\ CUBOID $028.72728 .72784 .759-28.727-28.727-0.001$ \\ * PART \#4 Array of drums: X by $Y$ by $Z$ \\ ARRAY 114 \\ * Part (\#3) placed in array 4 times \\ (3)*4 \\ * PART \#5 Array container / Concrete Floor (12in) \& Ceiling (8in) \\ NEST 2 \\ CUBOID P4 57.454 57.454 339.040.00.0 0. \\ * ceiling(339.04cm+8in) floor (0-12in) \\ CUBOD $757.45457 .454359 .360 .00 .0-30.48$ \\ * Ieflective surfaces on $X$ and $Y$ surfaces of outer cube \\ ALBEDO 1.01 .00 .01 .01 .00 .0 \\ * PART \#6 Cementation can (cemented residue $113 \mathrm{~g}$ Pu, steel can, \\ PVCbag) \\ NEST 3 \\ ZCYL $8 \quad 6.98517 .8130 .033$ \\ ZCYL 36.98817 .8160 .030 \\ ZCYL 47.01817 .8460 .000 \\ * strtstage, endstage, thistperstage, time(min), -1 \\ $\begin{array}{llllll}-5 & 30 & 1000 & 300 & \text { STDV } 0.002 & -1\end{array}$ \\ MULTIPOINT 4 \\ 29. 29. 10. 1 \\ 29. 29. 95.1 \\ 29. 29. 180.1 \\ 29.29 .265 .1 \\ END \\ CODE 7 \\ PSsVWpC \\ * $\mathbf{x y}$ \\ 0.129 .85 . 57.4 29. 85. 0.1 29. -10 . \\ * yz \\ 19 38. 10. 38. 38. 10. 191910 . \\ * $\mathrm{xy}$ \\ 19. 1920. $38.19 .20 .1919-1$ \\ END
}

* CEMDS_a Array of Drums, 2 cans $(2 @ 100 \mathrm{~g})$ Pu arrange drum side FISSION 


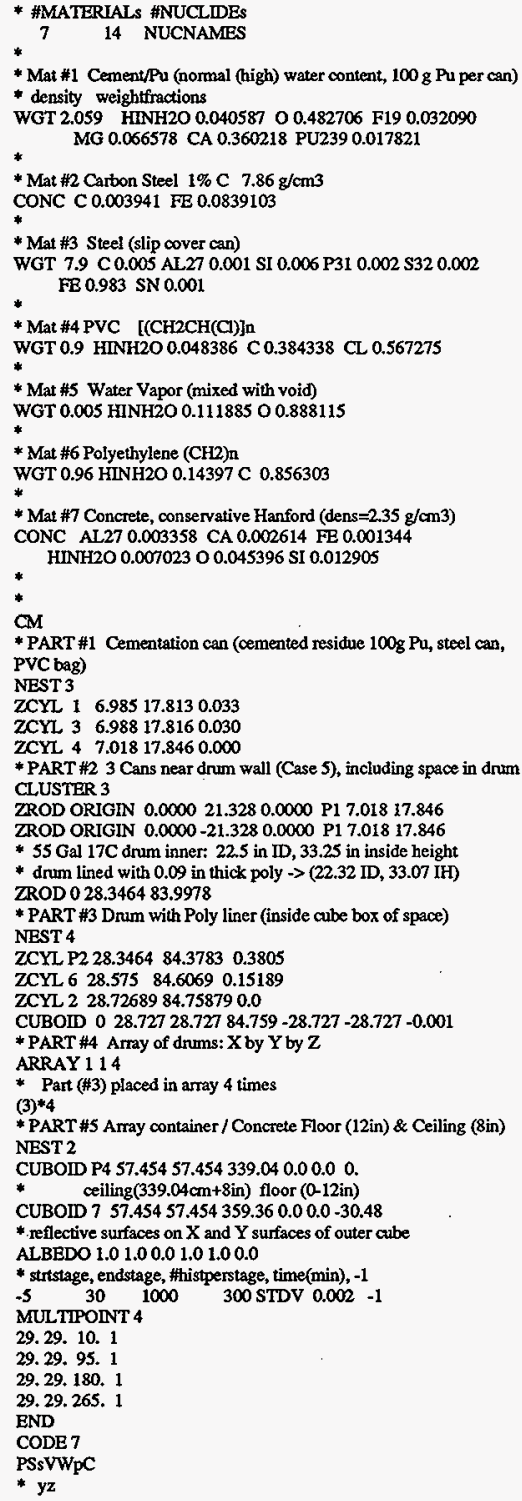

0.15085 . 57.45085 . $0.150-5$.

* yz

28.7 57.4 20. 28.76 .1 20. 28.757 .4 -2.

* xy

.157 .48 .57 .457 .48 .1 .18 .

END

* CEMDS_2a Array of Drums, 2 cans $(1 @ 113 g, 1 @ 87 g)$ Pu arrange drum wall

FISSION

$\begin{array}{ccc}\text { * \#MATERIALs \#NUCLIDEs } \\ 8 & 14 & \text { NUCNAMES }\end{array}$

* Mat \#1 Cement/Pu (normal (high) water content, 87 g Pu per can)

* density weightfractions

WGT 2.059 HINH2O 0.04068300 .483844 F19 0.032165 MG 0.066735 CA 0.361068 PU239 0.015504

* Mat fl Carbon Steel $1 \%$ C $7.86 \mathrm{~g} / \mathrm{cm}^{3}$

CONC C 0.003941 FB 0.0839103

*

* Mat \#3 Steel (slip cover can)

WGT 7.9 C 0.005 AL27 0.001 \$I 0.006 P31 0.002 \$32 0.002 FE 0.983 SN 0.001

* Mat \#4 PVC [(CH2CH(Cl)]n

WGT 0.9 HINH2O 0.048386 C 0.384338 CL 0.567275

*

* Mat \#S Water Vapor (mixed with void)

WGT 0.005 HINH2O 0.11188500 .888115

* Mat \#6 Polyethylene (CH2)n

WGT 0.96 HINH2O $0.14397 \mathrm{C} 0.856303$

*

* Mat \#7 Concrete, conservative Hanford (dens=2.35 g/cm3)

CONC AL27 0.003358 CA 0.002614 FE 0.001344 HINH2O 0.00702300 .045396 \$I 0.012905

*

* Mat \#8 Cement/Pu (nomal (high) water content, 113 g Pa per can)

* density weightfractions

WGT 2.059 HINH2O 0.04049200 .481567 F19 0.032014 MG 0.066421 CA 0.359369 PU239 0.020138

$\mathrm{CM}$

* PART \#1 Cementation can (cemented residue $87 \mathrm{~g}$ Pu, steel can, PVC bag)

NEST 3

ZCYL 16.98517 .8130 .033

ZCYL $3 \quad 6.98817 .8160 .030$

ZCYL $4 \quad 7.018 \quad 17.8460 .000$

* PART \#2 3 Cans near drum wall (Case 5), including space in drum CLUSTER 3

ZROD ORIGIN 0.000021 .3280 .0000 P6 7.018 17.846

ZROD ORIGIN $0.0000-21.3280 .0000$ P1 7.018 17.846

* 55 Gal 17C drum inner. 22.5 in ID, 33.25 in inside height

* drum lined with 0.09 in thick poly $\rightarrow(22.32 \mathrm{ID}, 33.07 \mathrm{IH})$

ZROD 028.346483 .9978

* PART \#3 Drum with Poly liner (inside cube box of space) NEST 4

ZCYL P2 28.3464 84.3783 0.3805

ZCYL $628.575 \quad 84.6069 \quad 0.15189$

ZCYL 228.7268984 .758790 .0

CUBOID $028.72728 .72784 .759-28.727-28.727-0.001$

* PART \#4 Array of dums: X by $Y$ by $Z$

ARRAY 114

- Part (\#3) placed in array 4 times

$(3) * 4$

* PART \#5 Amay container / Concrete Floor (12in) \& Ceiling (8in)

NEST 2

CUBOID P4 57.454 57.454339.040.00.0 0. 


\section{HNF-SD-SQA-CSA-525 Rev. 0}

* ceiling(339.04cm+8in) floor (0-12in)

CUBOID $757.45457 .454359 .360 .00 .0-30.48$

* reflective suffaces on $X$ and $Y$ surfaces of outer cube

ALBEDO 1.0 1.00.01.01.00.0

* PART \#6 Cementation can (cemented residue 113g Pu, steel can, PVC bag)

NEST 3

ZCYL $8 \quad 6.98517 .8130 .033$

ZCYL $3 \quad 6.98817 .8160 .030$

ZCYL $4 \quad 7.01817 .8460 .000$

* strtstage, endstage, 䊉istperstage, time( $\mathrm{min}),-1$

$\begin{array}{lllllll}-5 & 30 & 1000 & 300 \text { STDV } 0.002 & -1\end{array}$

MULTIPOINT 4

29. 29. 10. 1

29. 29. 95.1

29. 29. 180.1

29. 29. 265 .

BND

CODE7

PSsVWpC

* xy

$0.129 .85,57.429 .85$. $0.129 .-10$.

* yz

1938. 10. 38.38. 10. 191910.

* xy

19.19 20. 38. 19. 20. $1919-1$

END

* CEMD2_acl Anray of Drums, 3 cans $66.67 \mathrm{~g}$ Pu ea arrang drum center

FISSION

* "MATERIALs \#NUCLIDEs

$7 \quad 14$ NUCNAMES

$*$

- Mat \#1 Cement/Pu (66.67 g Pu per can)

* Water weight fraction: 0.24 , equivilent to $H$ conc assuming all $H$ from $\mathrm{H} 2 \mathrm{O}$

* density weightfractions

WGT 2.059 HINH2O $0.026857 \quad 00.407088$ F19 0.038753 MG 0.080403 CA 0.435018 PU239 0.011881

* Mat \#2 Carbon Steel $1 \%$ C $7.86 \mathrm{~g} / \mathrm{cm} 3$

CONC C 0.003941 FE 0.0839103

* Mat \#3 Steel (slip cover can)

WGT 7.9 C 0.005 AL27 0.001 SI 0.006 P31 $0.002 \$ 320.002$ FE 0.983 SN 0.001

* Mat \#4 PVC [(CH2CH(Cl)]n

WGT 0.9 HINH2O $0.048386 \cdot C 0.384338$ CL 0.567275

* Mat 45 Water Vapor (mixed with void)

WGT 0.005 HINH2O 0.11188500 .888115

* Mat \#6 Polyethylene ( $\mathrm{CH} 2)$ n

WGT $0.96 \mathrm{HHNH} 2 \mathrm{O} 0.14397 \mathrm{C} 0.856303$

* Mat \#7 Concrete, conservative Hanford (dens $=2.35 \mathrm{~g} / \mathrm{cm} 3$ )

CONC AL27 0.003358 CA 0.002614 FE 0.001344 HINH2O 0.00702300 .045396 SI 0.012905

CM

* PART \#1 Cementation can (cemented residue, steel can, PVC bag) NEST 3

ZCYL $1 \quad 6.98517 .8130 .033$

ZCYL 36.98817 .8160 .030

ZCYL $4 \quad 7.01817 .8460 .000$

* PART \#2 3 Cans near drum center (Case 2), including space in drum

CLUSTER 4
ZROD ORIGIN 0.00008 .10370 .0000 P1 7.01817 .846 ZROD ORIGIN 7.0181 -4.05190 .0000 P1 7.01817 .846 ZROD ORIGIN $-7.0181-4.05190 .0000$ P1 7.01817 .846

* 55 Gal $17 \mathrm{C}$ drum inner: 22.5 in ID, 33.25 in inside height

* drum lined with 0.09 in thick poly $\rightarrow$ (22.32 ID, $33.07 \mathrm{IH})$

ZROD 0 28.3464 83.9978

* PART \#3 Drum with Poly liner (inside cube box of space) NEST 4

ZCYL P2 28.3464 $84.3783 \quad 0.3805$

ZCYL $628.575 \quad 84.6069 \quad 0.15189$

ZCYL 228.7268984 .758790 .0

CUBOID 0 28.727 28.727 84.759 -28.727 -28.727-0.001

* PART \#4 Amay of drums: $X$ by $Y$ by $Z$

ARRAY 114

* Part (\$3) placed in array 4 times

(3)*4

* PART \#5 Array container / Concrete Floor (12in) \& Ceiling (8in) NEST 2

CUBOID P4 57.454 57.454 339.04 0.00.0 0

* ceiling( $339.04 \mathrm{~cm}+8 \mathrm{in})$ floor (0-12in)

CUBOID 7 57.454 57.454 359.36 0.0 0.0 -30.48

* reflective surfaces on $X$ and $Y$ surfaces of outer cube

ALBEDO 1.01 .00 .01 .01 .00 .0

* strtstage, endstage, fhistperstage, time(min), -1

$\begin{array}{lllll}-10 & 30 & 1000 & 300 & \text { STDV } .002-1\end{array}$

MULTTPOINT 4

29. 29. 10. 1

29. 29. 95.1

29. 29. 180.1

29. 29. 265. 1

END

CODE 7

PSsVWpC

* $x y$

$0.129 .85 .57 .429 .85,0.129 .-10$.

- yz

1938. 10. 38. 38. 10 . 191910

* $x y$

19. 19 20. 38. 19.20. $1919-1$

END

- CEMD2_ac3 Array of Drums, 3 cans $66.67 \mathrm{~g}$ Pu ea arrang drum center

FISSION

* \#MATERIALs \#NUCLIDEs

$7 \quad 14$ NUCNAMES

* Mat \#l Cement/Pa (66.67 g Pu per can)

* Water weight fraction: 0.29 , equivilent to $H$ conc assuming all $H$ from $\mathrm{H} 2 \mathrm{O}$

* density weightfractions

WGT 2.059 HINH2O $0.032452 \quad 00.43853$ F19 0.036163 MG 0.07503 CA 0.405944 PU239 0.011881

* Mat \#2 Carbon Steel $1 \%$ C $7.86 \mathrm{~g} / \mathrm{cm} 3$

CONC C 0.003941 FR 0.0839103

* Mat \#3 Steel (slip cover can)

WGT 7.9 C 0.005 AL27 0.001 SI 0.006 P31 0.002 S32 0.002 FE 0.983 SN 0.001

* Mat \#4 PVC [(CH2CH(Cl)]n

WGT 0.9 HINH2O 0.048386 C 0.384338 CL 0.567275

* Mat \#5 Water Vapor (mixed with void)

WGT 0.005 HINH2O 0.111885 O 0.888115

* Mat \#6 Polyethylene (CH2)n

WGT 0.96 HINH2O $0.14397 \mathrm{C} \quad 0.856303$ 


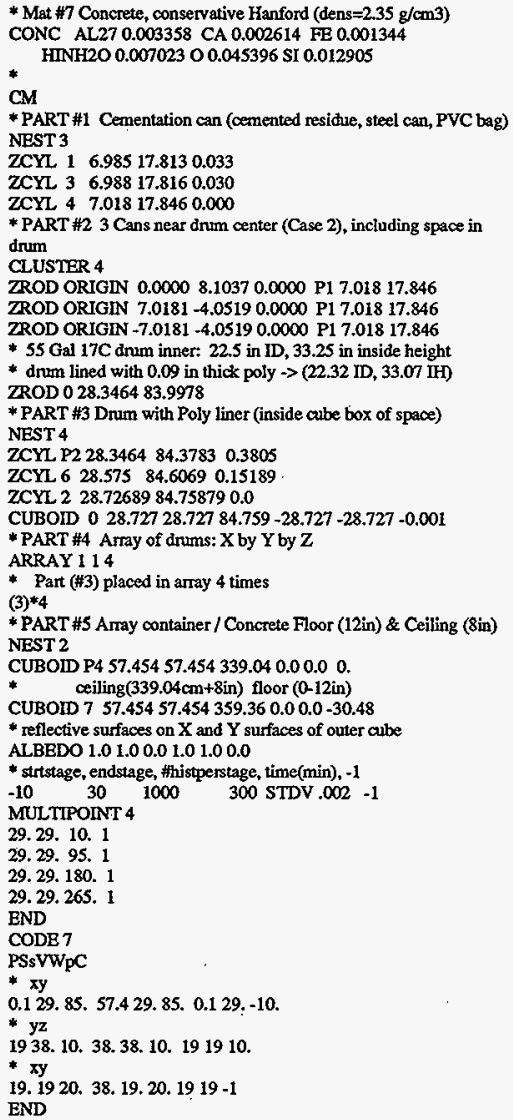

* CEMD2 ac5 Array of Drums, 3 cans $66.67 \mathrm{~g}$ Pu ea arrang drum center FISSION

* Mat \#1 Cement/Pu (66.67 g Pu per can)

* Water weight fraction: 0.32 , equivilent to $\mathrm{H}$ conc assuming all $\mathrm{H}$ from $\mathrm{H} 2 \mathrm{O}$

* density weightfractions

WGT 2.059 HNNH2O 0.03804700 .469973 F19 0.033573 MG 0.069656 CA 0.37687 PU239 0.011881

* Mat \#2 Carbon Steel $1 \%$ C $7.86 \mathrm{~g} / \mathrm{cm} 3$ CONC C 0.003941 FE 0.0839103
* Mat \#3 Steel (slip cover can)

WGT 7.9 C 0.005 AL27 0.001 \$I 0.006 P31 $0.002 \$ 320.002$ FE 0.983 SN 0.001

* Mat \#4 PVC [(CH2CH(C) $)]$

WGT 0.9 HINH2O 0.048386 C 0.384338 CL 0.567275

* Mat \#5 Water Vapor (mixed with void)

WGT 0.005 HINH2O 0.11188500 .888115

- Mat \#6 Polyethylene.(CH2)n

WGT 0.96 HINH2O 0.14397 C 0.856303

* Mat \#7 Concrete, conservative Hanford (dens=2.35 g/cm3)

CONC AL27 0.003358 CA 0.002614 FE 0.001344 HINH2O 0.00702300 .045396 SI 0.012905

$\mathrm{CM}$

* PART \#1 Cementation can (cemented residue, steel can, PVC bag) NEST 3

ZCYL 16.98517 .8130 .033

ZCXL $3 \quad 6.98817 .8160 .030$

ZCXL $4 \quad 7.01817 .8460 .000$

* PART \#2 3 Cans near drum center (Case 2), including space in drum

CLUSTER 4

ZROD ORIGIN 0.00008 .10370 .0000 P1 7.01817 .846

ZROD ORIGIN 7.0181 -4.0519 0.0000 P1 7.018 17.846

ZROD ORIGIN $-7.0181-4.05190 .0000$ P1 7.01817 .846

* 55 Gal 17C drum inner: 22.5 in ID, 33.25 in inside height

* dnum lined with 0.09 in thick poly $\rightarrow$ (22.32 ID, $33.07 \mathrm{IH}$ )

ZROD 0 28.346483.9978

* PART \#3 Drum with Poly liner (inside cube box of space)

NEST 4

ZCYL P2 28.3464 $84.3783 \quad 0.3805$

ZCYL 628.57584 .60690 .15189

ZCYL 228.7268984 .758790 .0

CUBOID $028.72728 .72784 .759-28.727-28.727-0.001$

* PART \#4 Artay of drums: $X$ by $Y$ by $Z$

ARRAY 114

* Part (\#3) placed in array 4 times

(3)*4

* PART \#5 Array container/Concrete Floor (12in) \& Ceiling (8in) NEST 2

CUBOID P4 57.454 57.454 339.04 0.0 0.0 0.

* ceiling $(339.04 \mathrm{~cm}+8$ in) floor $(0-12 \mathrm{in})$

CUBOID $757.45457 .454359 .360 .00 .0-30.48$

* reflective surfaces on $X$ and $Y$ surfaces of outer cube

ALBEDO 1.0 1.0 0.0 1.0 1.0 0.0

* strtstage, endstage, fhistperstage, time(min), -1

$\begin{array}{llllll}-10 & 30 & 1000 \quad 300 \text { STDV } .002 & -1\end{array}$

MULTIPOINT 4

29. 29. 10. 1

29. 29.95 . 1

29. 29.180 .1

29. 29. 265. 1

END

CODE 7

PSsVWpC

* xy

$0.129 .85 .57 .429,85,0.129,-10$.

* yz

1938. 10. 38. 38. 10. 191910 .

* xy

19. 1920 . 38. 19.20.1919-1

BND

* CEMD2_ac7 Array of Drums, 3 cans 66.67 g Pu ea arrang drum center

FISSION 
HNF-SD-SQA-CSA-525 Rev. 0

* \#MATERIALs \#NUCLIDEs

$7 \quad 14$ NUCNAMES

* Mat \#1 Cement/Pu (66.67 g Pu per can)

* Water wejght fraction: 0.40 , equivilent to $H$ conc assuming all $H$ from $\mathrm{H} 2 \mathrm{O}$

* density weightfractions

WGT 2.059 HINH2O 0.04476200 .507704 F19 0.030465 MG 0.063207 CA 0.341981 PU239 0.011881

$\star$

* Mat 22 Carbon Steel $1 \%$ C $7.86 \mathrm{~g}^{\mathrm{cm} 3}$

CONC C 0.003941 FE 0.0839103

$+$

* Mat 43 Steel (slip cover can)

WGT 7.9 C 0.005 AL27 0.001 SI 0.006 P31 $0.002 \mathrm{S32} 0.002$ FE 0.983 SN 0.001

* Mat \#4 PVC [(CH2CH(Cl)]n

WGT 0.9 HINH2O 0.048386 C 0.384338 CL 0.567275 $\bullet$

* Mat \#5 Water Vapor (mixed with void)

WGT 0.005 HINH2O 0.11188500 .888115

*

* Mat \#6 Polyethylene (CH2)n

WGT 0.96 HNH2O 0.14397 C 0.856303

*

- Mat \#7 Concrete, conservative Hanford (dens=2.35 g/cm3)

CONC AL27 0.003358 CA 0.002614 FE 0.001344

HINH 200.00702300 .045396 SI 0.012905

$\mathrm{CM}$

* PART \#1 Cementation can (cemented residue, steel can, PVC bag) NEST 3

ZCYL $1 \quad 6.98517 .8130 .033$

ZCYL $3 \quad 6.98817 .8160 .030$
PSsVWp

* $\mathbf{x y}$

$0.129 .85 .57 .429 .85 .0 .129 . \cdot 10$.

* yz

1938.10 .38 .38 .10 .191910$.

* $\mathbf{x y}$

19. $1920.38 .19 .20 .1919-1$

END

* CEMD2_ac9 Array of Drums, 3 cans $66.67 \mathrm{~g}$ Pu ea arrang drum center

FISSTON

* \#MATERIALs \#NUCLIDEs

$7 \quad 14$ NUCNAMES

* Mat 11 CementPa (66.67 g Pu per can)

* Water weight fraction: 0.44 , equivilent to $H$ conc assuming all $\mathrm{H}$ from $\mathrm{H2O}$

* density weightfractions

WGT 2.059 HINH2O 0.04923800 .532858 F19 0.028393 MG 0.058908 CA 0.318722 PU239 0.011881

* Mat \#2 Carbon Steel $1 \%$ C $7.86 \mathrm{~g} / \mathrm{cm} 3$

CONC C 0.003941 FE 0.0839103

* Mat \#3 Steel (slip cover can)

WGT 7.9 C0.005 AL27 0.001 SI 0.006 P31 0.002 S32 0.002 FE 0.983 SN 0.001

* Mat \#4 PVC [(CH2CH(C)]n

WGT 0.9 HWNH2O 0.048386 C 0.384338 CL 0.567275

$*$

* Mat \#S Water Vapor (mixed with void)

WGT 0.005 HINH2O 0.11188500 .888115 


\section{HNF-SD-SQA-CSA-525 Rev. 0}

* cetting(339.04cm+8in) floor (0-12in)

CUBOID $757.45457 .454359 .360 .00 .0-30.48$

* reflective surfaces on $X$ and $Y$ surfaces of outer cube

ALBEDO 1.0 1.0 0.0 1.0 1.0 0.0

* strtstage, endskage, \#istperstage, time(min), -1

$\begin{array}{llllll}-10 & 30 & 1000 & 300 & \text { STDV } 0.002 & -1\end{array}$

MULTIPOINT 4

29. 29. 10. 1

29. 29. 95.1

29. 29. 180 . 1

29. 29. 265. 1

END

CODE 7

PSsVWpC

* $x y$

$0.129 .85,57.429 .85,0.129 .-10$.

* yz

1938. 10. 38. 38. 10. 191910 .

* $x y$

19. $1920.38 .19 .20 .1919-1$

END

- CEMD2_ac11 Array of Drums, 3 cans $66.67 \mathrm{~g}$ Pu ea arrang drum center FISSION

* \#Materials \#Nuclidos

14 NUCNAMES

* Mat \#1 Cement/Pu (66.67 g Pu per can)

* Water weight fraction: 0.48 , equivilent to $H$ conc assuming all $H$ from $\mathrm{H} 2 \mathrm{O}$

* density weightfractions

WGT 2.059 HINH2O $0.053714 \quad 0.558012$ F19 0.026321

$*$ MG 0.054609 CA 0.295463 PU239 0.011881

* Mat \#2 Carbon Steel $1 \%$ C $7.86 \mathrm{~g} / \mathrm{cm} 3$

CONC C 0.003941 FE 0.0839103

* Mat \#3 Steel (slip cover can)

WGT 7.9 C 0.005 AL27 0.001 SI 0.006 P31 0.002 S32 0.002 FE 0.983 SN 0.001

* Mat \#4 PVC [(CH2CH(Cl)]n

WGT 0.9 HINH2O 0.048386 C 0.384338 C. 0.567275

* Mat \#5 Water Vapor (mixed with void)

WGT 0.005 HINH2O 0.11188500 .888115

*

* Mat \#6 Polyethylene (CH2)n

WGT 0.96 HINH2O 0.14397 C 0.856303

* Mat \#7 Concrete, conservative Hanford (dens $=2.35 \mathrm{~g} / \mathrm{cm} 3$ )

CONC AL27 0.003358 CA 0.002614 FE 0.001344 IINH2O 0.00002300 .045396 SI 0.012905

$\mathrm{CM}$

* PART \#1 Cementation can (cemented residue, steel can, PVC bag) NEST 3

ZCYL I 6.98517 .8130 .033

ZCYL 36.98817 .8160 .030

ZCYL $4 \quad 7.01817 .8460 .000$

* PART \#2 3 Cans near drum center (Case 2), including space in dinm

CLIUSTER 4

ZROD ORIGIN 0.0000 8.1037 0.0000 P1 7.018 17.846

ZROD ORIGIN 7.0181 -4.05190 .0000 Pl 7.018 17.846 ZROD ORIGIN $-7.0181+4.05190 .0000$ P1 7.018 17.846

* $55 \mathrm{Gal} 17 \mathrm{C}$ dnum inner 22.5 in ID, 33.25 in inside height

* drum lined with 0.09 in thick poly $\rightarrow$ (22.32 ID, 33.07 IH)

ZROD 028.346483 .9978
- PART \#3 Drum with Poly liner (inside cube box of space) NEST 4

ZCYL P2 28.3464 $84.3783 \quad 0.3805$

ZCYL, $628.575 \quad 84.60690 .15189$

ZCYL 228.7268984 .758790 .0

CUBOID $028.72728 .72784 .759-28.727-28.727-0.001$

* PART \#4 Array of drums: X by Y by Z

ARRAY 114

* Part (\#3) placed in array 4 times

$(3) * 4$

* PART \#5 Array container / Concrete Floor (12in) \& Ceiling (8in)

NEST 2

CUBOID P4 57.454 57.454 339.040.00.0 0 .

* ceiling $(339.04 \mathrm{~cm}+8 \mathrm{in})$ floor (0-12in)

CUBOID $757.45457 .454359 .360 .00 .0-30.48$

* reflective sufaces on $X$ and $Y$ sufaces of outer cube

ALBEDO 1.01 .00 .01 .01 .00 .0

* strtstage, endstage, \#histperstage, time(min), -1

$\begin{array}{llllll}-10 & 30 & 1000 & 300 & \text { STDV } 0.002 & -1\end{array}$

MULTIPOINT 4

29. 29. 10.1

29. 29. 95.1

29. 29. 180.1

29. 29. 265 .

END

CODB 7

PSsVWPC

* xy

$0.129 .85 .57 .429 .85 .0 .129 .-10$.

* yz

1938. 10. 38. 38. 10. 191910.

* $x y$

19. $1920.38 .19 .20 .1919-1$

BND

- CEMD2_ac13 Array of Drums, 3 cans $66.67 \mathrm{~g}$ Pu ea arrang drum center

FISSION

* \#MATERTals \#NUCLIOES

$7 \quad 14$ NUCNAMES

* Mat \#1 Cement/Pu (66.67 g Pu per can)

* Water weight fraction: 0.52 , equivilent to $H$ conc assuming all $H$ from $\mathrm{H} 2 \mathrm{O}$

* density weightfractions

WGT 2.059 HINH2O 0.05819 O 0.583166 F19 0.024249 MG 0.050311 CA 0.272203 PU239 0.011881

* Mat \#2 Carbon Steel $1 \%$ C $7.86 \mathrm{~g} / \mathrm{cm} 3$

CONC C $0.003941 \mathrm{FE} 0.0839103$

* Mat \#3 Steel (slip cover can)

WGT 7.9 C 0.005 AL27 0.001 SI 0.006 P31 0.002 S32 0.002 FE 0.983 SN 0.001

* Mat \#4 PVC I(CH2CH(C)]n

WGT 0.9 HINH2O 0.048386 C 0.384338 CL 0.567275

* Mat \#S Water Vapor (mixed with void)

WGT 0.005 HINH2O 0.11188500 .888115

* Mat \#6 Polyethylene (CH2)n

WGT 0.96 HINH2O 0.14397 C 0.856303

*

- Mat $\# 7$ Concrete, conservative Hanford (dens=2.35 g/cm 3 )

CONC AL27 0.003358 CA $0.002614 \mathrm{FB} 0.001344$ HINH2O 0.00702300 .045396 SI 0.012905

CM

* PART \#1 Cementation can (cemented residue, steel can, PVC bag) 
NEST 3

ZCYL $1 \quad 6.98517 .8130 .033$

ZCYL $3 \quad 6.98817 .8160 .030$

ZCYL $4 \quad 7.01817 .8460 .000$

* PART \#2 3 Cans near drum center (Case 2), including space in drum

CLUSTER 4

ZROD ORIGIN $0.0000 \quad 8.10370 .0000$ P1 7.018 17.846

ZROD ORIGIN 7.0181 -4.05190.0000 P1 7.018 17.846

ZROD ORIGIN -7.0181 -4.05190 .0000 P1 7.01817 .846

* 55 Gal 17C drum inner: 22.5 in ID, 33.25 in inside height

* drum lined with 0.09 in thick poly $\rightarrow(22.32 \mathrm{ID}, 33.07 \mathrm{IH})$ ZROD 0 28.3464 83.9978

* PART \#3 Drum with Poly liner (inside cube box of space) NEST 4

ZCYLP2 28.3464 $84.3783 \quad 0.3805$

ZCYL $6 \quad 28.575 \quad 84.6069 \quad 0.15189$

ZCYL 228.7268984 .758790 .0

CUBOID $028.72728 .72784 .759-28.727-28.727-0.001$

* PART 44 Array of drums: $X$ by $Y$ by $Z$

ARRAY 114

* Part (\#3) placed in array 4 times

(3)*4

* PART \#S Amay container / Concrete Floor (12in) \& Ceiling (8in) NEST 2

CUBOID P4 57.454 57.454 339.04 0.00.0 0.

* ceiling $(339.04 \mathrm{~cm}+8 \mathrm{in})$ floor $(0-12 \mathrm{in})$ CUBOID $757.45457 .454359 .360 .00 .0-30.48$

* reflective surfaces on $X$ and $Y$ surfaces of outer cube

ALBEDO 1.01 .00 .01 .01 .00 .0

* strtstage, endstage, fhistperstage, time(min), -1

$\begin{array}{lllll}-10 & 30 & 1000 & 300 & \text { STDV } 0.002-1\end{array}$

MULTIPOINT 4

29. 29. 10. 1

29. 29. 95.1

29. 29.180 .

29.29.265. 1

END

CODE 7

PSsVWpC

* $x y$

$0.129 .85,57.429 .85,0.129,-10$.

* yz

19 38. 10. 38. 38. 10. 191910 .

* xy

19. 19 20. 38. 19. 20. $1919-1$

END

* CEMD2_ac15 Array of Drums, 3 cans $66.67 \mathrm{~g}$ Pu ea arrang drum center

FISSION

* *MATERIALs \#NUCLIDEs

$7 \quad 14$ NUCNAMES

*

* Mat \#1 Cement/Pu (66.67 g Pu per can)

* Water weight fraction: 0.60 , equivilent to $H$ conc assuming all $H$

from $\mathrm{H} 2 \mathrm{O}$

* density weightfractions

WGT 2.059 HINH2O 0.06714300 .633475 F19 0.020105 MG 0.041713 CA 0.225684 PU239 0.011881

* Mat \#2 Carbon Steel $1 \%$ C $7.86 \mathrm{~g} / \mathrm{cm} 3$

CONC C 0.003941 FE 0.0839103

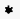

* Mat \#3 Steel (slip cover can)

WGT 7.9 C 0.005 AL27 0.001 SI 0.006 P31 0.002 S32 0.002 FE 0.983 SN 0.001

* Mat \#4 PVC [(CH2CH(Cl)]n

WGT 0.9 HINH2O 0.048386 C 0.384338 CL 0.567275
* Mat \#5 Water Vapor (mixed with void)

WGT 0.005 HINH2O 0.11188500 .888115

* Mat \#6 Polyethylene (CH2)n

WGT $0.96 \mathrm{HINH} 2 \mathrm{O} 0.14397 \mathrm{C} 0.856303$

* Mat \#7 Concrete, conservative Hanford (dens $=2.35 \mathrm{~g} / \mathrm{cm} 3$ )

CONC AL27 0.003358 CA 0.002614 FB 0.001344

HINH2O 0.00702300 .045396 SI 0.012905

$\mathrm{CM}$

* PART\#1 Cementation can (cemented residue, steel can, PVC bag) NEST 3

ZCYL 16.98517 .8130 .033

ZCYL $3 \quad 6.98817 .8160 .030$

ZCYL $4 \quad 7.018 \quad 17.8460 .000$

* PART $\$ 23$ Cans near drum center (Case 2), including space in

drum

CLUSTER 4

ZROD ORIGIN 0.00008 .10370 .0000 P1 7.01817 .846

ZROD ORIGIN $7.0181-4.05190 .0000$ P1 7.01817 .846

ZROD ORIGIN -7.0181 -4.05190 .0000 P1 7.018 17.846

* 55 Gal $17 \mathrm{C}$ drum inner: 22.5 in ID, 33.25 in inside height

* drum lined with 0.09 in thick poly $\rightarrow$ (22.32 ID, $33.07 \mathrm{IH})$

ZROD 0 28.3464 83.9978

*PART \#3 Drum with Poly liner (inside cube box of space) NEST 4

ZCYL P2 28.3464 $84.3783 \quad 0.3805$

ZCYL $628.575 \quad 84.6069 \quad 0.15189$

ZCYL 228.7268984 .758790 .0

CUBOID 0 28.727 28.727 84.759-28.727-28.727 -0.001

* PART \#4 Array of drums; $X$ by $Y$ by $Z$

ARRAY 1 I 4

* Part (\#3) placed in array 4 times

(3)*4

* PART \#5 Array container / Concrete Floor (12in) \& Ceiling (8in) NEST 2

CUBOID P4 57.454 57.454 339.04 0.0 0.0 0.

* ceiling $(339.04 \mathrm{~cm}+8 \mathrm{in})$ floor $(0-12 \mathrm{in})$

CUBOID $757.45457 .454359 .360 .00 .0-30.48$

* reflective surfaces on $X$ and $Y$ surfaces of outer cube

ALBEDO 1.0 1.0 0.0 1.0 1.0 0.0

* strtstage, endstage, fhistperstage, time(min), -1

$\begin{array}{llllll}-10 & 30 & 1000 & 300 & \text { STDV } 0.002-1\end{array}$

MULTIPOINT 4

29. 29. 10. 1

29. 29. 95.1

29. 29. 180.1

29. 29. 265.1

END

CODE 7

PSsWWpC

* xy

$0.129 .85 .57 .429 .85 .0 .129 .-10$.

* yz

1938.10 .38 .38 .10 .191910$.

* $x y$

19. $1920.38 .19 .20 .1919-1$

BND

* CEMD2_b Array of Drums, 3 cans $66.67 \mathrm{~g}$ Pu ea arrang drum center

FISSION

* \#MATERIALs \#NUCLIDEs

$7 \quad 14$ NUCNAMES

* Mat \#1 Cement/Ru (nomal (high) water content, $66.67 \mathrm{~g}$ Pu per can)

* density weightfractions

WGT 2.059 HINH2O 0.04083300 .485625 F19 0.032284 


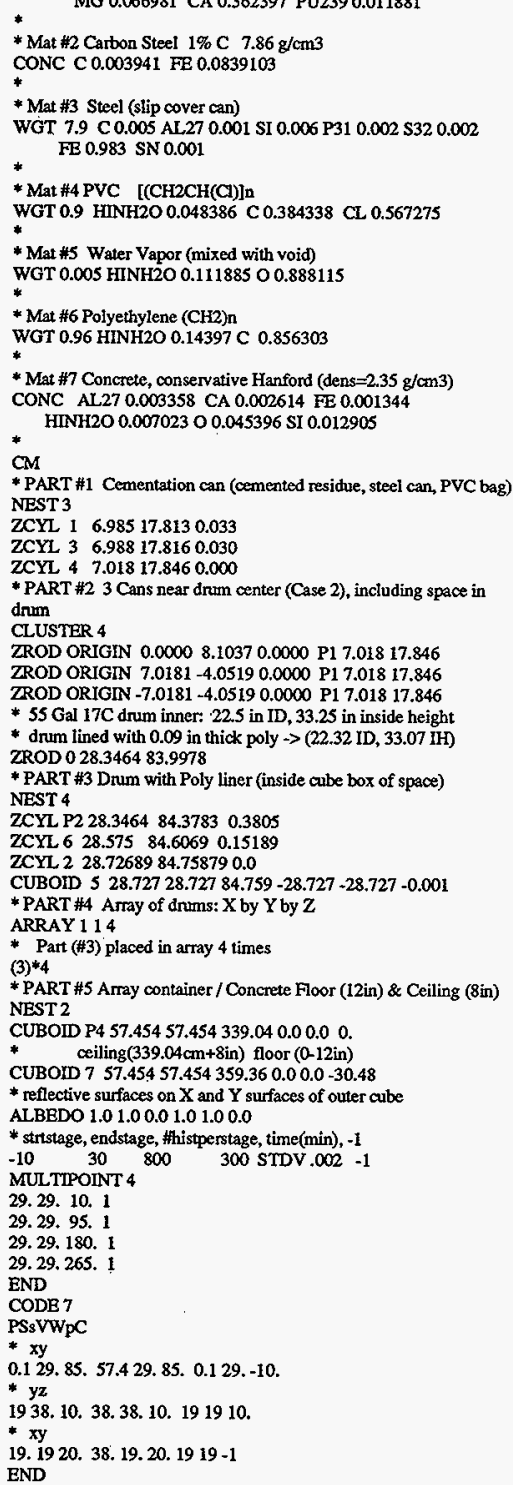

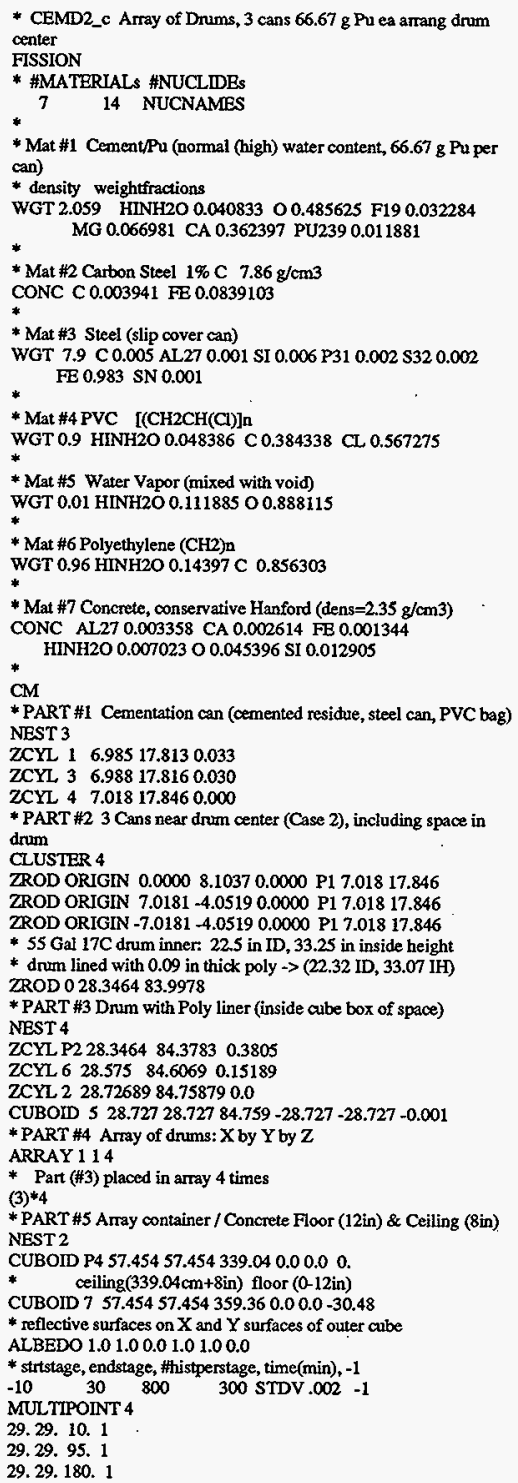


29. 29. 265.1

END

CODE 7

PSsVWpC

* $x y$

0.129 . 85. 57.4 29. 85. 0.1 29. -10 .

* yz

19 38. 10. 38.38.10. 191910.

* xy

19. 1920.38 . 19. $20.1919-1$

END

- CEMD2_d Array of Drums, 3 cans $66.67 \mathrm{~g}$ Pu ea arang drum center

FISSION

* \#ATERIALs \#NUCLIDEs

*

$7 \quad 14$ NUCNAMES

* Mat \#1 Cement/Pu (nomal (high) water content, $66.67 \mathrm{~g}$ Pu per

can)

- density weightfractions

WGT 2.059 HINH2O 0.04083300 .485625 Fi9 0.032284 MG 0.066981 CA 0.362397 PU2390.011881

-

* Mat \#2 Carbon Steel $1 \%$ C $7.86 \mathrm{~g} / \mathrm{cm} 3$

CONC C 0.003941 FE 0.0839103

*

* Mat \#3 Steel (slip cover can)

WGT 7.9 C 0.005 AL27 0.001 \$I 0.006 P31 $0.002 \$ 320.002$ FE 0.983 SN 0.001

$*$

* Mat \#4 PVC [(CH2CH(Cl)]n

WGT 0.9 HINH2O 0.048386 C 0.384338 CL 0.567275

*

* Mat \#5 Water Vapor (mixed with void)

WGT 0.1 HINH2O 0.11188500 .888115

$*$

* Mat \#6 Polyethylene (CH2)n

WGT 0.96 HINH2O 0.14397 C 0.856303

*

* Mat $\$ 7$ Concrete, conservative Hanford (dens $=2.35 \mathrm{~g} / \mathrm{cm} 3$ )

CONC AL27 0.003358 CA 0.002614 FE 0.001344

* HINH 200.00702300 .045396 SI 0.012905

CM

* PART \#1 Cementation car (cemented residue, steel can, PVC bag) NEST 3

ZCYL 16.98517 .8130 .033

ZCYL $3 \quad 6.98817 .8160 .030$

ZCYL $4 \quad 7.01817 .8460 .000$

* PART \#2 3 Cans near drum center (Case 2), including space in dnum

CLUSTER 4

ZROD ORIGN 0.00008 .10370 .0000 P1 7.01817 .846

ZROD ORIGIN 7.0181 -4.05190 .0000 PI 7.01817 .846

ZROD ORIGIN -7.0181 -4.05190 .0000 P1 7.018 17.846

* 55 Gal $17 \mathrm{C}$ drum inner: 22.5 in ID, 33.25 in inside height

* drum lined with 0.09 in thick poly $\rightarrow$ (22.32 ID, 33.07 IH) ZROD 028.346483 .9978

* PART \#3 Drum with Poly liner (inside cube box of space) NEST 4

ZCYL P2 28.3464 $84.3783 \quad 0.3805$

ZCYL $628.575 \quad 84.6069 \quad 0.15189$

ZCYL 228.7268984 .758790 .0

CUBOID 5 28.727 28.727 84.759-28.727-28.727-0.001

* PART \#4 Array of drums: X by $Y$ by $Z$

ARRAY 114

* Part (\#3) placed in array 4 times

(3)*4

* PART \#S Array container/Concrete Floor (12in) \& Ceiling (8in)
NEST 2

CUBOID P4 57.454 57.454 339.04 0.00.0 0.

* ceiling( $339.04 \mathrm{~cm}+8$ in) floor (0-12in)

CUBOID $757.45457 .454359 .360 .00 .0-30.48$

* reflective surfaces on $X$ and $Y$ surfaces of outer cube

ALBEDO 1.0 1.0 0.0 1.0 1.00.0

* strtstage, endstage, 仿istperstage, time(min), -1

$\begin{array}{lllll}-10 & 30 & 800 & 300 \text { STDV } .002 & -1\end{array}$

MULTIPOINT 4

29. 29. 10. 1

29. 29. 95.1

29.29. 180.1

29. 29. 265. 1

END

CODB 7

PSsWWPC

* $x y$

$0.129 .85 .57 .429 .85 .0 .129 .-10$.

* yz

19 38. 10. 38. 38.10. 191910.

* $\mathbf{x y}$

19. 19 20. 38. 19.20. $1919-1$

END

* CEMD2_e Array of Drums, 3 cans $66.67 \mathrm{~g}$ Pu ea arrang drum

center

FISSION

* \#MATERIALs \#NUCLDEs

$7 \quad 14$ NUCNAMES

* Mat \#1 Cement/Pu (nomal (high) water content, $66.67 \mathrm{~g}$ Pu per can)

* density weightractions

WGT 2.059 HINH2O 0.04083300 .485625 F19 0.032284 MG 0.066981 CA 0.362397 PU239 0.011881

* Mat \#2 Carton Steel $1 \%$ C $7.86 \mathrm{~g} / \mathrm{cm}^{3}$

CONC C 0.003941 FE 0.0839103

*

* Mat \#3 Steel (slip cover can)

WGT 7.9 C 0.005 AL27 0.001 SI 0.006 P31 0.002 \$32 0.002 FE 0.983 SN 0.001

* Mat \#4 PVC [(CH2CH(Cl)]n

WGT 0.9 HINH 200.048386 C 0.384338 CL 0.567275

*

* Mat 45 Water Vapor (mixed with void)

WGT 1.0 HINH2O 0.11188500 .888115

* Mas \#6 Polyethylene (CH2)n

WGT $0.96 \mathrm{HINH} 200.14397 \mathrm{C} 0.856303$

*

* Mat \#7 Concrete, conservative Hanford (dens=2.35 g/cm3)

CONC AL27 0.003358 CA 0.002614 FE 0.001344

HINH2O 0.00702300 .045396 SI 0.012905

CM

* PART \#1 Cementation can (cemented residue, steel can, PVC bag) NEST 3

ZCYL $1 \quad 6.98517 .8130 .033$

ZCYL $3 \quad 6.988 \quad 17.8160 .030$

ZCYL $4 \quad 7.01817 .8460 .000$

* PART \#2 3 Cans near dnum center (Case 2), including space in drum

CLUSTER 4

ZROD ORIGIN 0.00008 .10370 .0000 P1 7.01817 .846

ZROD ORIGIN 7.0181 -4.05190 .0000 P1 7.01817 .846

ZROD ORIGIN $-7.0181+4.05190 .0000$ P1 7.018 17.846

* 55 Gal 17C dnum inner: 22.5 in ID, 33.25 in inside hejght

* drum lined with 0.09 in thick poly $->(22.32 \mathrm{ID}, 33.07 \mathrm{IH})$ 
ZROD 0 28.3464 83.9978

* PART \#3 Drum with Poly liner (inside cube box of space) NEST 4

ZCYL P2 28.3464 $84.3783 \quad 0.3805$

ZCYL $628.575 \quad 84.6069 \quad 0.15189$

ZCYL 228.7268984 .758790 .0

CUBOID 5 28.727 $28.72784 .759-28.727-28.727-0.001$

* PART \#4 Array of drums: $X$ by $Y$ by $Z$

ARRAY 114

* Part (\#3) placed in array 4 times

(3)*4

- PART \#S Array container / Concrete Floor (12in) \& Ceiling (8in)

NEST 2

CUBOID P4 57.454 57.454 339.04 0.00.0 0

* ceiling $(339.04 \mathrm{~cm}+8 \mathrm{in})$ floor (0-12in)

CUBOW $757.45457 .454359 .360 .00 .0-30.48$

* reflective surfaces on $X$ and $X$ surfaces of outer cube

ALBEDO 1.0 1.00.0 1.01.00.0

* strtstage, endstage, fhistperstage, time(min), -1

$\begin{array}{llll}-10 & 30 & 800 & 300\end{array}$

MULTIPOINT 4

29. 29. 10. 1

29. 29. 95.1

29. 29. 180.

29. 29. 265. 1

BND

CODE 7

PSsVWpC

* xy

$0.129 .85 .57 .429 .85 .0 .129 .-10$.

* yz

1938. 10. 38.38.10. 191910

* xy

19. 19 20, 38, 19, 20, $1919-1$

END

* CEMD2 f Array of Drums, 3 cans $66.67 \mathrm{~g}$ Pu ea arrang drum center

FISSION

* \#MATERIALs \#NUCLIDEs

$7 \quad 14$ NUCNAMES

* Mat \#1 Cement/Pu (normal (high) water content, 66.67 g Pu per

can)

* density weightfractions

WGT 2.059 HINH2O 0.04083300 .485625 F19 0.032284 MG 0.066981 CA 0.362397 PU239 0.011881

* Mat \#2 Carbon Steel $1 \%$ C $7.86 \mathrm{~g} / \mathrm{cm}^{3}$

CONC C 0.003941 FE 0.0839103

*

* Mat \#3 Steel (slip cover can)

WGT 7.9 C 0.005 AL27 0.001 SI 0.006 P31 $0.002 \$ 320.002$ FE 0.983 SN 0.001

* Mat \#4 PVC [(CH2CH(Cl)]n

WGT 0.9 HINH 200.048386 C 0.384338 CL 0.567275

* Mat \#5 Water Vapor (mixed with void)

WGT 0.005 HINH2O 0.11188500 .888115

* Mat \#6 Polyethylene (CH2)n

WGT 0.96 HINH $200.14397 \mathrm{C} 0.856303$

* Mat \#7 Concrete, conservative Hanford (dens $=2.35 \mathrm{~g} / \mathrm{cm} 3$ )

CONC AL27 0.003358 CA 0.002614 FE 0.001344

HINH2O 0.00702300 .045396 SI 0.012905

$\mathrm{CM}$

* PART \#1 Cementation can (cemented residue, steel can, PVC hag)
NEST 3

ZCYL 16.98517 .8130 .033

ZCYL $3 \quad 6.98817 .8160 .030$

ZCYL $4 \quad 7.01817 .8460 .000$

* PART \#2 3 Cans near drum center (Case 2), including space in drum

CLUSTER 4

ZROD ORIGIN 0.00008 .10370 .0000 P1 7.018 17.846

ZROD ORIGIN 7.0181 -4.05190 .0000 P1 7.01817 .846

ZROD ORIGIN $-7.0181-4.05190 .0000$ P1 7.01817 .846

* 55 Gal 17C drum inner: 22.5 in ID, 33.25 in inside height

* drum lined with 0.09 in thick poly $\rightarrow$ (22.32 ID, $33.07 \mathrm{IH})$

ZROD 528.346483 .9978

* PART \#3 Drum with Poly liner (inside cube box of space) NEST 4

ZCYL P2 28.3464 $84.3783 \quad 0.3805$

ZCYL $6 \quad 28.575 \quad 84.6069 \quad 0.15189$

ZCYL 228.7268984 .758790 .0

CUBOID $028.72728 .72784 .759-28.727-28.727-0.001$

* PART \#4 Array of dums: $X$ by $Y$ by $Z$

ARRAY 114

* Part (\$3) placed in array 4 times

$(3) * 4$

* PART \#5 Array container / Concrete Floor (12in) \& Ceiling (8in) NEST 2

CUBOID P4 57.454 57.454 339.04 0.00.0 0 .

* ceiling $(339.04 \mathrm{~cm}+8$ in) floor $(0-12$ in)

CUBOID 7 57.454 $57.454359 .360 .00 .0-30.48$

* reflective surfaces on $X$ and $Y$ surfaces of outer cube

ALBEDO 1.01.00.01.01.00.0

* strtstage, endstage, \#histperstage, time(min), -1

$\begin{array}{lllll}-10 & 30 & 800 & 300 \text { STDV .002 } & -1\end{array}$

MULTTPONT 4

29.29. 10. 1

29. 29. 95.1

29. 29.180 .1

29. 29. 265. 1

BND

CODE 7

PSsVWpC

* $\mathrm{xy}$

$0.129 .85 .57 .429 .85 .0 .129 .-10$.

* yz

1938. 10. 38. 38. 10. 191910.

* xy

19. 19 20. 38. 19. $20.1919-1$

END

* CEMD2_g Array of Drums, 3 cans $66.67 \mathrm{~g}$ Pu ea arrang drum

center

FISSION

* \#MATERIALs \#NUCLIDEs

$7 \quad 14$ NUCNAMES

* Mat \#1 Cement/Pu (normal (high) water content, 66.67 g Pu per can)

* density weightfractions

WGT 2.059 HINH2O 0.04083300 .485625 F19 0.032284 MG 0.066981 CA 0.362397 PU239 0.011881

* Mat \#2 Carbon Steel $1 \%$ C $7.86 \mathrm{~g} / \mathrm{cm} 3$

CONC C 0.003941 FE 0.0839103

*

* Mat \#3 Steel (slip cover can)

WGT $7.9 \mathrm{C} 0.005$ AL,27 0.001 \$I 0.006 P31 $0.002 \$ 320.002$ FE 0.983 SN 0.001

* Mat \#4 PVC [( $\mathrm{CH} 2 \mathrm{CH}(\mathrm{Cl})] \mathrm{n}$

WGT 0.9 HINH2O 0.048386 C 0.384338 Cl 0.567275 


\section{HNF-SD-SQA-CSA-525 Rev. 0}

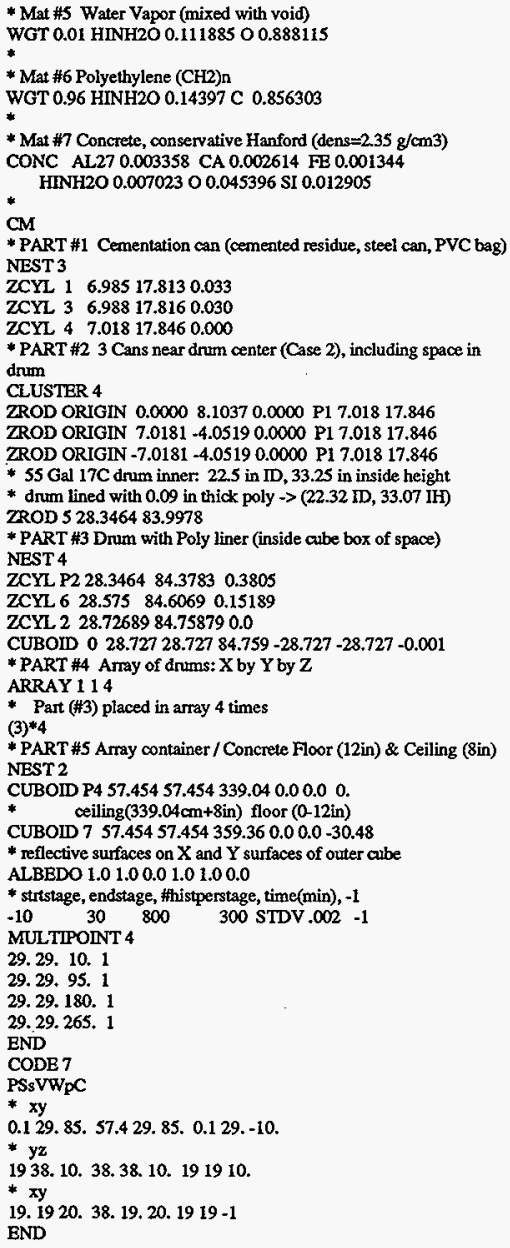

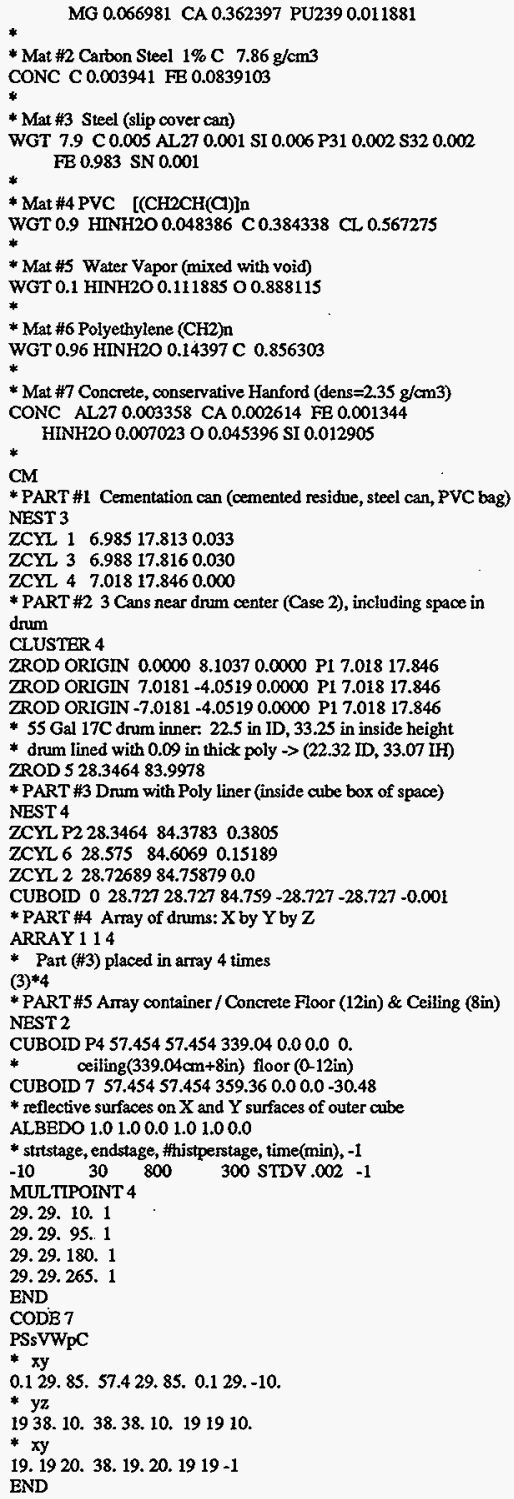




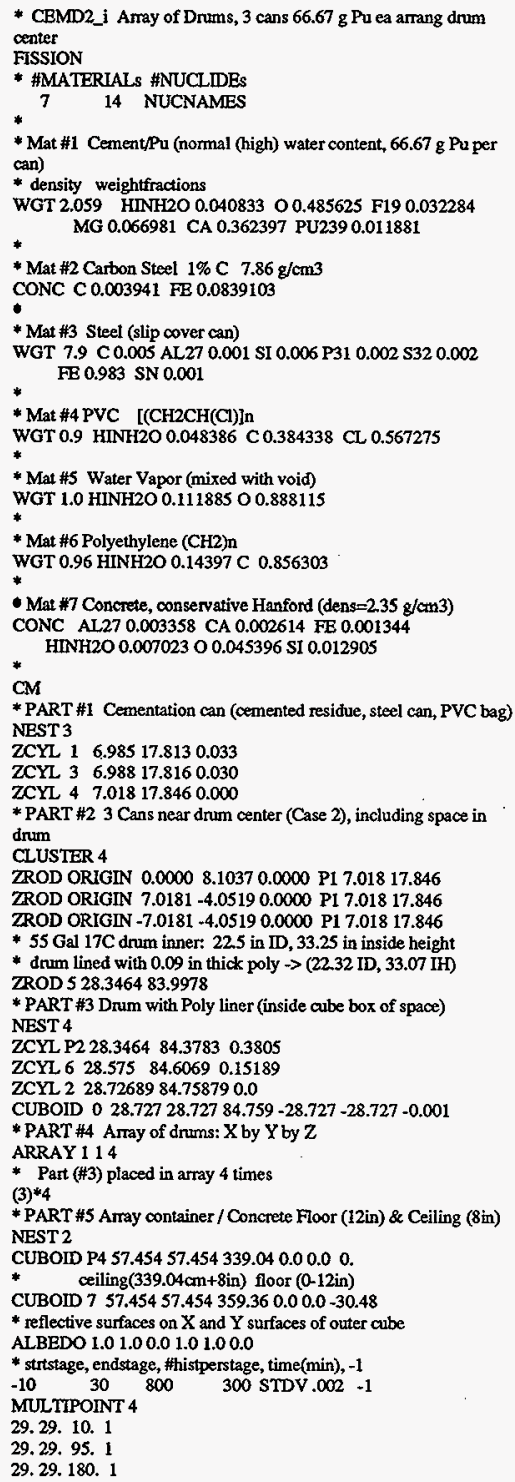

29. 29.265. 1

END

CODE 7

PSsVWpC

* xy

0.1 29.85. 57.4 29. 85. $0.129 .-10$.

* yz

1938. 10. 38. 38. 10. 191910.

* $x y$

19. 19 20. 38. 19.20. $1919-1$

END

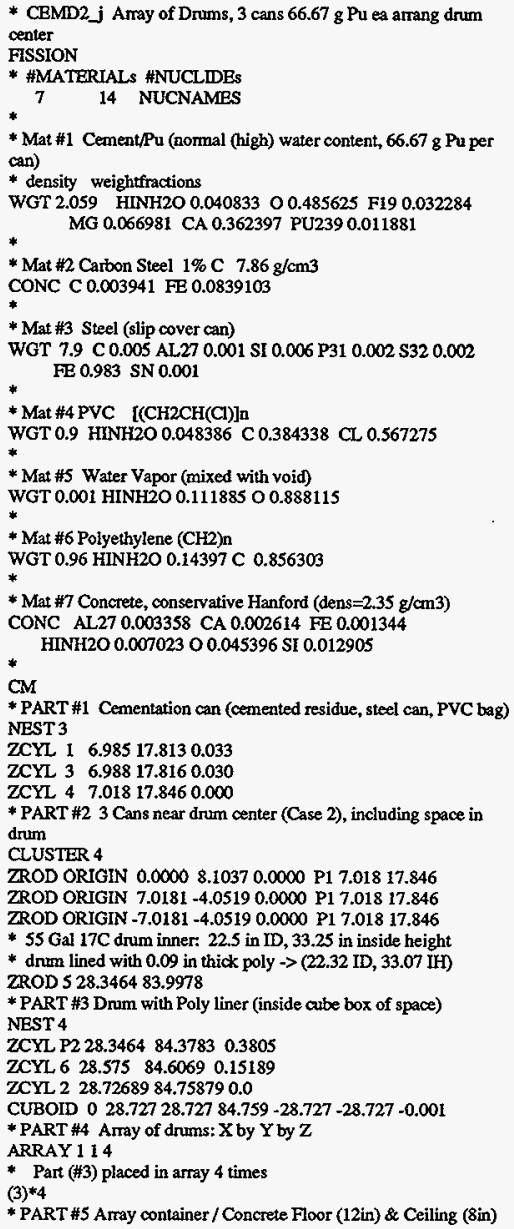


NEST 2

CUBOID P4 57.454 \$7.454 339.04 0.00.0 0 .

- ceiling(339.04cm+8in) floor (0-12in)

CUBOID $757.45457 .454359 .360 .00 .0-30.48$

- reflective surfaces on $X$ and $Y$ surfaces of outer cube

ALBEDO 1.0 1.00.0 1.0 1.00.0

* strtstage, endstage, thistperstage, time(min), -1

$\begin{array}{lllll}-10 & 30 & 800 & 300 \text { STDV } .002 & -1\end{array}$

MULTIPOINT 4

29. 29. 10. 1

29. 29. 95.1

29. 29. 180.1

29. 29. 265. 1

END

CODE 7

PSsVWpC

* xy

$0.129 .85,57.429 .85 .0 .129 .-10$.

* yz

19 38. 10. 38. 38. 10. 191910.

* xy

19. 19 20. 38. 19.20. $1919-1$

END

* CEMD2_k Array of Drums, 3 cans $66.67 \mathrm{~g}$ Pu ea arrang drum

center

FISSION

- hMATERLals mNuclides

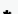

$7 \quad 14$ NUCNAMES

* Mat \#1 Cement/Pa (normal (high) water content, 66.67 g Pu per can)

* density weightfractions

WGT 2.059 HINH2O 0.04083300 .485625 F19 0.032284 MG 0.066981 CA 0.362397 PU239 0.011881

* Mat \#2 Carbon Steel $1 \%$ C $7.86 \mathrm{~g} / \mathrm{cm} 3$

CONC C $0.003941 \mathrm{FE} 0.0839103$

$+$

* Mat \#3 Steel (slip cover can)

WGT 7.9 C 0.005 AL27 0.001 SI 0.006 P31 0.002 S32 0.002 FE 0.983 SN 0.001

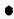

* Mat \#4 PVC [(CH2CH(Cl)]n

WGT 0.9 HINH 200.048386 C 0.384338 CL 0.567275

- Mat \#5 Water Vapor (mixed with void)

WGT 0.0005 HINH2O 0.11188500 .888115

$*$

* Mat \#6 Polyethylene (CH2)n

WGT 0.96 HINH2O $0.14397 \mathrm{C} \quad 0.856303$

* Mat \#7 Concrete, conservative Hanford (dens $=2.35 \mathrm{~g} / \mathrm{cm} 3$ )

CONC AL27 0.003358 CA 0.002614 FE 0.001344

HINH2O 0.00702300 .045396 SI 0.012905

*

$\mathrm{CM}$

- PART \#1 Cementation can (certented residue, steel can, PVC bag) NEST 3

ZCYL 16.98517 .8130 .033

ZCYL $3 \quad 6.98817 .8160 .030$

ZCYL 47.01817 .8460 .000

* PART \#2 3 Cans near dnm center (Case 2), including space in drum

CLUSTER 4

ZROD ORIGIN 0.00008 .10370 .0000 P1 7.018 17.846

ZROD ORIGIN 7.0181 -4.0519 0.0000 P1 7.018 17.846

ZROD ORIGIN -7.0181 -4.0519 0.0000 P1 7.018 17.846

- $55 \mathrm{Gal} 17 \mathrm{C}$ drum inner: 22.5 in $\mathrm{ID}, 33.25$ in inside height

* drum lined with 0.09 in thick poly $\rightarrow(22.32 \mathrm{ID}, 33.07 \mathrm{IH})$
ZROD 528.346483 .9978

* PART \#3 Drum with Poly liner (inside cube box of space)

NEST 4

ZCYL P2 $28.3464 \quad 84.3783 \quad 0.3805$

ZCYL $628.575 \quad 84.6069 \quad 0.15189$

ZCYL 2 28.72689 84.758790 .0

CUBOID $0 \quad 28.72728 .72784 .759-28.727-28.727-0.001$

* PART \#4 Amay of drums: $X$ by $Y$ by $Z$

ARRAY 114

* Part (\#3) placed in array 4 times

(3)*4

* PART \#5 Array container/Concrete Floor (12in) \& Ceiling (8in)

NEST 2

CUBOID P4 57.454 57.454 339.04 0.00.0 0.

* ceiling $(339.04 \mathrm{~cm}+8 \mathrm{in})$ floor $(0-12 \mathrm{in})$

CUBOID $757.45457 .454359 .360 .00 .0-30.48$

* reflective surfaces on $X$ and $Y$ surfaces of outer cube

ALBEDO 1.0 1.0 0.0 1.0 1.0 0.0

* stristage, endstage, \#histperstage, time(min), -1

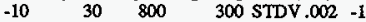

MULTIPOINT 4

29. 29. 10. 1

29. 29. 95.1

29. 29. 180. 1

29. 29. 265.1

END

CODE 7

PSsVWpC

* $\mathrm{xy}$

0.129 .85 .57 .429 .85 . $0.129 .-10$.

- yz

1938. 10. 38. 38. 10. 191910.

* $\mathrm{xy}$

19. $1920.38 .19 .20 .1919-1$

END

* CEMD2_and Array of Drums, 3 cans $66.67 \mathrm{~g}$ Pu ea arrang drum center no drum mat

FISSION

* \#MATERIALs \#NUCLIDEs

$7 \quad 14$ NUCNAMES

* Mat \#1 Cement/Pu (normal (high) water content, $66.67 \mathrm{~g}$ Pu per

can)

* density weightractions

WGT 2.059 HINH2O 0.040833 O 0.485625 F19 0.032284 MG 0.066981 CA 0.362397 PU239 0.011881

* Mat \#2 Carbon Steel $1 \%$ C $7.86 \mathrm{~g} / \mathrm{cm}^{3}$

CONC C 0.003941 FE 0.0839103

$*$

* Mat \#3 Steel (slip cover can)

WGT 7.9 C 0.005 AL27 0.001 S1 0.006 P31 $0.002 \$ 320.002$

* FE 0.983 SN 0.001

* Mat \#4 PVC [(CH2CH(C)]n

WGT 0.9 HINH 200.048386 C 0.384338 CL 0.567275

* Mat \#5 Water Vapor (mixed with void)

WGT 0.005 HINH2O 0.11188500 .888115

*

* Mat \#6 Polyethylene (CH2)n

WGT 0.96 HINH2O $0.14397 \mathrm{C} 0.856303$

$*$

* Mat \#7 Concrete, conservative Hanford (dens $=2.35 \mathrm{~g} / \mathrm{cm} 3$ )

CONC AL27 0.003358 CA 0.002614 FE 0.001344

HINH2O 0.00702300 .045396 SI 0.012905

$\mathrm{CM}$

* PART \#1 Cementation can (cemented residue, steel can, PVC bag) 
NEST 3

ZCYL 1 6.985 17.8130 .033

ZCYL $3 \quad 6.988 \quad 17.8160 .030$

ZCYL $4 \quad 7.018 \quad 17.8460 .000$

- PART \#2 3 Cans near dnum center (Case 2), including space in drum

CLUSTER 4

ZROD ORIGIN $0.0000 \quad 8.10370 .0000$ P1 7.01817 .846

ZROD ORIGW 7.0181 -4.05190 .0000 P1 7.018 17.846

ZROD ORIGIN -7.0181 -4.05190 .0000 P1 7.018 17.846

* 55 Gal 17C drum inner: 22.5 in ID, 33.25 in inside height

* drum lined with 0.09 in thick poly $\rightarrow(22.32 \mathrm{ID}, 33.07 \mathrm{IH})$ ZROD 028.346483 .9978

* PART \#3 Drum with Poly liner (inside cube box of space) NEST 4

ZCYL P2 28.3464 $84.3783 \quad 0.3805$

ZCYL $628.575 \quad 84.6069 \quad 0.15189$

ZCYL 028.7268984 .758790 .0

CUBOID $028.72728 .72784 .759-28.727-28.727-0.001$

* PART \#4 Array of drums: $X$ by $Y$ by $Z$

ARRAY 114

* Part (\#3) placed in array 4 times

(3)*4

* PART \#5 Array container / Concrete Floor (12in) \& Ceiling (8in) NEST 2

CUBOID P4 57.454 57.454 339.04 0.00.0 0 .

* ceiling $(339.04 \mathrm{~cm}+8 \mathrm{in})$ floor $(0-12 \mathrm{in})$

CUBOID $757.45457 .454359 .360 .00 .0-30.48$

* reflective surfaces on $X$ and $Y$ surfaces of outer cube

ALBEDO 1.0 1.0 0.0 1.0 1.0 0.0

* strtstage, endstage, thistperstage, time(min), - I

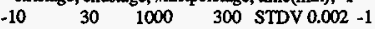

MULTTPOINT 4

29. 29. 10. 1

29. 29. 95.1

29. 29. 180. 1

29. 29. 265.1

END

CODE 7

PSsWWpC

* xy

$0.129 .85 .57 .429 .85 .0 .129,-10$.

* yz

19 38. 10. 38.38.10. 191910 .

* xy

19. 19 20. 38. 19. 20. $1919-1$

END

* CEMD2_ac17 Array of Drums, 3 cans $66.67 \mathrm{~g}$ Pu ea arrang dium center

FISSION

* \#MATERIALs \#NUCLIDEs

$7 \quad 14$ NUCNAMES

*

* Mat \#1 Cement/Pu (66.67 g Pu percan)

* Water weight ftaction: 0.70 , equivilent to $\mathrm{H}$ conc assuming all $\mathrm{H}$ from $\mathrm{H} 2 \mathrm{O}$

* density weightfractions

WGT 2.059 HINH2O 0.07833300 .69636 F19 0.014925 MG 0.030965 CA 0.167536 PU239 0.011881

* Mat \#2 Carbon Steel $1 \%$ C $7.86 \mathrm{~g} / \mathrm{cm} 3$

CONC C 0.003941 FE 0.0839103

C

* Mat \#3 Steel (slip cover can)

WGT 7.9 C 0.005 AL27 0.001 SI 0.006 P31 0.002 \$32 0.002 FE 0.983 SN 0.001

* Mat \#4 PVC [(CH2 CH(C) $)$ n

WGT 0.9 HINH2O 0.048386 C 0.384338 C 0.567275
* Mat \#5 Water Vapor (mixed with void)

WGT 0.005 HINH2O 0.11188500 .888115

*

* Mat \#6 Polyethylene (CH2)n

WGT 0.96 HINH2O 0.14397 C 0.856303

- Mat \#7 Concrete, conservative Hanford (dens $=2.35 \mathrm{~g} / \mathrm{cm} 3$ )

CONC AL27 0.003358 CA 0.002614 FE 0.001344 HINH 200.00702300 .045396 SI 0.012905

$\mathrm{CM}$

* PART \#1 Cementation can (cemented residue, steel can, PVC bag)

NEST 3

ZCYL $1 \quad 6.98517 .8130 .033$

ZCYL $3 \quad 6.98817 .8160 .030$

ZCYL $4 \quad 7.01817 .8460 .000$

* PART \#2 3 Cans near drum center (Case 2), including space in drum

CLUSTER 4

ZROD ORIGIN 0.00008 .10370 .0000 P1 7.018 17.846

ZROD ORIGIN 7.0181 -4.0519 0.0000 P1 7.018 17.846

ZROD ORIGIN $-7.0181-4.05190 .0000$ P1 7.01817 .846

* $55 \mathrm{Gal} 17 \mathrm{C}$ arum inner. $22.5 \mathrm{in} \mathrm{ID,} 33.25$ in inside height

* deum lined with 0.09 in thick poly $\rightarrow(22.32 \mathrm{ID}, 33.07 \mathrm{IH})$ ZROD 0 28.346483.9978

* PART \#3 Drum with Poly liner (inside cube box of space)

NEST 4

ZCYL P2 $28.346484 .3783 \quad 0.3805$

ZCYL $628.575 \quad 84.6069 \quad 0.15189$

ZCYL 228.7268984 .758790 .0

CUBOID $0228.72728 .72784 .759-28.727-28.727-0.001$

* PART \#4 Array of dnms: $X$ by $Y$ by $Z$

ARRAY 114

* Part (\#3) placed in array 4 times

(3)*4

* PART \#5 Array container / Concrete Floor (12in) \& Ceiling (8in)

NEST 2

CUBOID P4 57.454 57.454 339.04 0.00.0 0.

* ceiling $(339.04 \mathrm{~cm}+8 \mathrm{in})$ floor (0-12in)

CUBOID $757.45457 .454359 .360 .00 .0-30.48$

* reflective surfaces on $X$ and $Y$ surfaces of outer cube

ALBEDO 1.0 1.0 0.0 1.0 1.0 0.0

* strtstage, endstage, 集istperstage, time(min), -1

$\begin{array}{lllll}-10 & 30 & 1000 & 300 & \text { STDV } 0.002-1\end{array}$

MULTTPOINT 4

29. 29. 10. 1

29. 29. 95.1

29. 29. 180. 1

29. 29. 265.1

END

CODE 7

PSsVWpC

* $\mathrm{xy}$

$0.129 .85 .57 .429 .85,0.129 .-10$.

* yz

19 38. 10. 38. 38. 10. 191910 .

* xy

19. 1920 . 38. 19.20. $1919-1$

END

* spherel Array of Drums, sphere $200 \mathrm{~g} \mathrm{Pu}$ arrange drum center bottom

FISSION

* \#MATERLALs \#NUCLIDEs

$7 \quad 14$ NUCNAMES

* Mat \#1 Cement/Pu (nomal (high) water content, $200 \mathrm{~g} \mathrm{Pu}$ in total sphere)

* density weightfractions 
WGT 2.059 HINH2O 0.04058700 .482706 F19 0.03209 MG 0.066578 CA 0.360218 PU239 0.017821

* Mat H2 Carbon Steel $1 \%$ C $7.86 \mathrm{~g} / \mathrm{cm} 3$

CONC C 0.003941 FE 0.0839103

* Mat \#3 Steel (slip cover can)

WGT 7.9 C 0.005 AL27 0.001 \$I 0.006 P31 0.002 S32 0.002 FE 0.983 SN 0.001

* Mat \#4 PVC [(CH2CH(Cl)]n

WGT 0.9 HINH2O 0.048386 C 0.384338 CL 0.567275

* Mat \#5 Water Vapor (mixed with void)

WGT 0.0005 HINH2O 0.11188500 .888115

* Mat \#6 Polyethylene (CH2)n

WGT $0.96 \mathrm{HINH} 200.14397 \mathrm{C} 0.856303$

$*$

* Mat \#7 Concrete, conservative Hanford (dens=2.35 g/cm3)

CONC AL27 0.003358 CA 0.002614 FE 0.001344 HINH2O 0.00702300 .045396 SI 0.012905

$*$

$\mathrm{CM}$

* PART \#1 Cementation Sphere (cemented residue)

NEST 2

SPIERE ORIGIN 0011.015

SPHERB ORIGN 0011.0110 .917

* PART \#2 3 Cans near drum center (Case 2), including space in drum

NEST 2

SPHERE ORIGN O 011.0 P1 10.917

* 55 Gal $17 \mathrm{C}$ drum inner: 22.5 in ID, 33.25 in inside height

* drum lined with 0.09 in thick poly $\rightarrow(22.32 \mathrm{ID}, 33.07 \mathrm{IH})$

ZROD 028.346483 .9978

* PART \#3 Drum with Poly liner (inside cube box of space) NEST 4

ZCYL P2 28.3464 $84.3783 \quad 0.3805$

ZCYL $628.575 \quad 84.60690 .15189$

ZCYL 228.7268984 .758790 .0

CUBOID $028.72728 .72784 .759-28.727-28.727-0.001$

* PART \#4 Amay of drums; X by Y by $Z$

ARRAY 114

* Part (\#3) placed in array 4 times

(3)*4

* PART \#5 Array container / Concrete Floor (12in) \& Ceiling (8in)

NEST 2

CUBOID P4 57.454 57.454339.040.00.00.

* ceiling(339.04cm+8in) floor (0-12in)

CUBOID $757.45457 .454359 .360 .00 .0-30.48$

* reflective surfaces on $X$ and $Y$ surfaces of outer cube

ALBBDO 1.01 .00 .01 .01 .00 .0

* strtstage, endstage, \#histperstage, time (min), -1

$\begin{array}{llll}-5 & 30 \quad 800 \quad 300 \text { STDV } 0.002-1\end{array}$

MULTIPOINT 4

29. 29. 10. 1

29. 29. 95.1

29. 29. 180. 1

29. 29.265 .

END

CODE 7

PSsVWpC

* $\mathbf{x y}$

$0.129 .85 .57 .429 .85,0.129,-10$.

$+\mathbf{y z}$

19 38. 10. 38.38.10. 191910 .

* $\mathbf{x y}$

19. 1920.38 . 19.20. $1919-1$

END
* CBMD2_andp Array of Drums, 3 cans $66.67 \mathrm{~g}$ Pu ea arrang drum center no dium mat

FISSION

* MATERIALs \#NUCLIDEs

*

* Mat \#1 Cement/Pu (normal (high) water content, $66.67 \mathrm{~g}$ Pa per

an)

* density weightfractions

WGT 2.059 HINH2O 0.04083300 .485625 F19 0.032284 MG 0.066981 CA 0.362397 PU239 0.011881

* Mat \#2 Carbon Steel $1 \%$ C $7.86 \mathrm{~g} / \mathrm{cm}^{3}$

CONC C 0.003941 FE 0.0839103

$*$

* Mat \#3 Steel (slip cover can)

WGT 7.9 C 0.005 AL27 0.001 SI 0.006 P31 $0.002 \$ 320.002$ FE 0.983 SN 0.001

$*$

* Mat \#4 PVC [(CH2CH(Cl)]n

WGT 0.9 HINH2O 0.048386 C 0.384338 CL 0.567275

* Mat \#5 Water Vapor (mixed with void)

WGT 0.005 HINH2O 0.11188500 .888115

* Mat \#6 Polyethylene $(\mathrm{CH} 2)$ n

WGT 0.96 HINH2O $0.14397 \mathrm{C} \quad 0.856303$

* Mar \#7 Concrete, conservative Hanford (dens=2.35 g/cm3)

CONC AL27 0.003358 CA 0.002614 FE 0.001344 HINH2O 0.007023 O 0.045396 SI 0.012905

$\mathrm{CM}$

* PART \#1 Cementation can (cemented residue, steel can, PVC bag) NEST 3

ZCYL 16.98517 .8130 .033

ZCYL $3 \quad 6.98817 .8160 .030$

ZCYL $4 \quad 7.01817 .8460 .000$

* PART \#2 3 Cans near dnum center (Case 2), including space in drum

CLUSTER 4

ZROD ORIGIN 0.00008 .10370 .0000 PI 7.01817 .846

ZROD ORIGIN 7.0181 -4.05190 .0000 PI 7.018 17.846

ZROD ORIGIN -7.0181 -4.0519 0.0000 P1 7.018 17.846

* $55 \mathrm{Gal} 17 \mathrm{C}$ drum inner. $22.5 \mathrm{in}$ ID, 33.25 in inside height

* drum lined with 0.09 in thick poly $\rightarrow$ (22.32 ID, 33.07 IH) ZROD 028.346483 .9978

* PART \#3 Drum with Poly liner (inside cube box of space)

NEST 4

ZCYL P2 28.3464 $84.3783 \quad 0.3805$

ZCYL $028.575 \quad 84.6069 \quad 0.15189$

ZCYL 0 28.72689 84.758790 .0

CUBOID $0 \quad 28.72728 .72784 .759-28.727-28.727-0.001$

* PART \#4 Array of drums: $X$ by Y by $Z$

ARRAY 114

* Part (\#3) placed in array 4 times

$(3) * 4$

* PART \#5 Array container / Concrete Floor (12in) \& Ceiling (8in) NEST 2

CUBOID P4 57.454 57.454 339.04 0.00.0 0 .

* ceiling $(339.04 \mathrm{~cm}+8 \mathrm{in})$ floor $(0-12 \mathrm{in})$

CUBOID $757.45457 .454359 .360 .00 .0-30.48$

* reflective surfaces on $X$ and $Y$ surfaces of outer cube

ALBEDO 1.01 .00 .01 .01 .00 .0

* strtstage, endstage, \#histperstage, time(min), -1

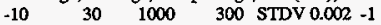

MULTIPOINT 4

29. 29. 10. 1

29. 29. 95.1

29. 29. 180.1

29. 29. 265. 1 
END

CODE 7

PSsVWpC

* xy

0.1 29. 85. $57.429 .85 .0 .129 .-10$.

* yz

1938.10. 38.38.10. 191910 .

* $x y$

19. $1920.38 .19 .20 .1919-1$

END

* CEMD2_ahis Array of Drums, 3 cans $66.67 \mathrm{~g}$ Pu ea arrang drum center

FISSION

* \#MATERIALs \#NUCLIDEs

*

$7 \quad 14$ NUCNAMES

* Mat \#1 Cement/Pu (normal (high) water content, $66.67 \mathrm{~g}$ Pu per

can)

* density weightfractions

WGT 2.059 HINH2O 0.04083300 .485625 F19 0.032284 MG 0.066981 CA 0.362397 PU239 0.011881

* Mat \#2 Carbon Steel $1 \%$ C $7.86 \mathrm{~g} / \mathrm{cm} 3$

CONC C 0.003941 FE 0.0839103

$*$

* Mat \#3 Steel (slip cover can)

WGT 7.9 C 0.005 AL27 0.001 SI 0.006 P31 0.002 \$32 0.002 FE 0.983 SN 0.001

$*$

* Mat \#4 PVC [(CH2CH(Cl)]n

WGT 0.9 HINH2O 0.048386 C 0.384338 CL 0.567275

*

* Mat \#5 Water Vapor (mixed with void)

WGT 0.005 HINH2O 0.11188500 .888115

$+$

* Mat \#6 Polyethylene ( $\mathrm{CH} 2$ )n

WGT 0.96 HINH2O 0.14397 C 0.856303

*

* Mat \#7 Concrete, conservative Hanford (dens $=2.35 \mathrm{~g} / \mathrm{cm} 3$ )

CONC AL27 0.003358 CA 0.002614 FE 0.001344 HINH 200.00702300 .045396 SI 0.012905

*

$\mathrm{CM}$

* PART \#1 Cementation can (cemented residue, steel can, PVC bag) NEST 3

ZCYL 16.98517 .8130 .033

ZCYL $3 \quad 6.98817 .8160 .030$

ZCYL $4 \quad 7.01817 .8460 .000$

* PART \#2 3 Cans near drum center (Case 2), including space in dnum

CLUSTER 4

ZROD ORIGIN 0.00008 .10370 .0000 P1 7.018 17.846

ZROD ORIGIN 7.0181 -4.0519 0.0000 P1 7.018 17.846 ZROD ORIGIN -7.0181 -4.0519 0.0000 P1 7.018 17.846

* 55 Gal 17C drum inner. 22.5 in ID, 33.25 in inside height

* drum lined with 0.09 in thick poly $\rightarrow$ (22.32 ID, $33.07 \mathrm{IK})$

ZROD 028.346483 .9978

* PART \#3 Drum with Poly liner (inside cube box of space) NEST 4

ZCYL P2 28.3464 $84.3783 \quad 0.3805$

ZCYL $628.575 \quad 84.6069 \quad 0.15189$

ZCYL 228.7268984 .758790 .0

CUBOID $028.72728 .72784 .759-28.727-28.727-0.001$

* PART \#4 Amay of diums: $X$ by $Y$ by $Z$

ARRAY 115

* Part (\#3) placed in array 5 times (high)

$(3) * 5$

* PART \#5 Array container / Concrete Floor (12in) \& Ceiling (8in) NEST 2
CUBOID P4 57.454 \$7.454 423.80 .00 .00 .

* ceiling $(339.04 \mathrm{~cm}+8 \mathrm{in})$ floor $(0-12 \mathrm{in})$

CUBOID 757.45457 .454 444.12 0.0 0.0 -30.48

* reflective surfaces on $X$ and $Y$ surfaces of outer cube

ALBEDO 1.0 1.00.0 1.0 1.0 0.0

* stristage, endstage, \#histperstage, time(min), -1

$\begin{array}{llllll}-10 & 30 & 1000 & 300 & \text { STDV } 0.002 & -1\end{array}$

MULTIPOINT 4

29. 29. 10. 1

29. 29. 95. 1

29. 29. 180.1

29. 29. 265.1

END

CODE 7

PSsVWpC

* xy

$0.129 .85 .57 .429 .85 .0 .129,-10$.

* y $z$

1938 . 10. 38. 38, 10. 191910 .

* $x y$

19.19 20. 38. 19.20.1919-1

END

* CEMD2_ahi6 Array of Drums, 3 cans $66.67 \mathrm{~g}$ Pu ea arrang drum

center

FISSION

* \#MATerials \#NUClmEs

*

$\begin{array}{lll}7 & 14 & \text { NUCNAMES }\end{array}$

* Mat \#1 Cement/Pu (nomal (high) water content, $66.67 \mathrm{~g} \mathrm{Pu}$ per can)

* density weightractions

WGT 2.059 HINH2O 0.040833 O 0.485625 F19 0.032284 MG 0.066981 CA 0.362397 PU239 0.011881

* Mat \#2 Carbon Steel $1 \%$ C $7.86 \mathrm{~g} / \mathrm{cm}^{3}$

CONC C 0.003941 FE 0.0839103

* Mat \$3 Steel (slip cover can)

WGT $7.9 \mathrm{C} 0.005$ AL.27 0.001 SI 0.006 P31 $0.002 \$ 320.002$ FE 0.983 SN 0.001

* Mat \#4 PVC [( $\mathrm{CH} 2 \mathrm{CH}(\mathrm{Cl})] \mathrm{n}$

WGT 0.9 HINH2O 0.048386 C 0.384338 Cl 0.567275

* Mat \#5 Water Vapor (mixed with void)

WGT 0.005 HINH2O 0.11188500 .888115

*

* Mat \#6 Poiyethylene ( $\mathrm{CH} 2$ )n

WGT $0.96 \mathrm{HINH} 2 \mathrm{O} 0.14397 \mathrm{C} \quad 0.856303$

* Mat \#7 Concrete, conservative Hanford (dens $=2.35 \mathrm{~g} / \mathrm{cm} 3$ )

CONC AL27 0.003358 CA 0.002614 FE 0.001344

HINH2O 0.007023 O 0.045396 SI 0.012905

$\mathrm{CM}$

* PART \#I Cementation can (cemented residue, steel can, PVC bag) NEST 3

ZCYL I 6.98517 .8130 .033

ZCYL 36.98817 .8160 .030

ZCYL $4 \quad 7.01817 .8460 .000$

* PART $\$ 23$ Cans near drum center (Case 2), including space in drum

CLUSTER 4

ZROD ORIGIN 0.00008 .10370 .0000 P1 7.01817 .846 ZROD ORIGIN $7.0181-4.05190 .0000$ PI 7.01817 .846 ZROD ORIGIN $-7.0181-4.05190 .0000$ P1 7.01817 .846

* 55 Gal 17C drum inner: 22.5 in ID, 33.25 in inside height

* drum lined with 0.09 in thick poly $\rightarrow(22.32 \mathrm{ID}, 33.07 \mathrm{IH})$

ZROD 0 28.3464 83.9978 
- PART \#3 Drum with Poly liner (inside cube box of space)

NEST 4

ZCYL P2 28.3464 $84.3783 \quad 0.3805$

ZCYL $628.575 \quad 84.60690 .15189$

ZCYL 2 28.72689 84.758790 .0

CUBOID $028.72728 .72784 .759-28.727$-28.727 - 0.001

* PART \#4 Array of drums: X by Y by $Z$

ARRAY 116

* Part (\#3) placed in array 6 times (high)

(3)*6

* PART \#5 Amay container / Concrete Floor (12in) \& Ceiling (8in)

NEST 2

CUBOID P4 57.454 57.454 508.56 0.00.0 0

* ceiling( $508.56 \mathrm{~cm}+8 \mathrm{in})$ floor (0-12in)

CUBOID 7 57.454 57.454 528.88 0.0 0.0 -30.48

* reflective surfaces on $X$ and $Y$ surfaces of outer cube

ALBEDO 1.0 1.0 0.0 1.01.0 0.0

* strtstage, endstage, \#histperstage, time(min), -1

$\begin{array}{llll}-10 & 30 & 1000 & 300 \\ \text { STDV } 0.002 & -1\end{array}$

MULTIPOINT 4

29. 29, 10. 1

29. 29. 95,1

29. 29. 180.1

29. 29. 265. 1

END

CODB 7

PSsWWpC

$*$ xy

$0.129 .85 .57 .429 .85 .0 .129 .-10$.

* yz

1938. 10. 38.38. 10. 191910.

* $x y$

19. 19 20. 38. 19.20. $1919-\mathrm{I}$

END

* CEMD2_a_ob2 Array of Drums, 2 cans @66.67 g, 1 @226g Pu ea arrang drum center

FISSION

* \#MATERIALs \#NUCLIDEs

$8 \quad 14$ NUCNAMES

* Mat \#1 Cement/Pu (normal (high) water content, 66.67 g Pu per

can)

* density weightfractions

WGT 2.059 HINH2O 0.04083300 .485625 F19 0.032284 MG 0.066981 CA 0.362397 PU239 0.011881

* Mat \#2 Carbon Steel $1 \%$ C $7.86 \mathrm{~g} / \mathrm{cm} 3$

CONC C $0.003941 \mathrm{FE} 0.0839103$

* Mat \#3 Steel (slip cover can)

WGT 7.9 C 0.005 AL 27 0.001 SI 0.006 P31 0.002 \$32 0.002 FE 0.983 SN 0.001

$*$

* Mat \#4 PVC [(CH2CH(C)]n

WGT 0.9 HINH2O 0.048386 C 0.384338 CL 0.567275

$*$

* Mat \#5 Water Vapor (mixed with void)

WGT 0.005 HINH2O 0.11188500 .888115

* Mat \#6 Polyethylene ( $\mathrm{CH} 2)$ n

WGT 0.96 HINH2O $0.14397 \mathrm{C} 0.856303$

*

* Mat \#7 Concrete, conservative Hanford (dens $=2.35 \mathrm{~g} / \mathrm{cm} 3$ )

CONC AL27 0.003358 CA 0.002614 FE 0.001344

HINH2O 0.00702300 .045396 SI 0.012905

$+$

* Mat \#3 Cement/Pu (normal (high) water content, 226 g Pu per can)

* density weightfractions

WGT 2.059 HINH2O0.03965900.47167 F190.031356

\section{MG 0.065056 CA 0.351983 PU2390.040275 \\ CM}

* PART \#1 Cementation can (cemented nesidue, steel can, PVC bag) NEST 3

ZCYL 16.98517 .8130 .033

ZCYL 36.98817 .8160 .030

ZCYL $4 \quad 7.01817 .8460 .000$

* PART \#2 3 Cans near drum center (Case 2), including space in drum

CLUSTER 4

ZROD ORIGIN 0.00008 .10370 .0000 P1 7.01817 .846

ZROD ORIGIN 7.0181 -4.05190 .0000 P1 7.01817 .846

ZROD ORIGIN -7.0181 -4.0519 0.0000 P1 7.018 17.846

* 55 Gal 17C dnum inner: 22.5 in $\mathrm{TD}, 33.25$ in inside height

* drum lined with 0.09 in thick poly $\rightarrow(22.32 \mathrm{ID}, 33.07 \mathrm{IH})$ ZROD 028.346483 .9978

* PART \#3 Drum with Poly liner (inside cube box of space)

NEST 4

ZCYL $2228.3464 \quad 84.3783 \quad 0.3805$

ZCYL $6 \quad 28.575 \quad 84.60690 .15189$

ZCYL 2 28.72689 84.75879 0.0

CUBOID $028.72728 .72784 .759-28.727-28.727-0.001$

* PART \#4 Array of drums: $X$ by $Y$ by $Z$

ARRAY 554

* Part \#3 placed in array 12 times then part \#7 placed once

* followed by part \#3 12 times in each of the 4 layers

* overbatch occurs 4 out of 25 drums $=16 \%$ of the time

(3)*128 (3)*12 (3)*128(3)*12 (3)*128(3)*12 (3)*128(3)*12

* PART \#5 Amay container / Concrete Floor (12in) \& Ceiling (8in) NEST 2

CUBOID P4 287.27 287.27 339.04 0.00.0 0 .

* ceiling $(339.04 \mathrm{~cm}+8 \mathrm{in})$ floor $(0-12 \mathrm{in})$

CUBOID $7287.27287 .27359 .360 .00 .0-30.48$

* reflective surfaces on $X$ and $Y$ surfaces of outer cube

ALBEDO 1.01 .00 .01 .01 .00 .0

* PART \#6 Cementation can (cemented residue, steel can, PVC bag) NEST 3

ZCYL \& 6.98517 .8130 .033

ZCYL $3 \quad 6.98817 .8160 .030$

ZCYL $4 \quad 7.01817 .8460 .000$

* PART \#7 3 Cans near drum center (Case 2), including space in drum

CLUSTER 4

ZROD ORIGIN 0.00008 .10370 .0000 P6 7.018 17.846

ZROD ORIGIN 7.0181 -4.05190 .0000 P1 7.018 17.846

ZROD ORIGIN -7.0181 -4.0519 0.0000 P1 7.018 17.846

* 55 Gal $17 \mathrm{C}$ drum inner. 22.5 in ID, 33.25 in inside hejght

* drum lined with 0.09 in thick poly $\rightarrow(22.32 \mathrm{ID}, 33.07 \mathrm{IH})$

ZROD 028.346483 .9978

* PART \#8 Drum with Poly liner (inside cube box of space)

NEST 4

ZCYL P7 28.3464 $84.3783 \quad 0.3805$

ZCYL $628.575 \quad 84.6069 \quad 0.15189$

ZCYL 228.7268984 .758790 .0

CUBOID $028.72728 .72784 .759-28.727-28.727-0.001$

* strtstage, endstage, 估i stperstage, time(min), -1

$\begin{array}{lllll}-10 & 30 & 1000 & 300 & \text { STDV } 0.003-1\end{array}$

MULTTPOINT 4

29.29. 10. 1

29. 29. 95.1

29. 29. 180. 1

29.29.265. I

END

CODB 7

PSsVWpC

* $x y$

$0.129 .85,57.429 .85$. 0.1 29. -10 .

* $\mathrm{yz}$

19 38. 10. 38.38, 10, 191910 . 


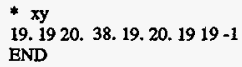

* CEMD2_a_ob3 Array of Drums, 2 cans @66.67 g, $1 @ 226 g$ Pu ea arrang drum center
NEST 2

CUBOID P4 287.27 287.27 339.040.0 0.0 0 .

* ceiling(339.04cm+8in) floor $(0-12 \mathrm{in})$

CUBOID $7287.27287 .27359 .360 .00 .0-30.48$

* reflective surfaces on $X$ and $Y$ surfaces of outer cube ALBEDO 1.01 .00 .01 .01 .00 .0

* PART \#6 Cementation can (cemented residue, steel can, PVC bag) NEST 3

ZCYL $8 \quad 6.98517 .8130 .033$

ZCYL, $3 \quad 6.988 \quad 17.816 \quad 0.030$

ZCYL $4 \quad 7.018 \quad 17.8460 .000$

* PART \#7 3 Cans near drum center (Case 2), including space in drum

CLUSTER 4

ZROD ORIGIN 0.00008 .10370 .0000 P6 7.018 17.846

ZROD ORIGIN 7.0181 -4.05190 .0000 P1 7.01817 .846

ZROD ORIGIN -7.0181 -4.05190 .0000 P1 7.018 17.846

* $55 \mathrm{Gal} 17 \mathrm{C}$ drum inner: 22.5 in ID, 33.25 in irside hejght

* dram lined with 0.09 in thick poly $\rightarrow(22.32$ ID, 33.07 IH) ZROD 028.346483 .9978

* PART 7 Drum with Poly liner (inside cube box of space) NEST 4

ZCYL P7 $28.346484 .3783 \quad 0.3805$

ZCYL $628.575 \quad 84.60690 .15189$

ZCYL 228.7268984 .758790 .0

CUBOID $028.72728 .72784 .759-28.727-28.727-0.001$

* strtstage, endstage, fhistperstage, time(min), -1

$\begin{array}{llllll}-10 & 30 & 1000 & 300 & \text { STDV } 0.003-1\end{array}$

MULTIPOINT 4

29. 29. 10. 1

29. 29. 95.1

29. 29.180 .1

29. 29. 265. 1

END

CODE 7

PSsVWPC

* xy

$0.129 .85 .57 .429 .85 .0 .129 .-10$.

* yz

1938. 10. 38.38 .10 .191910 .

* $x y$

19. 19 20. 38. 19.20. $1919-1$

END

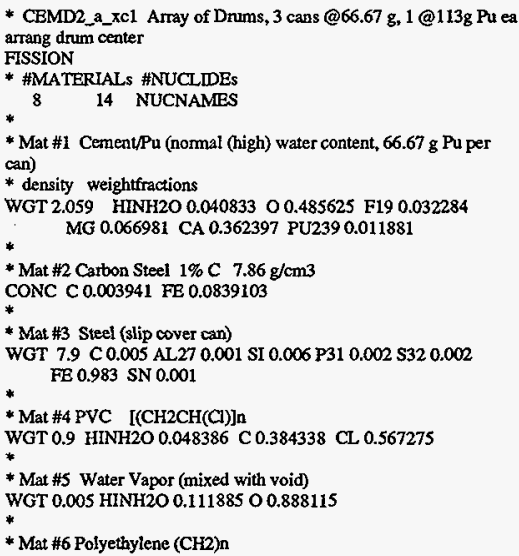




\section{HNF-SD-SQA-CSA-525 Rev. 0}

WGT 0.96 HINH2O 0.14397 C 0.856303

* Mat $\$ 7$ Concrete, conservative Hanford (dens=2.35 g/cm3)

CONC AL27 0.003358 CA 0.002614 FE 0.001344 HINH $200.00702300 .045396 \$ 10.012905$

* Mat \#8 Cement/Pu (normal (high) water content, $113 \mathrm{~g} \mathrm{Pu}$ per can)

* density wejghtfractions

WGT 2.059 HINH2O 0.04049200 .481567 F19 0.032014 MG 0.066421 CA 0.359369 PU239 0.020138

CM

* PART \#1 Cementation can (cemented residue, steel can, PVC bag) NEST 3

ZCYL $1 \quad 6.98517 .8130 .033$

ZCYL 3 6.98817 .8160 .030

ZCYL $4 \quad 7.01817 .8460 .000$

* PART \#2 3 Cans near drum center (Case 2), including space in drum

CLUSTER 4

ZROD ORIGIN 0.00008 .10370 .0000 P1 7.01817 .846 ZROD ORIGIN 7.0181 -4.05190 .0000 P1 7.01817 .846

ZROD ORIGIN $-7.0181-4.05190 .0000$ P1 7.018 17.846

* 55 Gal 17C drum inner: 22.5 in ID, 33.25 in inside height

* dnum lined with 0.09 in thick poly $\rightarrow(22.32 \mathrm{ID}, 33.07 \mathrm{IH})$ ZROD 028.346483 .9978

* PART \$3 Drum with Poly liner (inside cube box of space) NEST 4

ZCYL P2 28.3464 84.37830 .3805

ZCXL $6 \quad 28.575 \quad 84.6069 \quad 0.15189$

ZCYL, 228.7268984 .758790 .0

CUBOID 0 28.727 28.727 84.759 -28.727 -28.727-0.001

* PART \#4 Amay of drums: $X$ by $Y$ by $Z$

ARRAY 554

* Part \#3 placed in array 12 times then part $\$ 7$ placed once

- followed by part \#3 12 times in each of the bottom 2 layers

* overbatch occurs 2 out of 25 diums $=8 \%$ of the time

$(3) * 128(3) * 12(3) * 128(3) * 12(3) * 50$

* PART \#5 Amay container / Concrete Floor (12in) \& Ceiling (8in)

NEST 2

CUBOW P4 287.27 287.27339.040.00.0 0.

* ceiling(339.04cm+8in) floor (0-12in)

CUBOID 7287.27287 .27359 .36 0.0 0.0 -30.48

* reflective surfaces on $X$ and $Y$ surfaces of outer cube

ALBEDO 1.0 1.0 0.0 1.0 1.0 0.0

* PART $\$ 6$ Cementation can (cemented residue, steel can, PVC bag) NEST 3

ZCYL $8 \quad 6.98517 .8130 .033$

ZCYL $3 \quad 6.98817 .8160 .030$

ZCYL $4 \quad 7.01817 .8460 .000$

* PART 47 Cans + 1 Xtra near drum center (Case 2), including space in drum

CLUSTER 5

ZROD ORIGIN 0.00008 .10370 .0000 P6 7.018 17.846

ZROD ORIGIN 7.0181 -4.0519 0.0000 P1 7.018 17.846 ZROD ORIGIN -7.0181 -4.0519 0.0000 P1 7.018 17.846 ZROD ORIGIN $0.0000 \quad 0.000017 .8461$ P1 7.01817 .846

* $55 \mathrm{Gal} 17 \mathrm{C}$ drum inner: 22.5 in ID, 33.25 in inside height

* drum lined with 0.09 in thick poly $\rightarrow(22.32 \mathrm{ID}, 33.07 \mathrm{IH})$ ZROD 028.346483 .9978

* PART \#7 Drum with Poly liner (inside cube box of space) NEST 4

ZCYL P7 28.3464 $84.3783 \quad 0.3805$

ZCYL $6 \quad 28.575 \quad 84.6069 \quad 0.15189$

ZCYL 228.7268984 .758790 .0

CUBOID $028.72728 .72784 .759-28.727-28.727-0.001$

* strtstage, endstage, fhistperstage, time(min), -1

$\begin{array}{lllll}-10 & 30 & 1000 \quad 300 \text { STDV } 0.003-1\end{array}$

MULTIPOINT 4
29. 29. 10. 1

29. 29. 95.1

29.29.180. 1

29. 29. 265. 1

END

CODE 7

PSsVWpC

* xy

$0.129 .85 .57 .429 .85 .0 .129 .-10$.

* yz

19.38. 10. 38. 38.10. 191910.

* $x y$

19. 19 20. 38. 19. 20. $1919-1$

END

* CEMD2_a_xc2 Array of Drums, 3 cans @66.67 g, $1 @ 113 g$ Pu ea arrang drum center

FISSION

* \#MATERIALs \#NUCZIDEs

$8 \quad 14$ NUCNAMES

* Mat \#1 Cement/Pu (nomal (high) water content, $66.67 \mathrm{~g}$ Pu per can)

* density weightfractions

WGT 2.059 HWNH2O 0.04083300 .485625 Fi9 0.032284 MG 0.066981 CA 0.362397 PU239 0.011881

* Mat \#2 Carbon Steel $1 \%$ C $7.86 \mathrm{~g} / \mathrm{cm} 3$

CONC C 0.003941 FE 0.0839103

* Mat \#3 Stecl (slip cover can)

WGT 7.9 C 0.005 AL27 0.001 SI 0.006 P31 0.002 S32 0.002 FE 0.983 SN 0.001

* Mat \#4 PVC 【(CH2 $\mathrm{CH}(\mathrm{Cl})] \mathrm{n}$

WGT 0.9 HINH2O 0.048386 C 0.384338 CL 0.567275

*

* Mat \#5 Water Vapor (mixed with void)

WGT 0.005 HINH2O 0.11188500 .888115

* Mat \#6 Polyethylene (CH2)n

WGT 0.96 HINH2O $0.14397 \mathrm{C} 0.856303$

* Mat \#7 Concrete, conservative Hanford (dens $=2.35 \mathrm{~g} / \mathrm{cm} 3$ )

CONC AL27 0.003358 CA 0.002614 FE 0.001344

HINH 200.007023 O 0.045396 SI 0.012905

* Mat \#8 Cement/Pu (normal (high) water content, 113 g Pu per can)

* density weightractions

WGT 2.059 HINH2O 0.04049200 .481567 F19 0.032014 MG 0.066421 CA 0.359369 PU239 0.020138

$*$

CM

* PART \#1 Cementation can (cemented residue, steel can, PV̀C bag) NEST 3

ZCYL 16.98517 .8130 .033

ZCYL 36.98817 .8160 .030

ZCYL $4 \quad 7.01817 .8460 .000$

* PART \#2 3 Cars near drum center (Case 2), including space in

drum

CLUSTER 4

ZROD ORIGIN 0.00008 .10370 .0000 P1 7.01817 .846

ZROD ORIGIN 7.0181 -4.05190 .0000 PI 7.01817 .846

ZROD ORIGIN $-7.0181-4.05190 .0000$ P1 7.018 17.846

- 55 Gal 17C drum inner: 22.5 in $\mathrm{ID}, 33.25$ in inside height

* drum lined with 0.09 in thick poly $\rightarrow(22.32 \mathrm{ID}, 33.07 \mathrm{IH})$

ZROD 028.346483 .9978

* PART \#3 Drum with Poly liner (inside cube box of space) 


\section{HNF-SD-SQA-CSA-525 Rev. 0}

NEST 4

ZCYL P2 28.3464 $84.3783 \quad 0.3805$

ZCYL 6 28.575 84.60690 .15189

ZCYL 228.7268984 .758790 .0

CUBOID $028.72728 .72784 .759-28.727-28.727-0.001$

* PART \#4 Array of drums: $X$ by $Y$ by $Z$

ARRAY 554

* Pant \#3 placed in array 12 times then part $\# 7$ placed once

* followed by part \#3 12 times in each of the 4 layers

* overbatch occurs 4 out of 25 drums $=16 \%$ of the time

$(3) * 128(3) * 12(3) * 128(3) * 12(3) * 128(3) * 12(3) * 128(3) * 12$

* PART \#5 Amay container / Concrete Floor (12in) \& Ceiling (8in)

NEST 2

CUBOID P4 287.27 287.27 339.04 0.00.0 0

* ceiling $(339.04 \mathrm{~cm}+8 \mathrm{in})$ floor (0-12in)

CUBOID $7287.27287 .27359 .360 .00 .0-30.48$

* reflective surfaces on $X$ and $Y$ surfaces of outer cube

ALBEDO 1.0 1.00.0 1.0 1.0 0.0

* PART \#6 Cementation can (cemented residue, steel can, PVC bag) NEST 3

ZCYL \& 6.98517 .8130 .033

ZCYL $3 \quad 6.98817 .8160 .030$

ZCYL 47.01817 .8460 .000

* PART \#7 3 Cans + 1 Xtra near drum center (Case 2), including space in drum

CLUSTER 5

ZROD ORIGIN 0.00008 .10370 .0000 P6 7.018 17.846

ZROD ORIGIN 7.0181 -4.05190 .0000 P1 7.01817 .846

ZROD ORIGIN +7.0181 -4.05190 .0000 P1 7.018 17.846

ZROD ORIGIN $0.0000 \quad 0.000017 .8461$ P1 7.01817 .846

* 55 Gal $17 \mathrm{C}$ drum inner. 22.5 in ID, 33.25 in inside height

* dnum lined with 0.09 in thick poly $\rightarrow(22.32 \mathrm{mD}, 33.07 \mathrm{IH})$

ZROD 028.346483 .9978

* PART \#7 Drum with Poly liner (inside cube box of space)

NEST 4

ZCYL P7 $28.3464 \quad 84.3783 \quad 0.3805$

ZCYL $628.575 \quad 84.6069 \quad 0.15189$

ZCYL 228.7268984 .758790 .0

CUBOID $028.72728 .72784 .759-28.727-28.727-0.001$

* strtstage, endstage, thistperstage, time(min), -1

$\begin{array}{llll}-10 & 30 & 1000 & 300 \\ & \text { STDV } 0.003-1\end{array}$

MULTPOINT 4

29. 29. 10. 1

29. 29. 95.1

29. 29. 180.1

29. 29.265. 1

END

CODE 7

PSsVWpC

* $x y$

$0.129 .85 .57 .429 .85,0.129,-10$.

* yz

1938. 10. 38. 38.10. 191910 .

* xy

19. 19 20. 38. 19.20. $1919-1$

BND

* CEMD2_1 Array of Dnums, 3 cans $66.67 \mathrm{~g}$ Pu ea arrang drum center.

FISSION

* \#MATERIALs \#NUCLIDEs

$7 \quad 14$ NUCNAMES

* Mat \#1 CementPu (normal (high) water content, $66.67 \mathrm{~g}$ Pu per can)

* density weightfractions

WGT 2.059 HINH2O 0.04083300 .485625 F19 0.032284 MG 0.066981 CA 0.362397 PU239 0.011881

* Mat \#2 Carbon Steel $1 \%$ C $7.86 \mathrm{~g} / \mathrm{cm} 3$

\author{
CONC C $0.003941 \mathrm{FE} 0.0839103$ \\ * Mar \#3 Steel (slip cover can) \\ WGT 7.9 C 0.005 AL27 0.001 SI 0.006 P31 0.002 S32 0.002 \\ FE 0.983 SN 0.001 \\ * Mat \#4 PVC I(CH2CH(Cl)]n \\ WGT 0.9 HINH 200.048386 C 0.384338 CL 0.567275 \\ * Mat \#5 Water Vapor (mixed with void) \\ WGT 0.0001 HINH2O 0.11188500 .888115 \\ * Mat \#6 Polyethylene (CH2)n \\ WGT 0.96 HINH2O 0.14397 C 0.856303 \\ - Mat \#7 Concrete, conservative Hanford (dens=2.35 g/cm3) \\ CONC AL27 0.003358 CA 0.002614 FE 0.001344 \\ HINH2O 0.00702300 .045396 SI 0.012905 \\ $\mathrm{CM}$ \\ * PART \#1 Cementation can (cemented residue, steel car, PVC bag) \\ NEST 3 \\ ZCYL I 6.98517 .8130 .033 \\ ZCYL 36.98817 .8160 .030 \\ ZCYL $4 \quad 7.018 \quad 17.8460 .000$ \\ - PART \#2 3 Cans near drum center (Case 2), including space in \\ drum \\ CLUSTER 4 \\ ZROD ORIGIN 0.00008 .10370 .0000 P1 7.018 17.846 \\ ZROD ORIGIN $7.0181-4.05190 .0000$ P1 7.01817 .846 \\ ZROD ORIGIN -7.0181 -4.0519 0.0000 P1 7.018 17.846 \\ * 55 Gal 17C drum inner: 22.5 in ID, 33.25 in inside height \\ * drum lined with 0.09 in thick poly $\rightarrow$ (22.32 ID, $33.07 \mathrm{IH})$ \\ ZROD 528.346483 .9978 \\ * PART \#3 Drum with Poly liner (inside cube box of space) \\ NEST 4 \\ ZCYL P2 28.3464 $84.3783 \quad 0.3805$ \\ ZCYL $628.575 \quad 84.60690 .15189$ \\ ZCYL 2 28.72689 84.758790 .0 \\ CUBOID $028.72728 .72784 .759-28.727-28.727-0.001$ \\ * PART \#4 Array of drums: $X$ by $Y$ by $Z$ \\ ARRAY 114 \\ * Part ( $\$ 3$ ) placed in array 4 times \\ (3)*4 \\ * PART \#S ATray container / Concrete Floor (12in) \& Ceiling (8in) \\ NEST 2 \\ CUBOID P4 57.454 57.454 339.04 0.00.0 0. \\ * ceiling $(339.04 \mathrm{~cm}+8 \mathrm{in})$ floor $(0-12 \mathrm{in})$ \\ CUBOID $757.45457 .454359 .360 .00 .0-30.48$ \\ * reflective surfaces on $X$ and $Y$ surfaces of outer cube \\ ALBEDO 1.0 1.0 0.0 1.0 1.00.0 \\ * stitstage, endstage, thistperstage, time (min), -1 \\ $\begin{array}{llll}-10 & 30 \quad 800 & 300 & \text { STDV .002 }\end{array}$ \\ MULTIPONT 4 \\ 29. 29. 10. 1 \\ 29.29. 95.1 \\ 29. 29. 180. 1 \\ 29. 29. 265. 1 \\ END \\ CODE 7 \\ PSsVWpC \\ * $\mathrm{xy}$ \\ 0.1 29. 85. $57.429 .85,0.129 .-10$. \\ * yz \\ 19 38. 10. 38. 38. 10. 191910 . \\ * $x y$ \\ 19. 19 20. 38. 19. 20.1919-1 \\ END
}

* CEMD2_m Array of Drums, 3 cans $66.67 \mathrm{~g}$ Pu ea arrang drum 
center

FISSION

* \#MATERIALs \#NUCLIDEs

*

$7 \quad 14$ NUCNAMES

* Mat \#1 Cement/Pu (normal (high) water content, $66.67 \mathrm{~g}$ Pu per can)

* density weightfractions

WGT 2.059 HINH2O 0.04083300 .485625 F19 0.032284 MG 0.066981 CA 0.362397 PU239 0.011881

* Mat \#2 Carbon Steel $1 \%$ C $7.86 \mathrm{~g} / \mathrm{cm} 3$

CONC C 0.003941 FB 0.0839103

* Mat \#3 Steel (slip cover can)

WGT 7.9 C 0.005 AL27 0.001 SI 0.006 P31 0.002 S32 0.002 FE 0.983 SN 0.001

* Mat \#4 PVC [(CH2CH(Cl)]n

WOT 0.9 HINH2O 0.048386 C 0.384338 Cl 0.567275

*

* Mat \#S Water Vapor (mixed with void)

WGT $0.0005 \mathrm{HINH} 200.11188500 .888115$

* Mat \#6 Polyethylene ( $\mathrm{CH} 2$ )n

WGT 0.96 HINH2O 0.14397 C 0.856303

*

* Mat \#7 Concrete, conservative Hanford (dens $=2.35 \mathrm{~g} / \mathrm{cm} 3$ )

CONC AL27 0.003358 CA 0.002614 FE 0.001344 HNNH2O 0.00702300 .045396 SI 0.012905

$*$

$\mathrm{CM}$

* PART \#I Cementation can (cemented residue, steel can, PVC bag) NEST 3

ZCYL 16.98517 .8130 .033

ZCYL $3 \quad 6.98817 .8160 .030$

ZCYL $4 \quad 7.018 \quad 17,8460.000$

* PART \#2 3 Cans near drum center (Case 2), including space in drum

CLUSTER 4

ZROD ORIGIN 0.00008 .10370 .0000 P1 7.01817 .846

ZROD ORIGIN 7.0181 -4.0519 0.0000 P1 7.018 17.846

ZRROD ORIGIN -7.0181 -4.0519 0.0000 P1 7.018 17.846

* $55 \mathrm{Gal} 17 \mathrm{C}$ drum inner. 22.5 in ID, 33.25 in inside height

* drum lined with 0.09 in thick poly $\rightarrow(22.32 \mathrm{ID}, 33.07 \mathrm{IH})$

ZROD 028.346483 .9978

* PART \#3 Drum with Poly liner (inside cube box of space) NEST 4

ZCYL P2 28.3464 $84.3783 \quad 0.3805$

ZCYL $628.575 \quad 84.6069 \quad 0.15189$

ZCYL 2 28.72689 84.75879 0.0

CUBOID $528.72728 .72784 .759-28.727-28.727-0.001$

* PART \#4 Array of drums: $X$ by $Y$ by $Z$

ARRAY 114

* Part (\$3) placed in array 4 times

$(3) * 4$

* PART \#5 Array container / Concrete Floor (12in) \& Ceiling (8in)

NEST 2

CUBOID P4 57.454 57.454 339.04 0.00.0 0

ceiling $(339.04 \mathrm{~cm}+8 \mathrm{in})$ floor $(0-12 \mathrm{in})$

CUBOID 7 57.454 57.454 359.36 0.0 0.0 -30.48

* reflective surfaces on $X$ and $Y$ surfaces of outer cube

ALBEDO 1.01 .00 .01 .01 .00 .0

* strtstage, endstage, fhistperstage, time(min), -1

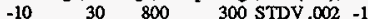

MULTTPOINT 4

29.29. 10. 1

29. 29. 95.1

29. 29.180 . 1

29. 29. 265 . 1

END
CODE 7

PSsVWpC

* xy

$0.129 .85 .57 .429 .85 .0 .129 .-10$

* yz

19 38. 10. 38. 38. 10. 191910

* xy

19. 19 20. 38. 19. 20. $1919-1$

BND

* CEMD2_anp Array of Drums, 3 cans $66.67 \mathrm{~g}$ Pu ea arrang drum center no drum mat

FISSION

* \#MATERIALs \#NUCLIDEs

$7 \quad 14$ NUCNAMES

$*$

* Mat \#l Cement/Ra (normal (high) water content, $66.67 \mathrm{~g}$ Pu per. can)

* density weightfractions

WGT 2.059 HINH2O 0.04083300 .485625 F19 0.032284

* MG 0.066981 CA 0.362397 PU239 0.011881

* Mat \#2 Carton Steel $1 \%$ C $7.86 \mathrm{~g} / \mathrm{cm}^{3}$

CONC C 0.003941 FE 0.0839103

* Mat \#3 Steel (slip cover can)

WGT 7.9 C 0.005 AL27 $0.001 \$ 10.006$ P31 $0.002 \$ 320.002$ FE 0.983 SN 0.001

- Mat \#4 PVC $[$ [(CH2CH(Cl)]n

WGT 0.9 HINH2O 0.048386 C 0.384338 CL 0.567275

*

* Mat \#5 Water Vapor (mixed with void)

WGT 0.005 HINH2O 0.11188500 .888115

* Mat \#6 Polyethylene (CH2)a

WGT 0.96 HINH2O 0.14397 C 0.856303

* Mat \#7 Concrete, conservative Hanford (dens $=2.35 \mathrm{~g} / \mathrm{cm} 3$ )

CONC AL27 0.003358 CA 0.002614 FE 0.001344 HINH2O 0.00702300 .045396 SI 0.012905

CM

* PART \#1 Cementation can (cemented residue, steel can, PVC bag) NEST 3

ZCYL 16.98517 .8130 .033

ZCYL $3 \quad 6.98817 .8160 .030$

ZCYL $4 \quad 7.01817 .8460 .000$

* PART \#2 3 Cans near drum center (Case 2), including space in

dnum

CLUSTER 4

ZROD ORIGIN 0.00008 .10370 .0000 P1 7.01817 .846

ZROD ORIGIN 7.0181 -4.05190 .0000 PI 7.01817 .846

ZROD ORIGIN $-7.0181-4.05190 .0000$ P1 7.01817 .846

* 55 Gal 17C drum inner: 22.5 in ID, 33.25 in inside height

* drum lined with 0.09 in thick poly $\rightarrow$ (22.32 ID, 33.07 IH)

ZROD 028.346483 .9978

* PART \#3 Drum with Poly liner (inside cube box of space)

NEST 4

ZCYL P2 28.3464 $84.3783 \quad 0.3805$

ZCYL $028.575 \quad 84.6069 \quad 0.15189$

ZCYL 228.7268984 .758790 .0

CUBOID $0 \quad 28.72728 .72784 .759-28.727-28.727-0.001$

*PART \#4 Array of dnums: X by Y by $Z$

ARRAY 114

* Part (\#3) placed in array 4 times

(3)*4

* PART \#5 Amry container / Concrete Floor (12in) \& Ceiling (8in)

NEST 2

CUBOID P4 57.454 57.454 339.04 0.00.0 0 . 
* $\quad$ ceiling( $339.04 \mathrm{~cm}+8$ in) floor (0-12in)

CUBOID $757.45457 .454359 .360 .00 .0-30.48$

* reflective surfaces on $X$ and $Y$ surfaces of outer cube

ALBEDO 1.01 .00 .01 .01 .00 .0

* strtstage, endstage, \#histperstage, time (min), -1

$\begin{array}{llllll}-10 & 30 & 1000 & 300 & \text { STDV } 0.002 & -1\end{array}$

MULTIPOINT 4

29. 29. 10. 1

29. 29. 95.1

29. 29. 180.1

29.29.265. 1

END

CODE 7

PSsVWpC

* $\mathrm{xy}$

$0.129 .85 .57 .429 .85,0.129 .-10$.

$* \mathrm{yz}$

1938. 10. 38.38.10. 191910 .

* xy

19. $1920.38 .19 .20 .1919-1$

END

* CEMD2_ahd Array of Drums, 3 cans $66.67 \mathrm{~g}$ Pu ea arrang dram center

FISSION

* \#MATERIALs \#NUCLIDEs

$7 \quad 14$ NUCNAMES

* Mat \#l Cement/Pu (normal (high) water content, $66.67 \mathrm{~g}$ Pu per

can)

* density weightfractions

WGT 2.059 HINH2O 0.04083300 .485625 F19 0.032284 MG 0.066981 CA 0.362397 PU239 0.011881

$\star$

* Mat \#2 Carbon Steel $1 \% \mathrm{C} 7.86 \mathrm{~g} / \mathrm{cm}^{3}$

CONC C $0.003941 \mathrm{FE} 0.0839103$

*

* Mat \#3 Steel (slip cover can)

WGT 7.9 C 0.005 AL27 0.001 SI 0.006 P31 0.002 \$32 0.002 FE 0.983 SN 0.001

* Mat \#4 PVC [ [(CH2CH(Cl)]n

WGT 0.9 HINH2O 0.048386 C 0.384338 CL 0.567275

* Mat \#5 Water Vapor (mixed with void)

WGT 0.005 HINH2O 0.11188500 .888115

*

* Mat \#6 Polyethylene (CH2)n

WGT 0.96 HNH 200.14397 C 0.856303

* Mat \#7 Concrete, conservative Hanford (dens $=2.35 \mathrm{~g} / \mathrm{cm} 3$ )

CONC AL27 0.003358 CA 0.002614 FE 0.001344 HINH2O 0.00702300 .045396 SI 0.012905

CM

* PART \#1 Cementation can (cemented residue, steel can, PVC bag) NEST 3

ZCYL $1 \quad 6.98517 .8130 .033$

ZCYL $3 \quad 6.988 \quad 17.8160 .030$

ZCYL $4 \quad 7.01817 .8460 .000$

* PART \#2 3 Cans near drum center (Case 2), including space in dnum

CLUSTER 4

ZROD ORIGIN $0.0000 \quad 8.10370 .0000$ Pl 7.018 17.846

ZROD ORIGIN 7.0181 -4.05190 .0000 P1 7.01817 .846 ZROD ORIGIN -7.0181 -4.0519 0.0000 P1 7.018 17.846

* 55 Gal 17C drum inner: 22.5 in ID, 33.25 in inside height

* drum lined with 0.09 in thick poly $\rightarrow$ (22.32 ID, $33.07 \mathrm{IH}$ )

ZROD 0 28.3464 83.9978

- PART \#3 Drum with Poly liner (inside cube box of space)
NEST 4

ZCYL P2 28.3464 $84.3783 \quad 0.3805$

ZCYL $628.575 \quad 84.60690 .15189$

ZCYL 228.650984 .758790 .0

CUBOID $028.6628 .6684 .759-28.66-28.66-0.001$

*PART \#4 Array of drums: $X$ by $Y$ by $Z$

ARRAY 114

* Part (\#3) placed in array 4 times

(3)*4

* PART \#5 Array container / Concrete Floor (12in) \& Ceiling (8in)

NEST 2

CUBOID P4 57.32 57.32 339.04 0.00.0 0 .

* ceiling(339.04cm+8in) floor (0-12in)

CUBOID $757.3257 .32359 .360 .00 .0-30.48$

* reflective surfaces on $X$ and $Y$ surfaces of outer cube

ALBEDO 1.0 1.0 0.0 1.0 1.0 0.0

* strtstage, endstage, fhistperstage, time(min), -1

$\begin{array}{llll}-10 & 30 & 1000 & 300\end{array}$

MULTIPOINT 4

29.29. 10. 1

29. 29. 95.1

29.29. 180.1

29. 29. 265.1

END

CODE 7

PSsVWpC

* $x y$

$0.129 .85 .57 .429 .85 .0 .129 .-10$.

* yz

19 38. 10. 38.38.10. 191910.

* $\mathbf{x y}$

19. $1920.38 .19 .20 .1919-1$

END

* CEMD2_aeric Array of Drums, 3 cans $66.67 \mathrm{~g}$ Pu ea arrang drum center

FISSION

* \#MATERIALs \#NUCLIDEs

$7 \quad 14$ NUCNAMES

* Mat \#1 Cement/Pu (normal (high) water content, $66.67 \mathrm{~g}$ Pu per

can)

* density weightfractions

WGT 2.059 HINH2O 0.04083300 .485625 F19 0.032284 MG 0.066981 CA 0.362397 PU239 0.011881

* Mat \#2 Carbon Steel $1 \%$ C $7.86 \mathrm{~g} / \mathrm{cm}^{3}$

CONC C 0.003941 FE 0.0839103

*

* Mat \#3 Steel (slip cover can)

WGT 7.9 C 0.005 AL27 0.001 SI 0.006 P31 0.002 \$32 0.002 FE 0.983 SN 0.001

* Mat \#4 PVC [(CH2CH(Cl)]n

WGT 0.9 HINH2O 0.048386 C 0.384338 CL 0.567275

* Mat \#S Water Vapor (mixed with void)

WGT 0.005 HINH2O 0.111885 O 0.888115

* Mat \#6 Polyethylene (CH2)n

WGT $0.96 \mathrm{HINH} 2 \mathrm{O} 0.14397 \mathrm{C} 0.856303$

* Mat \#7 Concrete, conservative Hanford (dens $=2.35 \mathrm{~g} / \mathrm{cm} 3$ )

CONC AL27 0.003358 CA 0.002614 FE 0.001344 HINH2O 0.00702300 .045396 SI 0.012905

CM

* PART \#1 Cementation can (cemented residue, stecl can, PVC bag) NEST 3

ZCYL 16.98517 .8130 .033 
ZCYL $3 \quad 6.98817 .8160 .030$

ZCYL $4 \quad 7.01817 .8460 .000$

* PART \#2 Druml (Case 2, Erickson), including space in drum CLUSTER 4

ZROD ORIGIN 2.41 -21.180.0000 P1 7.018 17.846

ZROD ORIGIN 15.081 -15.081 0.0000 P1 7.018 17.846

ZROD ORIGIN 21.18 -2.41 0.0000 P1 7.018 17.846

* 55 Gal 17C drum inner: 22.5 in ID, 33.25 in inside beight

* drum lined with 0.09 in thick poly $\rightarrow(22.32 \mathrm{ID}, 33.07 \mathrm{IH})$

ZROD 0 28.3464 83.9978

- PART \#3 Drum2 (Case 2, Brickson), including space in drum CLUSTER 4

ZROD ORIGIN -2.41 -21.18 0.0000 P1 7.018 17.846

ZROD ORIGIN -15.081 -15.081 0.0000 P1 7.018 17.846

ZROD ORIGIN -21.18 -2.41 0.0000 P1 7.018 17.846

* 55 Gal 17C drum inner: 22.5 in ID, 33.25 in inside height

* drum lined with 0.09 in thick poly $\rightarrow(22.32 \mathrm{ID}, 33: 07 \mathrm{IH})$

ZROD 028.346483 .9978

* PART \#4 Dnum3 (Case 2, Erickson), including space in drum CLUSTER 4

ZROD ORIGIN 2.4121 .180 .0000 P1 7.01817 .846

ZROD ORIGIN 15.08115 .0810 .0000 P1 7.01817 .846

ZROD ORIGIN 21.18 2.41 0.0000 P1 7.018 17.846

* 55 Gal 17C drum inner: 22.5 in ID, 33.25 in inside height

* drum lined with 0.09 in thick poly $\rightarrow$ (22.32 ID, $33.07 \mathrm{IH})$

ZROD 0 28.3464 83.9978

* PART H5 Drum4 (Case 2, Erickson), including space in drum CLUSTER 4

ZROD ORIGIN -2.4121 .180 .0000 PI 7.01817 .846

ZROD ORIGIN -15.081 15.081 0.0000 P1 7.018 17.846

ZROD ORIGIN -21.18 2.41 0.0000 P1 7.018 17.846

* $55 \mathrm{Gal} 17 \mathrm{C}$ drum inner: $22.5 \mathrm{in} \mathrm{ID}, 33.25$ in inside height

* drum lined with 0.09 in thick poly $\rightarrow$ (22.32 ID, $33.07 \mathrm{IH})$ ZROD 028.346483 .9978

* PART \#6 Drums (Case 2, Erickson), including space in dnum CLUSTER 4

ZROD ORIGIN 2.41 -21.18 66.1 P1 7.018 17.846

ZROD ORIGIN 15.081 -15.081 66.1 P1 7.018 17.846

ZROD ORIGIN 21.18-2.41 66.1 P1 7.018 17.846

* 55 Gal 17C drum inner: 22.5 in ID, 33.25 in inside height

* dnim lined with 0.09 in thick poly $\rightarrow(22.32 \mathrm{I}, 33.07 \mathrm{IH})$ ZROD 028.346483 .9978

- PART 77 Drum6 (Case 2, Erickson), including space in drum CLUSTER 4

ZROD ORIGIN $-2.41-21.1866 .1$ P1 7.018 17.846

ZROD ORIGIN - $15.081-15.08166 .1$ P1 7.01817 .846

ZROD ORIGIN -21.18-2.41 66.1 P1 7.018 17.846

* 55 Gal 17C drum inner: 22.5 in ID, 33.25 in inside height

* drum lined with 0.09 in thick poly $\rightarrow$ (22.32 ID, 33.07 IF)

ZROD 028.346483 .9978

* PART \#8 Drum7 (Case 2, Erickson), including space in drum CLUSTER 4

ZROD ORIGN 2.41 21.1866.1 P1 7.018 17.846

ZROD ORIGIN 15.081 15.081 66.1 P1 7.018 17.846

ZROD ORIGIN 21.18 2.41 66.1 P1 7.018 17.846

* 55 Gal $17 \mathrm{C}$ drum inner: 22.5 in ID, 33.25 in inside height

* drum lined with 0.09 in thick poly $\rightarrow$ (22.32 ID, $33.07 \mathrm{IH})$

ZROD 0 28.3464 83.9978

* PART \#9 Drum8 (Case 2, Erickson), including space in drum CLUSTER 4

ZROD ORIGIN -2.41 21.1866.1 P1 7.018 17.846

ZROD ORIGIN -15.081 15.081 66.1 P1 7.018 17.846

ZROD ORIGIN -21.18 2.41 66.1 P1 7.018 17.846

* 55 Gal 17C dnum inner: 22.5 in ID, 33.25 in inside height

* drum lined with 0.09 in thick poly $\rightarrow(22.32 \mathrm{ID}, 33.07 \mathrm{IH})$

ZROD 028.346483 .9978

- PART \#10 Drum with Poly liner (inside cube box of space) NEST 4

ZCYL P2 28.3464 $84.3783 \quad 0.3805$

ZCYL $6 \quad 28.575 \quad 84.6069 \quad 0.15189$

ZCYL 228.7268984 .758790 .0
CUBOID 0 28.727 28.727 84.759 -28.727-28.727-0.001 * PART \#11 Drum with Poly liner (inside cube box of space) NEST 4

ZCYL P3 $28.3464 \quad 84.3783 \quad 0.3805$

ZCYL $628.575 \quad 84.6069 \quad 0.15189$

ZCYL 2 28.72689 84.75879 0.0

CUBOID 0 28.727 28.727 84.759 -28.727 -28.727-0.001

* PART \#12 Drum with Poly liner (tinside cube box of space) NEST 4

ZCYL P4 28.3464 84.3783 0.3805

ZCYL $6 \quad 28.575 \quad 84.6069 \quad 0.15189$

ZCYL 228.7268984 .758790 .0

CUBOID $0 \quad 28.72728 .72784 .759-28.727-28.727-0.001$

* PART \#13 Drum with Poly liner (inside cube box of space) NEST 4

ZCYL P5 28.3464 84.3783 0.3805

ZCYL 6 28.575 $84.6069 \quad 0.15189$

ZCYL 2 28.72689 84.75879 0.0

CUBOID $028.72728 .72784 .759-28.727-28.727-0.001$

* PART \#14 Drum with Poly liner (inside cube box of space) NEST 4

ZCYL P6 28.3464 $84.3783 \quad 0.3805$

ZCYL 6 28.575 $84.6069 \quad 0.15189$

ZCYL 28.7268984 .758790 .0

CUBOID $0 \quad 28.72728 .72784 .759-28.727-28.727-0.001$

* PART \#15 Drum with Poly liner (inside cube box of space) NEST 4

ZCYL P7 $28.3464 \quad 84.3783 \quad 0.3805$

ZCXL 6 28.575 $84.6069 \quad 0.15189$

ZCYL 28.7268984 .758790 .0

CUBOID $028.72728 .72784 .759-28.727-28.727-0.001$

* PART \#16 Drum with Poly liner (inside cube box of space) NEST 4

ZCYL P8 28.3464 $84.3783 \quad 0.3805$

ZCYL $6 \quad 28.575 \quad 84.6069 \quad 0.15189$

ZCYL 228.7268984 .758790 .0

CUBOID 0 28.727 28.727 84.759 - 28.727 -28.727-0.001

* PART \#17 Drum with Poly liner (inside cube box of space) NEST 4

ZCYL P9 $28.346484 .3783 \quad 0.3805$

ZCYL $6 \quad 28.575 \quad 84.6069 \quad 0.15189$

ZCYL 228.7268984 .758790 .0

CUBOID 0 28.727 28.727 84.759 -28.727-28.727-0.001

- PART \#18 Array of drums: X by Y by Z

ARRAY 224

* Part (f) placed in array 2 times

(16 17 141512131011$) * 2$

* PART \#19 Array container/Concrete Floor (12in) \& Ceiling (8in)

NEST 2

CUBOID P18 114.908114 .908339 .040 .00 .00

* ceiling(339.04cm+8in) floor $(0-12 \mathrm{in})$

CUBOID $7114.908114 .908359 .360 .00 .0-30.48$

* reflective surfaces on $X$ and $Y$ surfaces of outer cube

ALBEDO 1.01 .00 .01 .01 .00 .0

* strtstage, endstage, thistperstage, time(min), -1

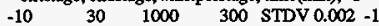

MULTIPOINT 4

80. 80.10 .1

80. 80. 95. 1

80. 80.180 .1

75. 75. 265. 1

END

CODE 7

PSsVWpC

* yz

0.15585 .57 .45585 . $0.155-5$.

* yz

5457.4 170. 54.1170 .5457 .4 -2.

* xy

.111470 .11411470 . .1.170.

* xy 
.1114100 .114114 100..1.1100.

END

* CEMD2_aerict Array of Drums, 3 cans $66.67 \mathrm{~g}$ Pu ea arrang drum center

FISSION

* \#MATERIALs \#NUCliDEs

$7 \quad 14$ NUCNAMES

$*$

* Mat \#1 Cement/Pu (normal (jigh) water content, $66.67 \mathrm{~g}$ Pa per can)

* density weightfractions

WGT 2.059 HINH2O 0.04083300 .485625 F19 0.032284 MG 0.066981 CA 0.362397 PU239 0.011881

*

* Mat $\# 2$ Carton Steel $1 \%$ C $7.86 \mathrm{~g} / \mathrm{cm} 3$

CONC C 0.003941 FE 0.0839103

*

* Mat \#3 Steel (slip cover can)

WGT 7.9 C 0.005 AL27 0.001-SI 0.006 P31 0.002 S32 0.002 FE 0.983 SN 0.001

* Mat \#4 PVC [(CH2CH(C)]n

WGT 0.9 HINH 200.048386 C 0.384338 C 0.567275

$*$

* Mat 45 Water Vapor (mixed with void)

WGT 0.005 HINH2O 0.11188500 .888115

*

* Mat \#6 Polyethylene (CH2)n

WGT 0.96 HINH2O 0.14397 C 0.856303

*

* Mat \#7 Concrete, conservative Hanford (dens=2.35 g/cm3)

CONC AL27 0.003358 CA 0.002614 FE 0.001344 HINH2O 0.00702300 .045396 SI 0.012905

CM

* PART \#1 Cementation can (cemented residue, steel can, PVC bag) NEST 3

ZCYL 1 6.985 17.8130 .033

ZCYL $3 \quad 6.98817 .8160 .030$

ZCYL $4 \quad 7.01817 .8460 .000$

- PART \#2 3 Cans near drum center (Case 2), including space in drom

CLUSTER 4

ZROD ORIGIN 0.0000 8.1037 0.0000 P1 7.018 17.846

ZROD ORIGIN 7.0181 -4.05190 .0000 PI 7.01817 .846 ZROD ORIGIN $-7.0181-4.05190 .0000$ P1 7.01817 .846

* 55 Gal $17 \mathrm{C}$ drum inner: 22.5 in ID, 33.25 in inside height

* drum lined with 0.09 in thick poly $\rightarrow(22.32 \mathrm{ID}, 33.07 \mathrm{IH})$

ZROD 028.346483 .9978

* PART \#3 3 Cans near dum center at top of drum (Case 2), including space in drum

CLUSTER 4

ZROD ORIGIN 0.00008 .103766 .1 P1 7.01817 .846

ZROD ORIGIN 7.0181 -4.051966 .1 P1 7.01817 .846

ZROD ORIGIN $-7.0181-4.051966 .1$ P1 7.018 17.846

* $55 \mathrm{Gal} 17 \mathrm{C}$ drum inner: 22.5 in ID, 33.25 in inside height

* drum lined with 0.09 in thick poly $\rightarrow(22.32 \mathrm{ID}, 33.07 \mathrm{IH})$ ZROD 028.346483 .9978

* PART \#4 Drum with Poly liner (inside cube box of space) NEST 4

ZCYL P2 $28.346484 .3783 \quad 0.3805$

ZCYL $6 \quad 28.575 \quad 84.60690 .15189$

ZCYL 228.7268984 .758790 .0

CUBOID 0 28.727 28.727 84.759-28.727 -28.727 -0.001

* PART \#5 Drum with Poly liner (inside cube box of space) NEST 4

ZCYL P3 $28.346484 .3783 \quad 0.3805$

ZCYL $6 \quad 28.575 \quad 84.6069 \quad 0.15189$

ZCYL 228.7268984 .758790 .0
CUBOID $028.72728 .72784 .759-28.727-28.727-0.001$

* PART \#6 Array of drums: X by Y by Z

ARRAY 224

- Part (\$) placed in artay 2 times

(55554444)*2

* PART \#7 Array container / Concrete Floor (12in) \& Ceiling (8in)

NEST 2

CUBOID P6 114.908 114.908 339.040.00.0 0.

* ceiling(339.04cm+8in) floor (0-12in)

CUBOID $7114.908114 .908359 .360 .00 .0-30.48$

* reflective surfaces on $X$ and $Y$ surfaces of outer cube

ALBEDO 1.0 1.00.0 1.0 1.00.0

* strtstage, endstage, \#histperstage, time(min), -1

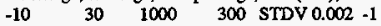

MULTIPOINT 4

40. 40. 10.1

40. 40. 95.1

40. 40.180 .1

35. 35. 265.1

END

CODE 7

PSsVWp C

* xy

$0.129 .85 .57 .429 .85 .0 .129 .-10$.

* yz

1938. 10. 38. 38. 10. 191910.

* $\mathrm{xy}$

19. $1920.38 .19 .20 .1919-1$

END

* CEMD2_aericc13 Array of Drums, 3 cans $66.67 \mathrm{~g}$ Pu ea arrang drum center

FISSION

* \#MATERIALs \#NUCLIDEs

$7 \quad 14$ NUCNAMES

*

* Mat \#1 Cement/Pu (66.67 g Pu per can)

* Water weight fraction: 0.52 , equivilent to $H$ conc assuming all $H$ from $\mathrm{H2O}$

* density weightfractions

WGT 2.059 HINH2O 0.05819 O 0.583166 F19 0.024249 MG 0.050311 CA 0.272203 PU239 0.011881

* Mat \#2 Carbon Steel $1 \%$ C $7.86 \mathrm{~g} / \mathrm{cm}^{3}$

CONC C 0.003941 FE 0.0839103

*

* Mat \#3 Steel (slip cover can)

WGT 7.9 C 0.005 AL27 0.001 SI 0.006 P31 0.002 \$32 0.002 FE 0.983 SN 0.001

$*$

* Mat \#4 PVC [(CH2CH(C)]n

WGT 0.9 HINH2O 0.048386 C 0.384338 CL 0.567275

* Mat \#5 Water Vapor (mixed with void)

WGT 0.005 HINH2O 0.111885 O 0.888115

$\star$

* Mat \#6 Polyethylene (CH2)n

WGT 0.96 HINH2O 0.14397 C 0.856303

* Mat \#7 Concrete, conservative Hanford (dens $=2.35 \mathrm{~g} / \mathrm{cm} 3$ )

CONC AL27 0.003358 CA 0.002614 FE 0.001344

HINH2O 0.007023 O 0.045396 SI 0.012905

$\mathrm{CM}$

* PART \#1 Cementation can (cemented residue, steel can, PVC bag) NEST 3

ZCYL $1 \quad 6.98517 .8130 .033$

ZCYL $3 \quad 6.98817 .8160 .030$

ZCYL $4 \quad 7.01817 .8460 .000$

* PART \#2 Drum1 (Case 2, Erickson), including space in drum 
CLUSTER 4

ZROD ORIGIN $2.41-21.180 .0000$ P1 7.018 17.846 ZROD ORIGIN $15.081-15.0810 .0000$ P1 7.01817 .846 ZROD ORIGIN $21.18-2.410 .0000$ P1 7.018 17.846

* 55 Gal 17C drum inner: 22.5 in ID, 33.25 in inside height * drum lined with 0.09 in thick poly $->(22.32 \mathrm{ID}, 33.07 \mathrm{IH})$ ZROD 028.346483 .9978

* PART \#3 Drum2 (Case 2, Erickson), including space in drum CLUSTER 4

ZROD ORIGIN $-2.41-21.180 .0000$ P1 7.018 17.846

ZROD ORIGIN -15.081-15.081 0.0000 P1 7.018 17.846

ZROD ORIGIN -21.18 -2.41 0.0000 P1 7.018 17.846

- 55 Gal $17 \mathrm{C}$ drum inner: 22.5 in $\mathrm{ID}, 33.25$ in inside height

* drum lined with 0.09 in thick poly $\rightarrow$ (22.32 ID, 33.07 iH) ZROD 0 28.3464 83.9978

- PART \#4 Drum3 (Case 2, Erickson), including space in drum CLUSTER 4

ZROD ORIGIN 2.4121 .180 .0000 P1 7.018 17.846

ZROD ORIGIN 15.08115 .0810 .0000 P1 7.018 17.846

ZROD ORIGIN 21.182 .410 .0000 P1 7.01817 .846

* 55 Gal $17 \mathrm{C}$ dram inner: 22.5 in ID, 33.25 in inside height

* drum lined with 0.09 in thick poly $\rightarrow(22.32 \mathrm{ID}, 33.07 \mathrm{IH})$ ZROD 0 28.3464 83.9978

* PART HS Drum4 (Case 2, Brickson), including space in drum CLUSTER 4

ZROD ORIGIN -2.41 21.18 0,0000 P1 7.018 17.846

ZROD ORIGIN -15.081 15.081 0.0000 P1 7.018 17.846

ZROD ORIGIN -21.18 2.41 0.0000 P1 7.018 17.846

* 55 Gal 17C drum inner: 22.5 in ID, 33.25 in inside height

* drum lined with 0.09 in thick poly $\rightarrow(22.32 \mathrm{ID}, 33.07 \mathrm{IH})$

ZROD 028.346483 .9978

* PART \#6 Drum5 (Case 2, Erickson), including space in drum CLUSTER 4

ZROD ORIGIN $2.41-21.1866 .1$ P1 7.018 17.846

ZROD ORIGIN 15.081 - 15.08166 .1 P1 7.018 17.846

ZROD ORIGIN 21.18-2.4166.1 PI 7.018 17.846

* 55 Gal 17C drum inner. 22.5 in ID, 33.25 in inside height

* drum lined with 0.09 in thick poly $\rightarrow$ (22.32 ID, 33.07 IH)

ZROD 0 28.3464 83.9978

* PART \#7 Drum6 (Case 2, Erickson), including space in drum CLUSTER 4

ZROD ORIGIN $-2.41 \quad-21.1866 .1$ P1 7.018 17.846

ZROD ORIGIN -15.081 -15.081 66.1 P1 7.018 17.846

ZROD ORIGIN -21.18 -2.41 66.1 P1 7.018 17.846

* $55 \mathrm{Gal} 17 \mathrm{C}$ drum inner. 22.5 in $\mathrm{ID}, 33.25$ in inside height

* drum lined with 0.09 in thick poly $\rightarrow(22.32 \mathrm{ID}, 33.07 \mathrm{IH})$

ZROD 028.346483 .9978

* PART \#8 Drum7 (Case 2, Erickson), including space in drum CLUSTER 4

ZROD ORIGIN 2.4121 .1866 .1 P1 7.01817 .846

ZROD ORIGIN 15.08115 .08166 .1 P1 7.018 17.846

ZROD ORIGIN 21.18 2.41 66.I P1 7.018 17.846

- $55 \mathrm{Gal} 17 \mathrm{C}$ drum inner: $22.5 \mathrm{in} \mathrm{ID}, 33.25$ in inside height

- drum lined with 0.09 in thick poly $\rightarrow(22.32 \mathrm{ID}, 33.07 \mathrm{IH})$

ZROD 028.346483 .9978

* PART \#9 Dum8 (Case 2, Brickson), including space in drum CLUSTER 4

ZROD ORIGIN -2.4121 .1866 .1 P1 7.01817 .846

ZROD ORIGIN - 15.08115 .08166 .1 P1 7.01817 .846

ZROD ORIGIN -21.18 2.41 66.1 P1 7.018 17.846

* $55 \mathrm{Gal} 17 \mathrm{C}$ drum inner. 22.5 in ID, 33.25 in inside height

* dnum lined with 0.09 in thick poly $\rightarrow$ (22.32 ID, 33.07 IH)

ZROD 0 28.3464 83.9978

* PART \#10 Drum with Poly liner (inside cube box of space) NEST 4

ZCYL P2 28.3464 $84.3783 \quad 0.3805$

ZCYL $6 \quad 28.575 \quad 84.60690 .15189$

ZCYL 28.7268984 .758790 .0

CUBOID $028.72728 .72784 .759-28.727$-28.727-0.001

* PART \#11 Drum with Poly liner (inside cube box of space) NEST 4
ZCYL P3 28.3464 $84.3783 \quad 0.3805$

ZCYL $6 \quad 28.575 \quad 84.6069 \quad 0.15189$

ZCYL 228.7268984 .758790 .0

CUBOID 0 28.727 28.727 84.759 -28.727 -28.727 -0.001

* PART \#12 Dram with Poly liner (inside cube box of space) NEST 4

ZCYL P4 28.3464 $84.3783 \quad 0.3805$

ZCYL $6 \quad 28.575 \quad 84.6069 \quad 0.15189$

ZCYL 228.7268984 .758790 .0

CUBOID $0 \quad 28.72728 .72784 .759-28.727-28.727-0.001$

* PART \#13 Drum with Poly liner (inside cube box of space) NEST 4

ZCYL P5 $28.346484 .3783 \quad 0.3805$

ZCYL $6 \quad 28.575 \quad 84.6069 \quad 0.15189$

ZCYL 228.7268984 .758790 .0

CUBOID $028.72728 .72784 .759-28.727$-28.727 - 0.001

* PART \#14 Drum with Poly liner (inside cube box of space) NEST 4

ZCYL P6 28.3464 $84.3783 \quad 0.3805$

ZCYL $628.575 \quad 84.6069 \quad 0.15189$

ZCYL 228.7268984 .758790 .0

CUBOID 0 28.727 28.727 84.759 -28.727 -28.727 - 0.001

* PART \#15 Drum with Poly liner (inside cube box of space) NEST 4

ZCYL P7 28.3464 $84.3783 \quad 0.3805$

ZCYL $6 \quad 28.575 \quad 84.60690 .15189$

ZCYL 228.7268984 .758790 .0

CUBOID 0 28.727 28.727 84.759 -28.727 -28.727 -0.001

* PART \#16 Drum with Poly liner (inside cube box of space) NEST 4

ZCYL P8 28.3464 $84.3783 \quad 0.3805$

ZCYL $628.575 \quad 84.60690 .15189$

ZCXL 228.7268984 .758790 .0

CUBOID $028.72728 .72784 .759-28.727-28.727-0.001$

* PART \#17 Drum with Poly liner (inside cube box of space)

NEST 4

ZCYL P9 28.3464 $84.3783 \quad 0.3805$

ZCYL $628.575 \quad 84.6069 \quad 0.15189$

ZCYL 228.7268984 .758790 .0

CUBOID $028.72728 .72784 .759-28.727-28.727-0.001$

*PART $\# 18$ Array of dums: $X$ by $Y$ by $Z$

ARRAY 224

* Part (H) placed in array 2 times

(16 17 141512131011$) * 2$

* PART \#19 Array container/Concrete Floor (12in) \& Ceiling (8in) NEST 2

CUBOID P18 114.908 114.908 339.04 0.0 0.0 0.

* ceiling(339.04cm+8in) floor (0-12in)

CUBOID 7 114.908 114.908 359.36 0.0 0.0-30.48

* reflective surfaces on $X$ and $Y$ surfaces of outer cube

ALBEDO 1.0 1.0 0.0 1.0 1.0 0.0

* strtstage, endstage, fhistperstage, time(min), -1

$\begin{array}{lllll}-10 & 30 & 1000 & 300 & \text { STDV } 0.003+1\end{array}$

80. 80. 10. 1

80.80 .95 .1

80. 80.180 .1

75. 75. 265.1

END

CODE 7

PSsVWpC

* xy

0.129 .85 . 57.4 29. 85. 0.1 29. -10 .

* yz

19 38. 10. 38. 38. 10. 191910 .

* xy

19. 19 20. 38. 19. 20. $1919-1$

END

* CEMD2_aericcr Array of Drums (Drums Crushed), 3 cans $66.67 \mathrm{~g}$ 
Pu ea arrang drum center

FISSION

* \#MATERIALs \#NUCLIDEs

$$
7 \quad 14 \text { NUCNAMES }
$$

* Mat *1 Cement/Pu (normal (high) water content, $66.67 \mathrm{~g}$ Pu per can)

* density weightfractions

WGT 2.059 HINH2O 0.04083300 .485625 F19 0.032284 MG 0.066981 CA 0.362397 PU239 0.011881

* Mat \#2 Carbon Steel $1 \%$ C $7.86 \mathrm{~g} / \mathrm{cm} 3$ (density altered for crushing -maintain mass)

CONC C 0.01338 FE 0.284945

- Mat \#3 Steel (stip cover can)

WGT 7.9 C 0.005 AL.27 0.001 \$I 0.006 P31 0.002 \$32 0.002 FE 0.983 SN 0.001

* Mat \#4 PVC [(CH2CH(C) )]n

WGT 0.9 HINH2O $0.048386 C 0.384338$ CL 0.567275

* Mat \#5 Water Vapor (mixed with void)

WGT 0.005 HINH2O 0.11188500 .888115

*

* Mat \#6 Polyethylene (CH2)n (density altered for crushing -maintain mass)

WGT 3.26 HINH2O $0.14397 \mathrm{C} 0.856303$

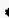

* Mat \#7 Concrete, conservative Hanford (dens $=2.35 \mathrm{~g} / \mathrm{cm} 3$ )

CONC AL27 0.003358 CA 0.002614 FE 0.001344

HINH2O 0.00702300 .045396 SI 0.012905

$*$

CM

* PART \#1 Cementation can (cemented residue, steel can, PVC bag) NEST 3

ZCYL $1 \quad 6.98517 .8130 .033$

ZCYL $3 \quad 6.98817 .8160 .030$

ZCYL $4 \quad 7.018 \quad 17.8460 .000$

* PART \#2 Druml (Case 2, Erickson), including space in drum CLUSTER 4

ZROD ORIGIN $2.41-21.180 .0000$ P1 7.018 17.846

ZROD ORIGIN 15.081-15.081 0.0000 P17.018 17.846

ZROD ORIGIN $21.18-2.410 .0000$ P1 7.01817 .846

* $55 \mathrm{Gal} 17 \mathrm{C}$ drum inner: 22.5 in ID, 33.25 in inside height

* drum lined with 0.09 in thick poiy $\rightarrow(22.32 \mathrm{ID}, 33.07 \mathrm{IH})$

ZROD 028.346420 .00

* PART \#3 Drum2 (Case 2, Erickson), including space in dnm CLUSTER 4

ZROD ORIGN -2.41 -21.18 0.0000 P1 7.018 17.846

ZROD ORIGIN $-15.081-15.0810 .0000$ P1 7.01817 .846

ZROD ORIGIN -21.18 -2.41 0.0000 P1 7.018 17.846

* 55 Gal $17 \mathrm{C}$ dnum inner: 22.5 in $\mathrm{ID}, 33.25$ in inside height

- drum lined with 0.09 in thick poly $\rightarrow(22.32 \mathrm{FD}, 33.07 \mathrm{IH})$

ZROD 028.346420 .00

- PART \#4 Drum3 (Case 2, Erickson), including space in drum CLUSTER 4

ZROD ORIGIN 24121.180 .0000 P1 7.018 17.846

ZROD ORIGIN 15.08115 .0810 .0000 P1 7.018 I7.846

ZROD ORIGIN 21.182 .410 .0000 P1 7.018 17.846

- $55 \mathrm{Gal} 17 \mathrm{C}$ drum inner: 22.5 in $\mathrm{ID}, 33.25$ in inside height

* drum lined with 0.09 in thick poly $\rightarrow(22.32 \mathrm{mD}, 33.07 \mathrm{IH})$

ZROD 028.346420 .00

* PART \#5 Drum4 (Case 2, Erickson), including space in drum CLUSTER 4

ZROD ORIGIN -2.4121 .180 .0000 P1 7.018 17.846

ZROD ORIGN - 15.08115 .0810 .0000 P1 7.018 17.846

ZROD ORIGIN -21.18 2.410.0000 PI 7.018 17.846

* 55 Gal $17 \mathrm{C}$ drum inner. 22.5 in $1 \mathrm{D}, 33,25$ in inside height

* drum lined with 0.09 in thick poly $\rightarrow$ (22.32 ID, $33.07 \mathrm{IH})$

ZROD 028.346420 .00
* PART \#6 Drums (Case 2, Erickson), including space in drum CLUSTER 4

ZROD ORIGIN $2.41-21.180 .00$ P1 7.01817 .846

ZROD ORIGIN 15.081-15.081 0.00 P1 7.018 17.846

ZROD ORIGIN 21.18 -2.410.00 P1 7.018 17.846

* 55 Gal $17 \mathrm{C}$ drum inner: 22.5 in ID, 33.25 in inside height

* dnim lined with 0.09 in thick poly $\rightarrow(22.32 \mathrm{ID}, 33.07 \mathrm{IH})$

ZROD 0 28.3464 20.00

* PART \#7 Drum6 (Case 2, Erickson), including space in drum CLUSTER 4

ZROD ORIGIN $-2.41+21.180 .00$ P1 7.018 17.846

ZROD ORIGIN - $15.081-15.0810 .00$ P1 7.018 17.846

ZROD ORIGIN -21.18 -2.41 0.00 P1 7.018 17.846

* 55 Gal 17C drum ianer, 22.5 in $\mathrm{D}, 33.25$ in inside height

* dnum lined with 0.09 in thick poly $\rightarrow(22.32 \mathrm{ID}, 33.07 \mathrm{IH})$

ZROD 028.346420 .00

* PART \#8 Drim7 (Case 2, Brickson), including space in drum CLUSTER 4

ZROD ORIGIN 2.4121 .180 .00 P1 7.01817 .846

ZROD ORIGIN 15.081 15.081 0.00 P1 7.018 17.846

ZROD ORIGIN 21.182 .410 .00 P1 7.01817 .846

* 55 Gal 17C drim inner: 22.5 in ID, 33.25 in inside height

- drum lined with 0.09 in thick poly $\rightarrow(22.32 \mathrm{ID}, 33.07 \mathrm{IH})$ ZROD 028.346420 .00

* PART \#9 Drum8 (Case 2, Erickson), including space in drum CLUSTER 4

ZROD ORIGIN -2.4121 .180 .00 P1 7.018 17.846

ZROD ORIGIN - 15.08115 .0810 .00 P1 7.018 17.846

ZROD ORIGIN -21.182 .410 .00 P1 7.018 17.846

* 55 Gal 17C drum inner: 22.5 in ID, 33.25 in inside height

- drum lined with 0.09 in thick poly $\rightarrow$ (22.32 ID, $33.07 \mathrm{IH})$ ZROD 028.346420 .00

* PART \#10 Dnum with Poly liner (inside cube box of space) NEST 4

ZCYL P2 28.3464 20.380S 0.3805

ZCYL $628.575 \quad 20.6091 \quad 0.15189$

ZCYL 228.7268920 .760990 .0

CUBOID $028.72728 .72720 .7612-28.727-28.727-0.001$

* PART \#11 Drum with Poly liner (inside cube box of space) NEST 4

ZCYL P3 28.3464 20.3805 0.3805

ZCYL $628.575 \quad 20.6091 \quad 0.15189$

ZCYL 228.7268920 .760990 .0

CUBOID 028.72728 .72720 .7612 -28.727 -28.727 -0.001

* PART \#12 Drum with Poly liner (inside cube box of space) NEST 4

ZCYL P4 28.3464 $20.3805 \quad 0.3805$

ZCXL 628.57520 .60910 .15189

ZCYL 228.7268920 .760990 .0

CUBOID 028.72728 .72720 .7612 -28.727 -28.727 - 0.001

* PART \#13 Drum with Poly liner (inside cube box of space) NEST 4

ZCYL PS 28.3464 20.3805 0.3805

ZCYL $628.575 \quad 20.6091 \quad 0.15189$

ZCYL 228.7268920 .760990 .0

CUBOM $028.72728 .72720 .7612-28.727-28.727-0.001$

* PART \#14 Drum with Poly liner (inside cube box of space) NEST 4

ZCYL P6 28.3464 20.3805 0.3805

ZCYL $628.575 \quad 20.6091 \quad 0.15189$

ZCYL 228.7268920 .760990 .0

CUBOM $028.72728 .72720 .7612-28.727-28.727-0.001$

* PART \#15 Drum with Poly liner (inside cube box of space) NEST 4

ZCYL P7 28.346420 .38050 .3805

ZCYL $628.575 \quad 20.60910 .15189$

ZCYL 228.7268920 .760990 .0

CUBOID $028.72728 .72720 .7612-28.727-28.727-0.001$

* PART \#16 Drum with Poly liner (inside cube box of space) NEST 4

ZCYL P8 28.3464 20.3805 0.3805 
Pu ea arrang drum center

FISSION

* \#MATERIALs \#NUCLIDEs

$7 \quad 14$ NUCNAMRS

* Mat \#1 Cement/Pu (nomal (high) water content, $66.67 \mathrm{~g}$ Pu per can)

* density weightfractions

WGT 2.059 HINH2O 0.04083300 .485625 F19 0.032284 MG 0.066981 CA 0.362397 PU239 0.011881

* Mat \#2 Carbon Steel $1 \%$ C $7.86 \mathrm{~g} / \mathrm{cm} 3$ (density altered for crushing -maintain mass)

CONC C 0.01338 FE 0.284945

* Mat 3 Steel (slip cover can)

WGT 7.9 C 0.005 AL27 0.001 SI 0.006 P31 0.002 S32 0.002 FE 0.983 SN 0.001

- Mat \#4 PVC [(CH2CH(Cl)]n

WGT 0.9 HINH2O 0.048386 C 0.384338 CL 0.567275

* Mat 45 Water Vapor (mixed with void)

WGT 0.005 HINH2O 0.11188500 .888115

$*$

* Mat ${ }^{*} 6$ Polyethylene (CH2)n (density altered for crushing -maintain mass)

WGT $3.26 \mathrm{HINH} 200.14397 \mathrm{C} 0.856303$

$*$

* Mat \#7 Concrete, consenvative Hanford (dens=2.35 $\mathrm{g} / \mathrm{cm} 3$ )

CONC AL27 0.003358 CA 0.002614 FB 0.001344

HINH2O 0.00702300 .045396 SI 0.012905

*

$\mathrm{CM}$

* PART \#1 Cementation can (cemented residue, steel can, PVC bag) NEST 3

ZCYL 16.98517 .8130 .033

ZCYL $3 \quad 6.98817 .8160 .030$

ZCYL $4 \quad 7.01817 .8460 .000$

* PART \#2 Drum1 (Case 2, Erickson), including space in drum CLUSTER 4

ZROD ORIGIN 2.41 -21.18 0.0000 P1 7.018 17.846

ZROD ORIGIN 15.081 -15.081 0.0000 P1 7.018 17.846

ZROD ORIGIN $21.18-2.410 .0000$ P1 7.01817 .846

* 55 Gal 17C drum inner: 22.5 in ID, 33.25 in inside height

* drum lined with 0.09 in thick poly $\rightarrow(22.32 \mathrm{ID}, 33.07 \mathrm{IH})$

ZROD 028.346420 .00

* PART \#3 Drim2 (Case 2, Erickson), including space in drum CLUSTER 4

ZROD ORIGIN $-2.41-21.180 .0000$ PI 7.01817 .846

ZROD ORIGIN -15.081-15.081 0.0000 P1 7.018 17.846

ZROD ORIGIN -21.18 -2.41 0.0000 P1 7.018 17.846

* $55 \mathrm{Gal} 17 \mathrm{C}$ drum inner. $22.5 \mathrm{in} \mathrm{DD}, 33.25$ in inside hejght

- dnum lined with 0.09 in thick poly $\rightarrow$ (22.32 ID, 33.07 IH)

ZROD 028.346420 .00

* PART \#4 Drum3 (Case 2, Erickson), including space in dnum CLUSTER 4

ZROD ORIGIN 2.4121 .180 .0000 PI 7.01817 .846

ZROD ORIGIN 15.081 15.0810 .0000 P1 7.018 17.846

ZROD ORIGIN 21.182 .410 .0000 P1 7.01817 .846

- 55 Gal 17C dnum inner: 22.5 in ID, 33.25 in inside height

* drum lined with 0.09 in thick poly $\rightarrow(22.32 \mathrm{ID}, 33.07 \mathrm{IH})$ ZROD 028.346420 .00

* PART \#5 Drum4 (Case 2, Erickson), including space in drum CLUSTER 4

ZROD ORIGIN -2.4121 .180 .0000 PI 7.018 17.846

ZROD ORIGIN -15.081 15.081 0.0000 P1 7.018 17.846

ZROD ORIGIN -21.182.41 0.0000 P1 7.018 17.846

* 55 Gal 17C drum inner: 22.5 in ID, 33.25 in inside height

* drum lined with 0.09 in thick poly $\rightarrow(22.32 \mathrm{ID}, 33.07 \mathrm{IH})$

ZROD 028.346420 .00
* PART \#6 Drums (Case 2, Erickson), including space in drum CLUSTER 4

ZROD ORIGIN $2.41-21.180 .00$ P1 7.018 17.846

ZROD ORIGIN $15.081-15.0810 .00$ P1 7.018 17.846

ZROD ORIGIN 21.18 -2.41 0.00 P1 7.01817 .846

* $55 \mathrm{Gal} 17 \mathrm{C}$ dnim inner: 22.5 in ID, 33.25 in inside height

* drum lined with 0.09 in thick poly $\rightarrow(22.32 \mathrm{ID}, 33.07 \mathrm{IH})$

ZROD 028.346420 .00

* PART \#7 Drum6 (Case 2, Erickson), including space in drum

CLUSTER 4

ZROD ORIGN $-2.41-21.180 .00$ P1 7.018 17.846

ZROD ORIGIN - $15.081 \cdot 15.0810 .00$ P1 7.018 17.846

ZROD ORIGIN -21.18 -2.41 0.00 P1 7.018 17.846

* $55 \mathrm{Gal} 17 \mathrm{C}$ drum inner. 22.5 in ID, 33.25 in inside height

* drum lined with 0.09 in thick poly $\rightarrow(22.32 \mathrm{ID}, 33.07 \mathrm{IH})$

ZROD 028.346420 .00

* PART \#8 Drum7 (Case 2, Erickson), including space in drum

CLUSTER 4

ZROD ORIGIN 2.4121 .180 .00 P1 7.01817 .846

ZROD ORIGIN 15.08115 .0810 .00 P1 7.018 17.846

ZROD ORIGIN 21.182.41 0.00 P1 7.018 17.846

* 55 Gal $17 \mathrm{C}$ drum inner: 22.5 in ID, 33.25 in inside height

* drum lined with 0.09 in thick poly $\rightarrow(22.32 \mathrm{ID}, 33.07 \mathrm{lH})$

ZROD 028.346420 .00

* PART \#9 Drum8 (Case 2, Erickson), including space in drum CLUSTER 4

ZROD ORIGIN -2.4121 .180 .00 P1 7.01817 .846

ZROD ORIGIN - 15.081 15.081 0.00 P1 7.018 17.846

ZROD ORIGIN -21.18 2.41 0.00 P1 7.018 17.846

* 55 Gal $17 \mathrm{C}$ drum inner: 22.5 in ID, 33.25 in inside height

* drum lined with 0.09 in thick poly $\rightarrow$ (22.32 ID, 33.07 IH) ZROD 0 28.3464 20.00

- PART \#10 Drum with Poly liner (inside cube box of space) NEST 4

ZCYL P2 28.3464 20.3805 0.3805

ZCYL $628.575 \quad 20.6091 \quad 0.15189$

ZCYL 228.7268920 .760990 .0

CUBOID $028.72728 .72720 .7612 \cdot 28.727-28.727 \cdot 0.001$

* PART \#11 Drum with Poly liner (inside cube box of space)

NEST 4

ZCYL P3 28.3464 20.3805 0.3805

ZCYL $628.575 \quad 20.6091 \quad 0.15189$

ZCYL 228.7268920 .760990 .0

CUBOID $028.72728 .72720 .7612-28.727-28.727-0.001$

* PART \#12 Drum with Poly liner (inside cube box of space)

NEST 4

ZCYL P4 28.3464 $20.3805 \quad 0.3805$

ZCYL $628.575 \quad 20.6091 \quad 0.15189$

ZCYL 228.7268920 .760990 .0

CUBOID $028.72728 .72720 .7612-28.727-28.727-0.001$

* PART \#13 Drum with Poly liner (inside cube box of space) NEST 4

ZCYL P5 28.346420 .38050 .3805

ZCYL $628.575 \quad 20.6091 \quad 0.15189$

ZCYL 228.7268920 .760990 .0

CUROID $028.72728 .72720 .7612-28.727-28.727-0.001$

* PART \#14 Drum with Poly liner (inside cube box of space)

NEST 4

ZCYL P6 28.3464 20.3805 0.3805

ZCYL $628.575 \quad 20.6091 \quad 0.15189$

ZCYL 228.7268920 .760990 .0

CUBOID $028.72728 .72720 .7612-28.727-28.727-0.001$

* PART \#15 Drum with Poly liner (inside cube box of space) NEST 4

ZCYL P7 28.3464 20.3805 0.3805

ZCYL $628.575 \quad 20.6091 \quad 0.15189$

ZCYL 228.7268920 .760990 .0

CUBOID $028.72728 .72720 .7612-28.727-28.727-0.001$

* PART \#16 Drum with Poly liner (inside cube box of space) NEST 4

ZCYL P8 28.3464 20.3805 0.3805 
ZCYL. $628.575 \quad 20.60910 .15189$

ZCYL 228.7268920 .760990 .0

CUBOID $028.72728 .72720 .7612-28.727-28.727-0.001$

* PART \#17 Drum with Poly liner (mside cube box of space) NEST 4

ZCYL P9 28.3464 20.3805 0.3805

ZCYL $628.575 \quad 20.6091 \quad 0.15189$

ZCYL 2 28.72689 20.76099 0.0

CUBOID $028.72728 .72720 .7612-28.727-28.727-0.001$

* PART \#18 Array of dnums: $X$ by $Y$ by $Z$

ARRAY 224

* Part (†) placed in array 2 times

(1617 14 1512131011)*2

* PART \#19 Amay container / Concrete Floor (12in) \& Ceiling (8in) NEST 2

CUBOID P18 114.908 114.908 83.0488 0.0 0.0 0 .

* ceiling (thin) floor (0-12in)

CUBOID 7 114.908 114.908 88.0 0.0 0.0 -30.48

* reflective surfaces on $X$ and $Y$ surfaces of outer cube

ALBEDO 1.0 1.0 0.0 1.0 1.00.0

* strtstage, endstage, fhistperstage, time(min), -1

$\begin{array}{lllll}-10 & 30 & 1000 & 300 & \text { STDV } 0.003\end{array}$

MULTIPOINT 4

80. 80. 10. 1

80. 80. 35. 1

80. 80.50 . 1

75. 75. 75. 1

END

CODE 7

PSsVWpC

* yz

$0.15585 .57 .45585,0.155-5$.

* yz

$5457.4170 .54 .1170 .5457 .4-2$.

* xy

111470.11411470 .1 .170

* $x y$

.1114100 .114114100 .1 .1100 .

END

* CEMD2_aericcr1 Array of Drums (Drums Crushed), 3 cans 66.67 g Pu ea arrang drum center

FISSION

* \#MATERIALs \#NUCLIDEs

$7 \quad 14$ NUCNAMES

* Mat \#1 Cement/Pu (normal (high) water content, $66.67 \mathrm{~g}$ Pu per can)

* density weightfractions

WGT 2.059 HINH2O 0.04083300 .485625 F19 0.032284 MG 0.066981 CA 0.362397 PU239 0.011881

* Mat \#2 Carbon Steel $1 \%$ C $7.86 \mathrm{~g} / \mathrm{cm} 3$

CONC C 0.003941 FE 0.0839103

*

* Mat \#3 Steel (slip cover can)

WGT 7.9 C 0.005 AL27 0.001 SI 0.006 P31 0.002 \$32 0.002 FE 0.983 SN 0.001

* Mat $\# 4$ PVC [(CH2CH(C)] ]

WGT 0.9 HINH2O 0.048386 C 0.384338 CL 0.567275

* Mat \#5 Water Vapor (mixed with yoid)

WGT 0.005 HINH2O 0.11188500 .888115

* Mat \#6 Polyethylene (CH2)n

WGT 0.96 HINH2O $0.14397 \mathrm{C} 0.856303$

* Mat \#7 Concrete, conservative Hanford (dens $=2.35 \mathrm{~g} / \mathrm{cm} 3$ )

CONC AL27 0.003358 CA 0.002614 FE 0.001344

\section{HINH2O 0.00702300 .045396 SI 0.012905}

* PART \#1 Cementation can (cemented residue, steel can, PVC bag) NEST 3

ZCYL 1 6.985 17.8130 .033

ZCYL $3 \quad 6.98817 .8160 .030$

ZCYL $4 \quad 7.01817 .8460 .000$

* PART \#2 Druml (Case 2, Erickson), including space in drum CLUSTER 4

ZROD ORIGIN $2.41+21.180 .0000$ PI 7.01817 .846

ZROD ORIGIN $15.081-15.0810 .0000$ P1 7.018 17.846

ZROD ORIGIN $21.18-2.410 .0000$ P1 7.01817 .846

* 55 Gal 17C dnum inner: 22.5 in ID, 33.25 in inside height

* drum lined with 0.09 in thick poly $\rightarrow(22.32 \mathrm{ID}, 33.07 \mathrm{IH})$

ZROD 0 28.346420.00

- PART \#3 Drum2 (Case 2, Erickson), including space in drum CLUSTER 4

ZROD ORIGIN $-2.41-21.180 .0000$ P1 7.018 17.846

ZROD ORIGIN $-15.081-15.0810 .0000$ P1 7.01817 .846

ZROD ORIGIN -21.18 -2.41 0.0000 P1 7.018 17.846

* 55 Gal $17 \mathrm{C}$ drum inner: $22.5 \mathrm{in} \mathrm{D}, 33.25$ in inside height

* drum lined with 0.09 in thick poly $\rightarrow(22.32 \mathrm{ID}, 33.07 \mathrm{IH})$ ZROD 028.346420 .00

* PART \#4 Dnim3 (Case 2, Erickson), including space in drum CLUSTER 4

ZROD ORIGIN 2.4121 .180 .0000 P1 7.01817 .846

ZROD ORIGIN 15.08115 .0810 .0000 P1 7.018 17.846

ZROD ORIGIN 21.182 .410 .0000 P1 7.01817 .846

* 55 Gal $17 \mathrm{C}$ dnum inner: $22.5 \mathrm{in} \mathrm{ID}, 33.25$ in inside height

* drum lined with 0.09 in thick poly $\rightarrow(22.32 \mathrm{ID}, 33.07 \mathrm{IH})$ ZROD 0 28.3464 20.00

* PART \#5 Dnum4 (Case 2, Erickson), including space in drum CLUSTER 4

ZROD ORIGIN -2.41 21.18 0.0000 P1 7.018 17.846

ZROD ORIGIN - $15.081 \quad 15.0810 .0000$ P1 7.018 17.846

ZROD ORIGIN -21.18 2.41 0.0000 P1 7.018 17.846

* 55 Gal 17C drum inner. 22.5 in $\mathrm{DD}, 33.25$ in inside height

* drum lined with 0.09 in thick poly $\rightarrow$ (22.32 ID, 33.07 IH)

ZROD 028.346420 .00

* PART \#6 Drums (Case 2, Erickson), including space in drum CLUSTER 4

ZROD ORIGIN $2.41-21.180 .00$ P1 7.018 17.846

ZROD ORIGIN $15.081-15.0810 .00$ P1 7.018 17.846

ZROD ORIGIN $21.18-2.410 .00$ P1 7.01817 .846

* 55 Gal 17C drum inner: 22.5 in ID, 33.25 in inside height

* drum lined with 0.09 in thick poly $\rightarrow>$ (22.32 ID, $33.07 \mathrm{IH})$

ZROD 028.346420 .00

* PART 47 Drum6 (Case 2, Erickson), including space in drum CLUSTER 4

ZROD ORIGIN $-2.41-21.180 .00$ P1 7.01817 .846

ZROD ORIGN - $15.081-15.0810 .00$ P1 7.01817 .846

ZROD ORIGIN -21.18 -2.410.00 P1 7.018 17.846

* 55 Gal $17 \mathrm{C}$ drum inner: 22.5 in ID, 33.25 in inside height

* drum lined with 0.09 in thick poly $\rightarrow$ (22.32 ID, 33.07 IH)

ZROD 0 28.3464 20.00

* PART \#8 Drum7 (Case 2, Erickson), including space in drum CLUSTER 4

ZROD ORIGIN 2.4121 .180 .00 P1 7.01817 .846

ZROD ORIGIN 15.08115 .0810 .00 P1 7.018 17.846

ZROD ORIGIN 21.182 .410 .00 P1 7.018 17.846

* $55 \mathrm{Gal} 17 \mathrm{C}$ drum inner: 22.5 in ID, 33.25 in inside height

* drum lined with 0.09 in thick poly $\rightarrow(22.32 \mathrm{ID}, 33.07 \mathrm{IH})$

ZROD 028.346420 .00

* PART 49 Drum8 (Case 2, Erickson), inciuding space in drum CLUSTER 4

ZROD ORIGIN -2.4121 .180 .00 P1 7.018 17.846

ZROD ORIGIN -15.081 15.081 0.00 P1 7.018 17.846

ZROD ORIGIN -21.18 2.41 0.00 P1 7.018 17.846

* $55 \mathrm{Gal} 17 \mathrm{C}$ drum inner. 22.5 in ID, 33.25 in inside height

* drum lined with 0.09 in thick poly $\rightarrow(22.32 \mathrm{ID}, 33.07 \mathrm{IH})$ 
HNF-SD-SQA-CSA-525 Rev. 0

ZROD 0 28.3464 20.00

* PART *10 Drum with Poly liner (inside cube box of space) NEST 4

ZCYL P2 28.3464 $20.3805 \quad 0.3805$

ZCYL $628.575 \quad 20.6091 \quad 0.15189$

ZCYL 228.7268920 .760990 .0

CUBOID $028.72728 .72720 .7612-28.727-28.727-0.001$

* PART\#11 Drum with Poly tiner (unside cube box of space) NEST 4

ZCYL P3 $28.346420 .3805 \quad 0.3805$

ZCYL $628.57520 .6091 \quad 0.15189$

ZCYL 228.7268920 .760990 .0

CUBOID $028.72728 .72720 .7612-28.727$-28.727 - 0.001

* PART \#12 Drum with Poly liner (inside cube box of space)

NEST 4

ZCYL P4 28.3464 20.3805 0.3805

ZCYL $628.575 \quad 20.6091 \quad 0.15189$

ZCYL 228.7268920 .760990 .0

CUBOID $028.72728 .72720 .7612-28.727-28.727-0.001$

- PART \#13 Drum with Poly liner (inside cube box of space)

NEST 4

ZCYL PS $28.346420 .3805 \quad 0.3805$

ZCYL $628.575 \quad 20.60910 .15189$

ZCYL 2 28.7268920.76099 0.0

CUBOID $028.72728 .72720 .7612-28.727-28.727-0.001$

* PART \#14 Drum with Poly liner (inside cube box of space)

NEST 4

ZCYL P6 28.3464 20.3805 0.3805

ZCYL $628.575 \quad 20.6091 \quad 0.15189$

ZCYL 228.7268920 .760990 .0

CUBOID $028.72728 .72720 .7612-28.727-28.727-0.001$

* PART \#15 Drum with Poly liner (inside cube box of space)

NEST 4

ZCYL P7 28.3464 20.3805 0.3805

ZCYL $6 \quad 28.575 \quad 20.6091 \quad 0.15189$

ZCYL 228.7268920 .760990 .0

CUBOID $028.72728 .72720 .7612-28.727-28.727-0.001$

* PART \#16 Drum with Poly linex (inside cube box of space)

NEST 4

ZCYL P8 28.3464 $20.3805 \quad 0.3805$

ZCYL $628.575 \quad 20.6091 \quad 0.15189$

ZCYL 228.7268920 .760990 .0

CUBOID $028.72728 .72720 .7612-28.727-28.727-0.001$

* PART \#17 Drum with Poly liner (inside cube box of space)

NEST 4

ZCYL P9 $28.346420 .3805 \quad 0.3805$

ZCYL $628.575 \quad 20.6091 \quad 0.15189$

ZCYL 228.7268920 .760990 .0

CUBOID $028.72728 .72720 .7612-28.727-28.727-0.001$

* PART \#18 Array of drums: $X$ by $Y$ by $Z$

ARRAY 224

* Part (\#) placed in array 2 times

(16 17 14 15 12131011$)^{* 2}$

* PART \#19 Array container / Concrete Floor (12in) \& Ceiling (8in)

NEST 2

CUBOID P18 114.908 114.908 83.0488 0.00.0 0.

- ceiling (thin) floor (0-12in)

CUBOID $7114.908114 .90888 .00 .00 .0-30.48$

* reflective surfaces on $X$ and $Y$ suffaces of outer cube

ALBEDO 1.0 1.0 0.0 1.0 1.0 0.0

* strtstage, endstage, thistperstage, time(min), -1

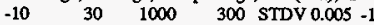

MULTIPOINT 4

80.80. 10. 1

80. 80 . 35. 1

80. 80.50 .1

75. 75. 75. 1

BND

CODE 7

PSsVWpC

* yz
0.15585 . 57.45585 . $0.155-5$.

* yz

$5457.4170 .54 .1170 .5457 .4-2$.

* xy

.111470 .11411470 ..1.170.

* xy

.1114100 .114114100 .1 .1100 .

END 


\begin{tabular}{|c|c|c|c|c|c|}
\hline \multirow{2}{*}{$\begin{array}{l}\text { To } \\
\text { Distribution }\end{array}$} & \multirow{2}{*}{\multicolumn{3}{|c|}{$\begin{array}{l}\text { From } \\
\text { Environmental and Nuclear } \\
\text { Initiatives }\end{array}$}} & \multicolumn{2}{|l|}{ Page 1 of 1} \\
\hline & & & & \multicolumn{2}{|c|}{ Date $01 / 13 / 97$} \\
\hline \multicolumn{4}{|c|}{ Project Titie/Work Order } & \multicolumn{2}{|c|}{ EDT No. 620278} \\
\hline \multicolumn{4}{|c|}{$\begin{array}{l}\text { CSER 96-027: Storage of Cemented Plutonium Residue Containers } \\
\text { in } 55 \text { Gallon Drums }\end{array}$} & ECN No. & \\
\hline Name & MSIN & $\begin{array}{c}\text { Text } \\
\text { With All } \\
\text { Attach. }\end{array}$ & Text Only & $\begin{array}{l}\text { Attach./ } \\
\text { Appendix } \\
\text { Only }\end{array}$ & $\begin{array}{l}\text { EDT/ECN } \\
\text { Only }\end{array}$ \\
\hline $\begin{array}{l}\text { G. G. Bergquest } \\
\text { D. G. Erickson } \\
\text { S. R. Gedeon } \\
\text { H. J. Goldberg } \\
\text { J. Greenborg } \\
\text { R. Gregory } \\
\text { K. E. Hillesland } \\
\text { D. A. Himes } \\
\text { R. M. Irwin } \\
\text { J. A. Locklair } \\
\text { E. M. Miller } \\
\text { L. T. Nirider } \\
\text { S. E. Nunn } \\
\text { R. J. Puigh } \\
\text { A. L. Ramble } \\
\text { R. F. Richard } \\
\text { S. P. Roblyer } \\
\text { V. E. Roetman } \\
\text { R. H. Ruben } \\
\text { K. N. Schwinkendorf } \\
\text { W. T. Watson } \\
\text { W. D. Wittekind } \\
\text { Central Files }\end{array}$ & 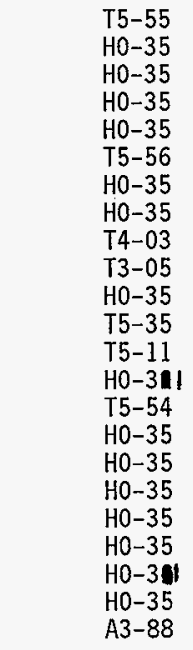 & $\begin{array}{l}x \\
x \\
x \\
x \\
x \\
x \\
x \\
x \\
x \\
x \\
x \\
x \\
x \\
x \\
x \\
x \\
x \\
x \\
x \\
x \\
x \\
x \\
x \\
x \\
x\end{array}$ & & & \\
\hline
\end{tabular}

